\title{
The relation between management control systems and shareholder value creation : three empirical studies
}

Citation for published version (APA):

Sampers, P. A. M. (2003). The relation between management control systems and shareholder value creation : three empirical studies. [Doctoral Thesis, Maastricht University]. Universitaire Pers Maastricht. https://doi.org/10.26481/dis.20030910ps

Document status and date:

Published: 01/01/2003

DOI:

10.26481/dis.20030910ps

Document Version:

Publisher's PDF, also known as Version of record

\section{Please check the document version of this publication:}

- A submitted manuscript is the version of the article upon submission and before peer-review. There can be important differences between the submitted version and the official published version of record.

People interested in the research are advised to contact the author for the final version of the publication, or visit the DOI to the publisher's website.

- The final author version and the galley proof are versions of the publication after peer review.

- The final published version features the final layout of the paper including the volume, issue and page numbers.

Link to publication

\footnotetext{
General rights rights.

- You may freely distribute the URL identifying the publication in the public portal. please follow below link for the End User Agreement:

www.umlib.nl/taverne-license

Take down policy

If you believe that this document breaches copyright please contact us at:

repository@maastrichtuniversity.nl

providing details and we will investigate your claim.
}

Copyright and moral rights for the publications made accessible in the public portal are retained by the authors and/or other copyright owners and it is a condition of accessing publications that users recognise and abide by the legal requirements associated with these

- Users may download and print one copy of any publication from the public portal for the purpose of private study or research.

- You may not further distribute the material or use it for any profit-making activity or commercial gain

If the publication is distributed under the terms of Article $25 \mathrm{fa}$ of the Dutch Copyright Act, indicated by the "Taverne" license above, 
The Relation Between Management Control Systems and Shareholder Value Creation

\author{
Three Empirical Studies
}


(C) P. Sampers, Heythuysen 2003 ISBN 90-5278-388-8 
The Relation Between Management Control Systems and Shareholder Value Creation

Three Empirical Studies

\section{PROEFSCHRIFT}

ter verkrijging van de graad van doctor aan de Universiteit Maastricht, op gezag van de rector Magnificus, Prof. dr A.C. Nieuwenhuijzen Kruseman, volgens het besluit van het College van Decanen, in het openbaar te verdedigen op woensdag 10 september 2003 om 16.00 uur

door

Peter Antonius Marie Sampers

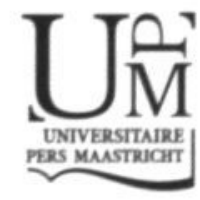


Promotores:

Prof. dr A.M.M. Blommaert

Prof. dr W.F.J. Buijink (Universiteit van Tilburg)

Beoordelingscommissie: Prof. dr E.H.J. Vaassen (voorzitter)

Prof. dr H.F.D. Hassink

Prof. dr C.C.P. Wolff 


\section{Preface}

Writing a dissertation while working in business and not being employed in the academic arena has certainly proved to be an interesting and challenging experience. Interesting, because it confronted me with a new perspective on business practice that was informed by scientific conventions and academic rigor. Challenging, because the time and energy necessary for such a project had to be carved out of an already full agenda. Nevertheless, I never regretted the decision to start this dissertation because it allowed me to reflect on aspects of my work that commanded my interest and aroused my curiosity. That I would finish this dissertation at a time when the business community is facing a fundamental credibility crisis and when cases of bad corporate governance are being uncovered across the world, is something that was certainly not expected when I started working on it. The creation of shareholder value is still of paramount importance for companies. Recent history, however, has brought sad but convincing proof that this objective can only be achieved when managers adhere to the highest standards of integrity and business ethics. Although this was not studied in the context of this dissertation, and is no more than a personal observation lacking any scientific proof, it does shed a new light on the research that I have performed.

Writing a dissertation is an individual process that cannot be accomplished without the help, stimulation, support and critical feedback from many. I would like to thank Tjeu Blommaert in particular for his encouragement and drive that helped me to start working on this dissertation in the first place. His commitment never failed and his busy schedule, after he joined industry, never stopped him from actively reviewing my work and helping me forward. Willem Buijink provided his help after the initial idea had already been developed, when the actual research in the field was being prepared. Without his in-depth knowledge of academic research, I would never have been able to complete this dissertation. He helped me to sharpen my ideas and challenged many views and assumptions that surfaced in the various drafts of the dissertation. I am grateful to both promoters for their positive attitude and never-failing enthusiasm.

Because I was not employed by Maastricht University my presence as a researcher there was less frequent than that of others, writing their dissertation in combination with working in academia. Although I was a "vreemde eend in de bijt" in that respect, I was always welcomed and supported by the members of the Department of Accounting and Information Management which was highly appreciated. I would like to thank them all, in particular Frank Moers, who was a constant sparring partner for both research and practical questions. I also thank Harold Hassink, Christian Wolff and Eddy Vaassen for their evaluation of the final manuscript.

All colleagues from Philips need a special mention here for their encouragement during the years that I was working on this dissertation. They provided me with a pleasant working environment, but also with enough room in my calendar to work on my research. 
I would like to thank my family and friends for their support and motivation. They helped me to find the energy to continue and ultimately complete the project. Most off all, I thank Alice for her love, patience and never failing belief in the successful completion of this journey.

\section{Peter Sampers}

Heythuysen, July 2003 


\section{Contents}

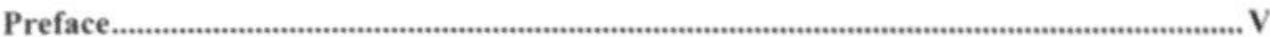

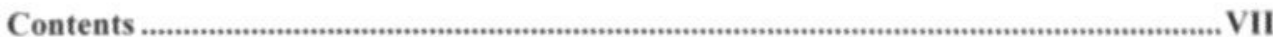

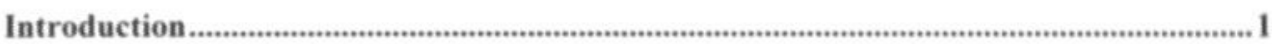

1.1 General $\ldots \ldots \ldots$

1.2 Value-based management

1.3 Management control systems ...................... 3

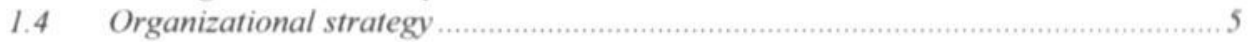

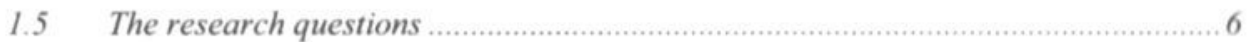

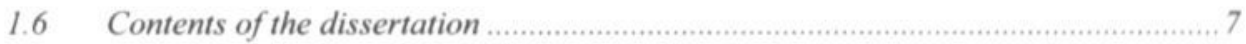

Value-based management, management control systems, and strategy: conceptual foundations

$2.1 \quad$ Introduction

$2.2 \quad$ The concept of value-based management $\ldots \ldots \ldots$

$2.3 \quad$ Management control concepts $\ldots . . . . . . . . . . .13$

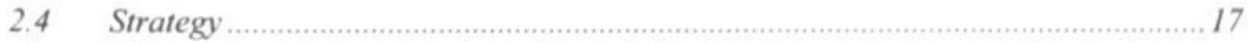

$2.5 \quad$ Summary and conclusions

Shareholder value creation and management control: empirical evidence .....................23

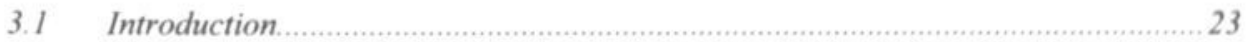

$3.2 \quad$ Value-based management practice and shareholder value creation …………........24

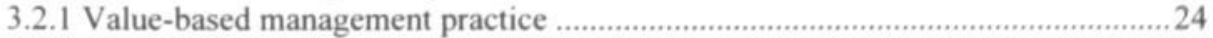

3.2.2 Value-based management and shareholder value creation ....................................29

3.3 The relation between management control system design and value creation …..... 32

3.4 Alignment of management control systems, strategy and value creation .................35

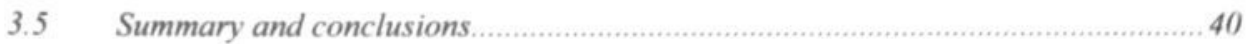




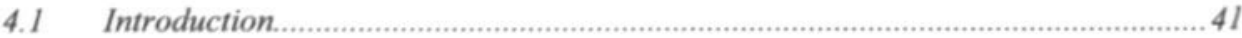

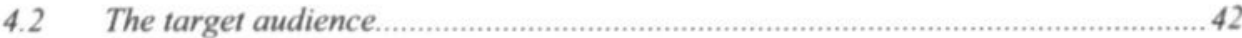

4.3 The research instruments ................................................................................ 43

4.3.1 Management control system characteristics ...........................................................43

4.3.2 Role of accounting information and level of delegation.........................................45

4.3.3 Application of value-based management ................................................................45

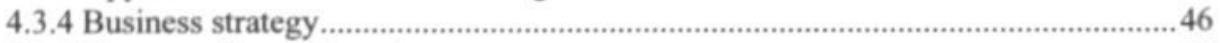

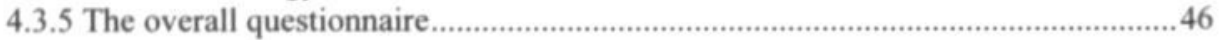

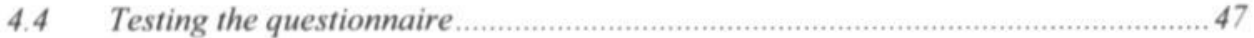

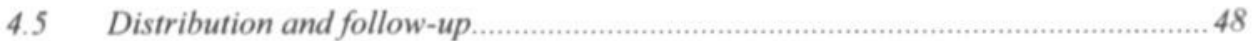

4.6 Response: representativeness and bias...............................................................49

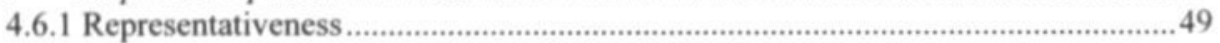

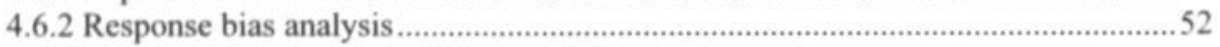

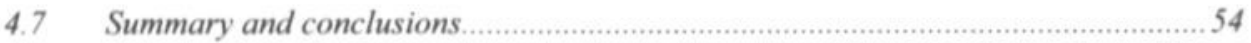

Value creation as central goal: does a value-based management focus create value? ...55

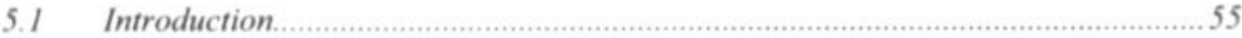

$5.2 \quad$ Previous research and the development of hypotheses...........................................56

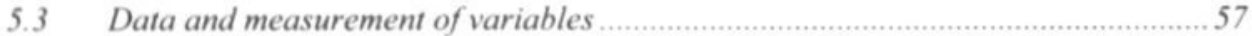

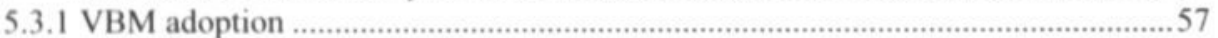

5.3.2 Shareholder value creation: RTSR and accounting performance measures ...........59

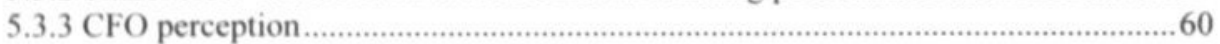

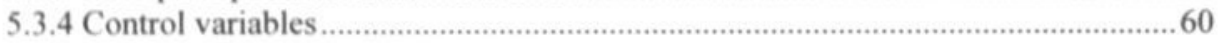

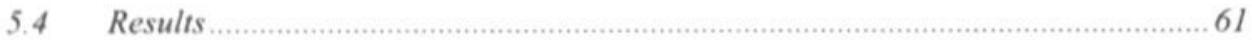

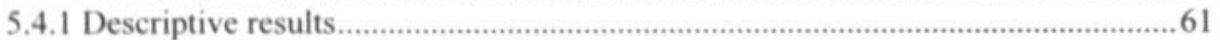

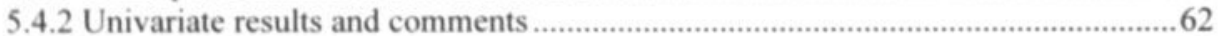

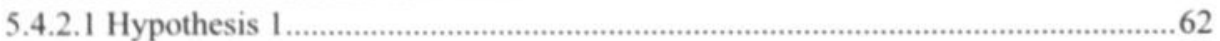

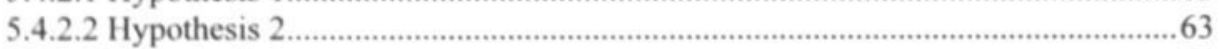

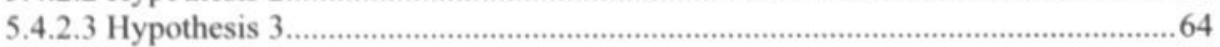

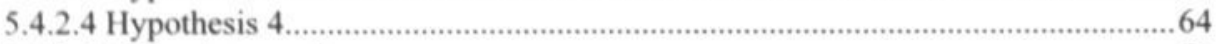

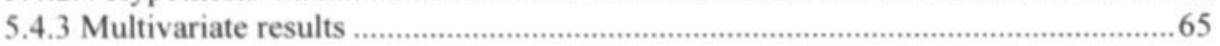

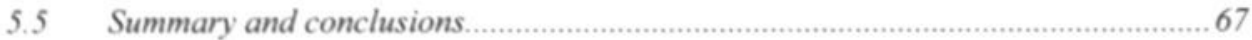

Do management control system characteristics explain value creation? ..........................69

6. I Introduction

6.2 Previous research and the development of hypotheses .........................................70

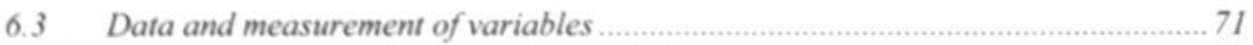

6.3.1 Management control system characteristics ................................................... 71

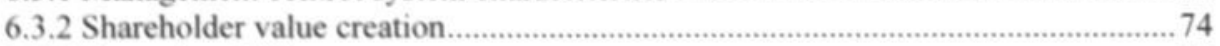

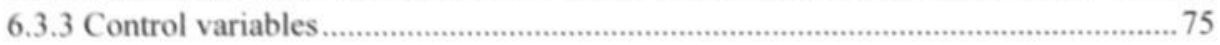

6.4 Results 
6.4.1 Univariate results and comments ................................................................... 75

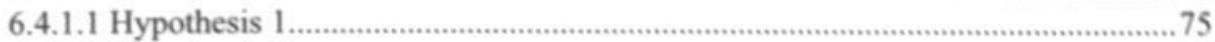

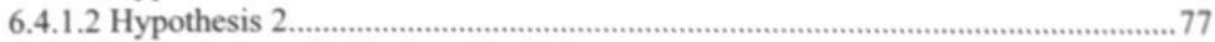

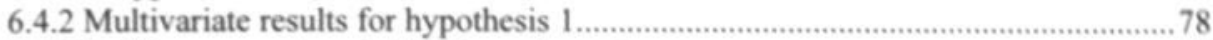

6.4.2.1 Management control system elements ............................................................. 79

6.4.2.2 Management control system factors …............................................................ 80

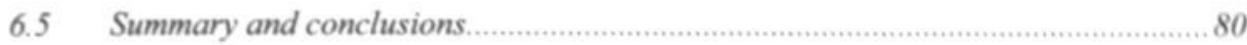

Does alignment of management control system and strategy explain shareholder value creation?

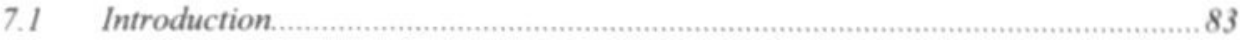

7.2 Previous research and the development of hypotheses ...........................................84

7.3 Data and measurement of variables ................................................................. 87

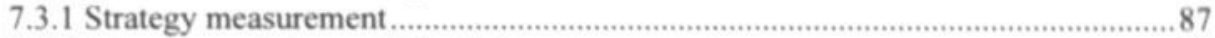

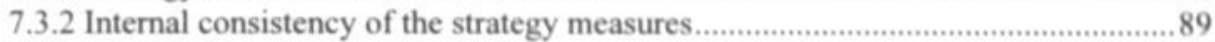

7.3.3 Shareholder value creation............................................................................... 90

7.3.4 Control variables ......................................................................................... 91

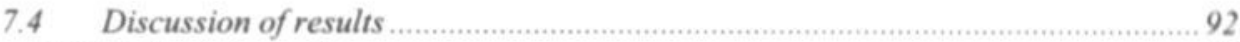

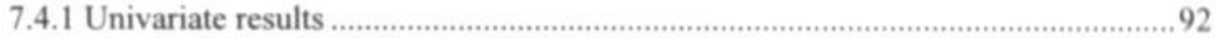

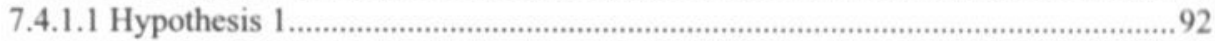

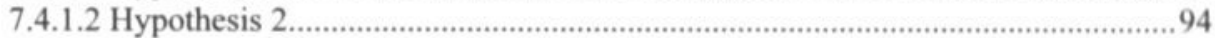

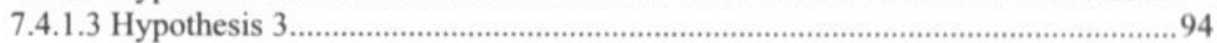

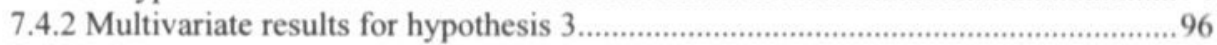

7.4.2.1 Management control system elements ............................................................96

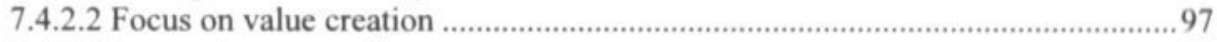

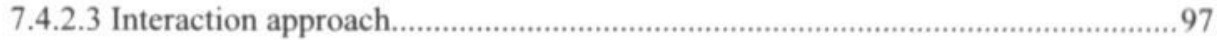

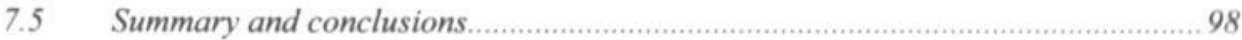

Overall summary and conclusions ......................................................................................101

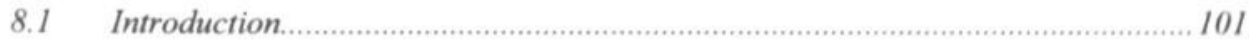

8.2 Summary of empirical findings ........................................................................ 101

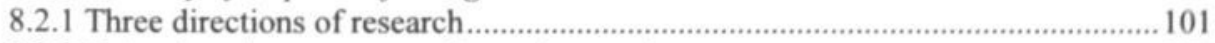

8.2.2 Value-based management focused control systems............................................ 102

8.2.3 Management control system characteristics ..................................................... 102

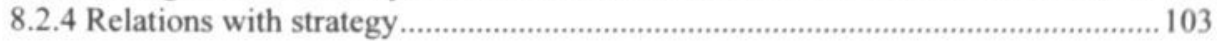

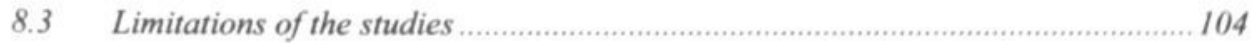

8.4 Conclusions, implications and directions for future research............................ 105

Appendix 1. A. Target audience and response ...................................................................109

Appendix 1. B. Companies excluded from target audience ...........................................113

Appendix 2. Summary of the research instrument..........................................................115 
References

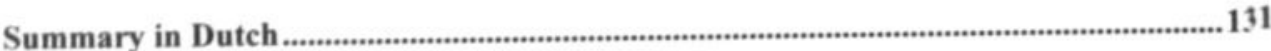

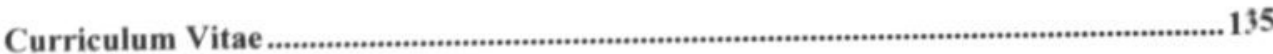




\section{Introduction}

\subsection{General}

The purpose of this dissertation is to empirically examine the relation between shareholder value creation and the design of management control systems in companies. The dissertation looks at listed companies; in this case, companies listed on the Amsterdam Exchanges. The topic and research questions stem from two streams of research, on the one hand research in the field of management accounting into the characteristics and effectiveness of management control systems and, on the other hand, research in the field of company strategy and corporate finance into value creation and value-based management. The focus of the research is on the question whether there is a relation between the design characteristics of the management control system of an organization and the creation of value for the shareholders of this organization.

In this dissertation management control is investigated from three different but related perspectives. First we will determine to what extent management of Dutch companies integrates value-based objectives in the design of management control systems and what the effect of this is on value creation. In practical terms the research question from this perspective can be formulated as: Does a value-based focus in management control indeed result in value creation? Second, we will investigate whether characteristics of management control systems in themselves explain value creation. Third, we will study the importance of the alignment between strategy and management control systems for value creation.

This dissertation attempts to contribute empirically to the academic literature on the relation between the design of management control systems and shareholder value creation. It also attempts to contribute to the evolving field of management control practice. This field is developing over time into a field that deals with "the generation or creation of value through the effective use of resources, through the use of technologies [e.g. work-methods and procedures, comment from the author] which examine the drivers of customer value, shareholder value, and organizational innovation" (IFAC 1998, see also Ittner \& Larcker 2000). 


\subsection{Value-based management}

Value-based management (VBM) has become an important theme for many companies over the last two decades, making the creation of shareholder value their central goal. It finds its origins in traditional economic theory and builds on the residual income concept that was already introduced in the 19th century (Arnold \& Davies 2000). The current attention for VBM, both from managers and from academics, can be explained by a growing recognition of the importance of shareholders as corporate stakeholders and by the efforts of a large community of management consultants who are promoting the concept. Rappaport (1986, 1988) was the first to present a comprehensive study on the importance of the creation of shareholder value. He singled out the creation of value for shareholders as the most important strategic objective for American listed companies.

Various definitions of value-based management have been introduced over time. In general terms, it can be defined as:

'... a formal, or systematic, approach to managing companies to achieve the objective of maximizing wealth creation and shareholder value over time'

(McTaggart et al. 1994, p. 47)

Perhaps the most comprehensive definition of value-based management is provided by Ittner and Larcker $(2000$, p. 3)

'This approach focuses on (1) defining and implementing strategies that provide the highest potential for shareholder value creation; (2) implementing information systems focused on value creation and underlying "drivers" of value across a company's business units, products, and customer segments; (3) aligning management processes, such as business planning and resource allocation, with value creation and; (4) designing performance measurement systems and incentive compensation plans that reflect value creation."

In essence the above definition can also be read as a definition of management control, with the addition that it focuses on the objective of shareholder value creation. In that respect it can be argued that VBM is a form of management control that has the creation of value for shareholders as its central goal.

Over the last decade, VBM has received considerable attention in the Netherlands also. A Dutch translation of Rappaport's book (1986) was published in 1988 and the subject was addressed in numerous publications, including those by Lewy $(1992,1998)$, Cools and Van der Ven (1995), Traas (1995 $\left.{ }^{a}, 1995^{b}, 1996\right)$, Van de Poel (1996), Dorsman and Rijken (1998), Langendijk et al. (1999), Blij and Dekker (2000), Bouwens and Van Lent (2000) and Steens (2000). From anecdotal evidence in the press and disclosures in annual reports we know that a number of Dutch companies are actively employing value-based management. Research by KPMG Consulting (1999) showed that $64 \%$ of large organizations in 7 countries across Europe stated that they apply VBM. Although the Netherlands was not included in the sample, there is no reason to suppose that the picture here is fundamentally different. 
The attention for EVA, Economic Value Added, a proprietary value-based performance measure introduced by the consulting firm Stern Stewart, has been one of the main driving forces behind the adoption of VBM in the last two decades. EVA received a lot of attention in the business press. Fortune Magazine was one of the first to start publishing on the subject (Tully 1993) and introduced an EVA performance ranking. Also in the Netherlands the leading business newspaper, Het Financieele Dagblad, went on the EVA track and published background articles and a ranking of the EVA performance of Dutch companies.

Most management consultants adopted VBM as a service they could offer to their corporate clients, a service that often encompassed the introduction of other acronyms for value-based performance measures. Stern Stewart offered its EVA concept and consulting services to companies across the world and made sure that successful VBM adopters received a lot of publicity (e.g. Coca Cola, Toys R Us, and Eli Lilly).

The consultants promoting this new concept did not provide strong empirical evidence in support of the relation between the adoption of VBM and the creation of value for shareholders. Anecdotal evidence from successful companies was used to underpin the importance of the new management concept.

The question that remains unanswered is whether the incorporation of VBM in a company's management control system does indeed contribute to the creation of (increased) value for shareholders. This is the basic question that is posed in this dissertation.

\subsection{Management control systems}

Thinking about management control has developed over time and is still evolving. This is best illustrated when we review the definitions of management control that were used by Robert Anthony, a leading researcher in this field, over time.

In the first edition of his book on planning and control systems that also carried this title, he defined management control as:

'The process by which managers assure that resources are obtained and used effectively and efficiently in the accomplishment of organization's objectives'

(Anthony 1965, p. 17).

The role of management according to Anthony in this quotation is to control an organization in such a way that it is assured that people in the organization take decisions and perform actions that lead to the realization of the organization's objectives. In the first edition of his book Anthony described a cybernetic concept of control that consisted of four components: observation, evaluation, modification and communication. These components were contained in the performance management system that consisted of target setting, measurement, corrective actions and the use of management information for communication and motivation. This cybernetic view of management control had limitations because of its disregard for two important considerations. First, management control needs to ensure that people act in accordance with an organization's policies and directives. This means that management control needs to influence the behavior of people working in organizations to ensure the realization of objectives. Second, management control cannot accept strategy as a given fact. 


\section{Chapter 1}

Anthony recognized the first, behavioral, aspect of management control.

He said that:

'Management control is primarily a process for motivating and influencing people to perform organization activities that will further the organization's goal'

(Anthony et al. 1984, p. 11)

Anthony also recognized the second aspect in later years. In the 1984 edition of his book he still started form the premise that strategy was a given fact and stated:

'The goals, strategies and policies are taken as given in the management control process' (Anthony et al. 1984, p. II)

In later editions of his work he widened the scope of management control and recognized that:

'...management control information can also provide the basis for thinking about new strategies ' (Anthony \& Govindarajan 1998, p. 9)

These steps sketch the evolution in Anthony's views of management control over time.

The field has also evolved by giving recognition to the importance of human behavior (e.g. Hopwood (1976), Merchant $\left(1985^{\mathrm{a}}\right)$, Flamholz et al. (1985)). In a further stream of developments, the impact of a changing environment and uncertainty on management control was introduced. This leads to the recognition that management control also has the objective of determining whether the organization's strategy is still appropriate and valid.

All this developed into a wider definition of management control systems introduced by Simons:

$\therefore$ the formal, information-based routines and procedures used by managers to maintain or alter patterns in organizational activities' (Simons 1994, p. 170)

Noteworthy in this definition is the inclusion of altering patterns in organizational activities. Simons justifies this addition by the need for organizations to respond to new strategies that "emerge in various corners of the organization" (Simons 1994, p. 170). This brings determination of the appropriateness of the current strategy into the scope of management control. Although the definition presented by Simons is very instrumental and focused on formal routines and procedures, he developed a richer model of management control, based on four levers of control (Simons $1995^{\mathrm{b}}$ ), that addresses informal processes and behavioral aspects.

It needs to be mentioned at this stage that opinions differ with regard to this strategic aspect of management control. Some authors (e.g. Anthony et al. 1984 and Merchant 1998) distinguish between strategic control, which deals with the question whether the organization's strategy is still valid, and management control, which concentrates on the question whether the employees of an organization behave appropriately, in view of the strategy. For the remainder of this dissertation strategic control will not be viewed separately but as a part of a broadly defined concept of management control, in line with the definition and views developed by Simons, and Anthony in his later work (Anthony \& Govindarajan 1998). 


\subsection{Organizational strategy}

From the preceding section it is clear that management control is necessary to ensure the realization of an organization's objectives: its mission and goal. How these objectives are to be attained is determined by the organization's strategy. Strategy has been defined in many ways. Various schools of thought have developed on the concept of strategy. Mintzberg et al. (1998) go so far as to describe 10 different schools. However, all schools have in common that the stated objective of organizational strategy is the determination of an organization's goals and objectives and the road to the achievement of these goals and objectives. This is already captured in an early definition of strategy introduced by Chandler:

the determination of the basic long term goals and objectives of an enterprise, and the adoption of courses of action and the allocation of resources necessary for carrying out these goals' (Chandler 1962, p. 13)

and is still applied today.

'Strategy can be broadly conceived as a course of action for achieving an organization's purpose' (De Wit \& Meyer 1999, p. 55)

Strategy is usually described on two levels: corporate strategy and business (competitive) strategy. According to Goold, Campbell and Alexander (1994), corporate strategy deals with two primary questions. In what business should the company invest its resources, either through ownership, minority holdings, joint ventures, or alliances? How should the parent company influence and relate to the businesses under its control?

Business strategy addresses the question how to create a sustainable and profitable competitive position for a business unit within a specific industry, segment or market (De Kluyver 2000 , p. 59). In essence it answers the question of how to compete.

Strategy making is the process that leads to the determination of an organization's long-term goals. This is not a discrete process with a beginning and an end. Starting from the definition of strategy as a 'a pattern in a stream of decisions' and based on empirical research in a number of companies, Mintzberg (1978) was able to distinguish between strategies that were intended and strategies that were realized without having been intended. The latter so-called emergent strategies are not consciously pre-conceived but develop when the organization adapts to influences from the environment in the implementation of strategy. This leads to the following distinction by Mintzberg:

'Intended strategies that get realized; these may be called deliberate strategies.

Intended strategies that do not get realized, perhaps because of unrealistic expectations, misjudgments about the environment, or changes during implementation; these may be called unrealized strategies. Realized strategies that were never intended, perhaps because no strategy was intended at the outset or perhaps because, the strategy that was intended got displaced along the way; these may be called emergent strategies.'

(Mintzberg 1978, p. 945) 
As was stated before, strategy addresses the determination of an organization's long-term goals. Both in practice and in theory, more and more recognition is given to the fact that, for public companies, the creation of value for shareholders should be the most important consideration in the determination of these goals. As a consequence of this, the concept of valuebased management was developed.

\subsection{The research questions}

Given the above, we have developed three questions that will be the subject of our empirical work. Evidently, many more questions are possible, but we will concentrate on these three. The three questions are related to each other because they attempt to obtain a deeper understanding of the actions of management that contribute to the creation of value for shareholders. The questions are (1) whether VBM, setting shareholder value creation as a central goal, actually contributes to value creation, (2) whether there is a relation between different characteristics of management control systems and value creation, and (3) what the relevance of the alignment of the management control system to company strategy is for the value creation?

For all three questions a measure for value creation needs to be used. We will measure value creation directly in the capital market. We will use Relative Total Shareholder Return (RTSR), i.e. the increase of the share price and dividends, divided by the share price at the beginning of the measurement period, corrected for the general performance of the market. In addition, in investigating the first question, we will look at performance in terms of return on equity and earnings per share, as well as the perception of CFO's with regard to the value creation performance of their company.

This research is intended to contribute to the literature on, and to our understanding of, management accounting practice in the three areas that will be investigated. Answering the first question will provide insight into whether value-based management indeed contributes to value creation. It can counterbalance the contributions from consultants to the VBM literature that contain limited verifiable information on the correlation between the application of value-based management and the actual creation of value for shareholders. The second part of the empirical work will provide insight into the impact on value creation of the different characteristics of management control systems. We will test whether characteristics of management control explain shareholder value creation. This can help practitioners and contribute to the normative literature on management control system design. In answering the third question we will contribute to the already considerable literature on elements of alignment between management control systems and strategy.

The conceptual foundation of the studies originates from three areas: strategy, finance and management control. Company strategy addresses the question of the determination of the long-term objectives of an organization. VBM is an approach to management that concentrates on a specific objective, the creation of value for shareholders, which is rooted in finance theory. Management control systems have been described in the management accounting literature as the tools that management uses to ensure the accomplishment of the organization's objectives. In companies that apply VBM this can be read as the tools that management uses to ensure that the creation of value for shareholders is realized. In this respect VBM can also be interpreted as a form of management control with a specific focus. Figure 1.1 provides an illustration of these foundations. 
Figure 1.1 Conceptual foundations of the studies

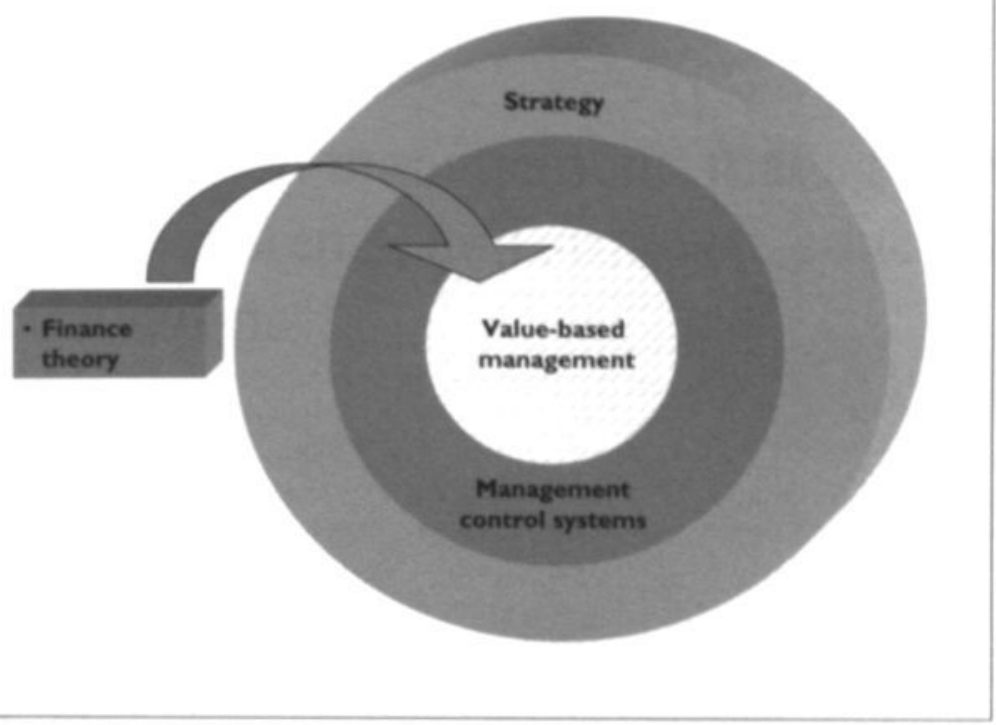

\subsection{Contents of the dissertation}

In the next chapter the notion of management control and the concepts of value-based management and organizational strategy will be discussed. It also reviews the historical development of management control thinking. The third chapter addresses relevant empirical research. In that chapter attention will focus on four important streams of empirical work that deal with value-based management practice, the effect of value-based management, the relation between value-based management and certain aspects of management control systems (notably incentive systems) and the relation between management control and strategy. In chapter four, the research method, survey, sample and response will be discussed. Some general information on the type of companies that responded will also be provided in that chapter. The three research questions and the development of the relevant hypotheses will be addressed in the subsequent chapters. Chapter five deals with the question whether a management focus on value creation indeed leads to superior total shareholder returns. RTSR of companies that have adopted VBM will be compared to companies that have not done so. The relation between management control practices and value creation will be discussed in chapter six. We will investigate to what extent characteristics of management control systems influence the creation of value for shareholders. In chapter seven we will investigate whether the strategic alignment of management control systems affects value creation. A summary of our findings and the main conclusions of our research are presented in the last chapter, which will also provide a number of recommendations for further research and for management accounting practitioners. 



\section{Value-based management, management control systems, and strategy: conceptual foundations}

\subsection{Introduction}

The first part of this chapter covers the concept of value-based management (VBM) and the multitude of value-based performance measures that can be used. It is not the intention to provide an all-inclusive overview of VBM approaches that have been developed by various consulting firms. The main focus will be to define what VBM is and to demonstrate how value-based performance is measured. The roots of value-based performance measures in financial theory and residual income concepts will be elaborated.

Then, traditional - normative - characterizations of the concept of management control, rooted in cybernetics and systems theory, will be discussed that were the foundation of the early literature on management control. Later additions on human behavior, empowerment and change will be described and the insights from contingency theory will be addressed, ending with a discussion of some overall frameworks for management control system design that have been developed in recent years.

After that we will discuss the concept of strategy. The strategic frameworks that have been developed to operationalize strategy will be addressed, as well as the distinction between corporate strategy and business strategy.

The interrelation between the above subjects was already recognized by Rappaport (1986) when he linked value creation, the objective of VBM, to strategy and performance management.

A summary of the conceptual foundations discussed will close this chapter. 


\subsection{The concept of value-based management}

Over the last 20 years value-based management, i.e. setting shareholder value creation as the overriding corporate objective, has enjoyed a growing popularity in company boardrooms and management consulting practice. No doubt one of the most important contributions to the development of this new management paradigm was that of Rappaport (1986). Although not the first to recognize the relative importance of shareholder value creation as a managerial objective, Rappaport can be credited with attempting to develop an integrated management model that would allow companies to ensure value creation. He clearly linked the determination of value creation to business strategy, performance management and measurement, and incentive systems. The book was written in view of the increasing interest in value creation in large industrial companies, mainly in the US. Rappaport explains this growing interest by a number of considerations:

- 'The threat of corporate takeovers by those seeking undervalued, undermanaged assets.

- Impressive endorsement by corporate leaders who have adopted the approach.

- The growing recognition that traditional accounting measures such as EPS and ROI are not reliably linked to increasing the value of the company's shares.

- Reporting of returns to shareholders along with other measures of performance in the business press such as Fortune's anmual ranking of the 500 leading industrial firms.

- A growing recognition that executives' long term compensation needs to be more closely tied to returns to shareholders. "

(Rappaport 1986, p. 3)

These considerations are recurring themes of VBM literature. The imperfections of accrualbased company accounting information are often cited (e.g. Rappaport 1986, Stewart 1991) as an important reason for failure to create value. In the end the underlying concern of critics of accounting information is that accounting-based information provides an unreliable proxy for cash flow information. The idea is that cash flows are key to value creation. From finance theory (Ross et al. 1996) we know that the value of assets in the capital markets is the discounted value of the free cash flows that will be generated by these assets. This translates into a causal relationship between the creation of value for shareholders and the creation of (free) cash flows by organizations.

A second consideration in most work on VBM is that executive compensation arrangements are a strong tool for companies that strive for value creation.

Chief executive support for value-based management is a third consideration. Well-known CEOs from highly regarded companies made it their key theme. Some of the most notable examples in the early days of VBM were Roberto Goizueta, the CEO of Coca-Cola, and Michael Eisner, the CEO of Walt Disney, both in the US (Black et al. 1998). In the UK, Boots and Lloyds Bank were among the VBM adopters that have been regularly mentioned as successful examples (Arnold \& Davies 2000).

In the Netherlands, adoption of VBM became a theme for company CEOs in the second half of the nineties, when among others Joop Jansen of Heijmans, a Dutch construction company, and Rijkman Groenink of ABN AMRO Bank became advocates of VBM (as stated in their respective annual reports). 
Although Rappaport was one of the first authors to describe an overall approach to valuebased management, he did not use the term VBM as such in his book. We find it in what can be called the second-generation VBM publications like Copeland et al. (1995) and McTaggart et al. (1994). As a managerial concept VBM is probably best defined by Copeland et al.:

'VBM is an approach to management whereby the company's overall aspirations, analytical techniques, and management processes are all aligned to help the company maximize its value by focusing management decision making on the key drivers of value (Copeland et al. 1995, p. 96)

VBM as an approach to management was developed from the premise that shareholder value creation is the single most important strategic objective for public, i.e. stock exchange listed, companies. This premise is supported by corporate finance theory that positions shareholders as the residual claim holders who bear the ultimate risk of the firm (Bouma 1980, Weston \& Brigham 1981, Ross et al. 1996). Economists have argued since the days of Adam Smith that maximizing shareholders' wealth is the ultimate objective of public companies (Amold \& Davies 2000). Other arguments to support the predominance of shareholder value have also been used, including the fact that maximizing the advantage for shareholders goes hand in hand with maximizing the value of the firm for other stakeholders (Copeland et al. 1995, Bughin \& Copeland 1997, Backes-Gellner \& Pull 1999, Ogden \& Watson 1999). The creation of shareholder value is also said to be in the long-term interest of corporate managers. When they fail to satisfy the return requirements of their shareholders they may face a hostile take-over or a conflict with shareholders that will lead to their replacement at some stage in time (Rappaport 1986). Agency theory can also be used to explain how value-based management and value-based performance measures in particular work (Bouwens \& Van Lent 2000, Garvey \& Milbourn 2000).

To be able to measure their success in creating value for shareholders, organizations need to apply performance measures that quantify value creation. The development of these measures has been a cornerstone of VBM. The basic concept for these measures is based on the work of early economists who developed the notion that return to shareholders is a requirement of business that should be included as part of the overall cost of capital (Alfred Marshall as quoted in Arnold \& Davies 2000, p. 14). Solomons (1983) made an important contribution to the development of performance measurement by recognizing that profit is an imperfect performance measure because it is influenced by accounting decisions, and disregards the amount of capital employed to create the profit. He solved the second shortcoming by proposing residual income as a superior performance measure that quantified the excess of income over the cost of capital employed to generate this income.

\section{Residual income $(\mathrm{RI})=$ Income $-($ Capital employed $x$ Cost of capital $)$}

Firms in the US, like General Motors and General Electric, have used the RI concept since the 1920s. General Electric is credited with having invented the name (Bromwhich \& Walker 1998). 
The residual income concept together with the understanding of the cost of capital based on the capital asset pricing model are the two cornerstones of the VBM performance measures that were developed over the last 20 years. The theoretical underpinning of residual income as the most appropriate value-based performance measure was strengthened by the recognition and theoretical proof that maximization of residual income is in fact consistent with maximization of the net present value of future cash flows (Bromwich \& Walker 1998. Biddle et al. 1999). However, one of Solomons' objections to traditional income-based per formance measures, the reliance on accrual accounting for income determination and distor tions as a consequence of the use of book values instead of market values for capital em ployed, was not solved by the introduction of RI as such.

VBM authors (Rappaport 1986, Stewart 1991, Copeland et al. 1995) recognized this omission and posited that value-based performance measures should be corrected for deficiencies of accrual accounting. Stern Stewart (Stewart 1991) used up to 164 adjustments to accounting information to correct for possible measurement errors in the determination of income and capital employed for the calculation of Economic Value Added (EVA).

Another value-based performance measure is Total Shareholder Return (TSR), the return that the shareholder obtains from dividends and accretion of the share price. This measure is readily available for all listed companies and is frequently used when companies are ranked on value creation performance (e.g. Boston Consulting Group 1999 and 2000). It is also becoming a frequently used parameter for management bonuses (Arnold \& Davies 2000).

The development of value based measurement frameworks was of importance for the acceptance and dissemination of VBM as a management concept. More recently, the focus in VBM literature has widened, and integration of value-based performance measures in the total management process is being addressed. The importance of linking VBM to strategy development has been stressed (Day \& Fahey 1990, Rappaport 1992). Also the introduction of a value-based mindset on all decision levels of the organization has been recognized as an important aspect of VBM. For example McTaggart et al. (1994, p. 10) observed that organizations need 'a set of principles that are understood by all managers and can be used to inform their judgment about which decisions or choices to make'.

It became more and more clear that VBM influences a wide variety of managerial tasks and that successful value creation cannot be achieved by simply introducing a value-based performance metric and tying incentive compensation to that metric. Haspeslach et al. (2001) describe five main elements that distinguish companies that have successfully implemented a VBM culture:

- explicit commitment to value creation;

- an environment receptive to changes (through training);

- broad-based incentive systems tied to value-based performance;

- willingness to make major organizational changes;

- broad and inclusive changes introduced to the companies' systems and processes.

That a wide variety of managerial tasks is affected by VBM is illustrated by table 2.1. 
Table 2.1 Managerial tasks affected by VBM according to Arnold and Davies (2000)

\begin{tabular}{|l|}
\hline Managerial task \\
\hline Strategy selection \\
\hline Resource allocation \\
\hline Planning and control systems \\
\hline Target setting and performance measurement \\
\hline Managerial reward systems \\
\hline Culture \\
\hline Structure \\
\hline Investor relations \\
\hline Corporate governance \\
\hline The role of the CEO \\
\hline Mergers and acquisitions \\
\hline Corporate valuation \\
\hline
\end{tabular}

Value-based management is described as 'a currently 'hot' topic in practice which is claimed to be changing financial management at the highest level in some of the world's largest companies' (Bromwhich 1998, p. 387). Indeed VBM is applied by a sizeable number of companies also in the Netherlands, and its implementation is inter-linked with management control system design and organizational strategy. But support for it is not unequivocal. Critical evaluations regularly appear (Zimmerman 1997, Mouritsen 1998, Kennedy 2000, Lev 2000) and a number of early VBM adopters have abandoned the application of VBM in the meantime. This dissertation will attempt to contribute to the evaluation of VBM as an 'approach to management'.

\subsection{Management control concepts}

In chapter 1, various definitions of management control have already been presented. Management control can be described as a cybernetic system consisting of a measurement device, a steering device, an assessing device, and an information flow. Anthony (1965) used two building blocks for his approach to management control: the organizational structure and the control process. Defining responsibility centers in an organization creates structure: units that are managed by accountable managers. Depending on the responsibility of the manager concerned, these units can be: revenue centers, cost centers, profit centers, or investment centers. The distinct responsibilities of managers in these centers are summarized in table 2.2 .

Table 2.2 Types of responsibility centers

\begin{tabular}{|l|l|}
\hline Type of responsibility center & Scope of managers responsibilities \\
\hline Revenue center & Sales revenue or similar financial output measure \\
\hline Cost center & Input in terms of costs, not related to output \\
\hline Profit center & Difference between revenue and costs \\
\hline Investment center & Profit in relation to capital employed to generate profit \\
\hline
\end{tabular}

Adapted from Anthony et al. (1984) 
The control process according to Anthony (1965) consists of four phases, which are: (1) programming, (2) budgeting, (3) operating and measuring, and (4) reporting and analysis. In the programming phase, activities are defined that an organization will undertake to realize it: objectives. They are the translation of the organization's strategy into concrete actions. Bud geting entails the translation of these plans into financial plans for the immediate future, usu ally the coming year, in line with the responsibility structure of the organization. In the thiri phase the plans are actually executed and input and output are measured. The last phase deal with the distribution of information for performance measurement and the analysis of devia tions from plans. This phase includes corrective actions by management when the actual per formance is not in line with plans. This is the cybernetic system approach to managemen control as defined before.

In the above view of management control, financial information is a key instrument. This lel to the development of management control theories that placed high reliance on accounting based information. The separation of management control from strategic control and tas: control further strengthened the accounting focus in early management control literature (e. f $_{\text {. }}$ Anthony 1965). Non-financial information was not addressed, as it was deemed to relate $\mathrm{v}$ task control only, and external information was not addressed because strategic planning ws outside of the domain of management control.

Over time, more and more attention was paid to the importance of influencing behavior of individuals working in organizations as an element of management control. Management control systems are a tool to guide decisions by individual members of the organization towards the objectives of the organization and to overcome differences between these objectives and the personal objectives of the individuals.

The influence of differences between the personal objectives and the objectives of organizations was the topic of a number of subsequent empirical studies into management control (Hopwood 1976, Ansari 1977, Ouchi 1977 and 1979, Merchant 1981, Flamholz et al. 1985). The main focus of these studies was the problem of obtaining cooperation among a collection of individuals or units who share only partly congruent objectives. Ways to overcome this problem and to create goal congruence and motivation were the outcome of these studies. It was established that participation in goal-setting enhanced commitment to achieving these goals. It was also established that goals should be perceived to be realistic and attainable in order to provide positive motivation. Both goals that are set at too high a level and goals that are too easy to achieve, de-motivate. The effectiveness of performance-related rewards was also addressed. Rewards must be contingent on performance, valued by employees, available in due time, equitable and based on a fair evaluation process.

Various authors have attempted to define components of management control systems. 
Anthony et al. (1984, p. 58) distinguished formal controls embedded in the organizational structure and processes, informal controls that are based on mutual commitments and group norms, and individual controls that are related to the intrinsic goals and aspirations of individuals. A distinction can also be made between output and behavior controls (Ouchi 1977), the first being based on the observation of the result of the behavior of employees and the second on the observation of the behavior itself. In a second approach to a classification of control, Ouchi (1979) distinguished market mechanisms, which are based on the price mechanism and reciprocity, bureaucratic mechanisms, which are based on explicit routines of monitoring and directing, and clan mechanisms, which are rooted in informal structures and shared values and beliefs. Administrative, social and self-controls are distinguished by Hopwood (1976), the first being designed to structure the process of decision-making in large organizations, the second emerging from shared values and mutual commitments of members of the organization, and the third coming from the individual motivation and needs of members of the organization. A classification introduced by Merchant $\left(1985^{a}, 1998\right)$ describes results, action and personnel and cultural controls. Results controls involve rewarding individuals for appropriate behavior and good results. Action controls are designed to ensure that employees perform actions that are known to be beneficial for the organization. Personnel and cultural controls ensure that employees control their own or each other's behaviors.

These characterizations of management control systems were developed in a traditional control framework that relied on the principles of cybernetics and that relied heavily on financial information and tools such as formal rules, responsibility centers and budgeting systems.

Subsequent authors argued that cybernetics based control systems were too limited to explain how organizations reacted to changes in business conditions (Otley 1994), empowerment $\left(\right.$ Simons $1995^{\mathrm{a}}$ ) and strategic change (Simons 1994). They argued that management control systems have to enable appropriate reactions to changes in circumstances and strategic uncertainties. They argued that this required that empowered employees are able to respond to outside influences from a clear understanding of the organization's goals and objectives. Simons (1990) argued that managers in successful organizations decided continuously about which controls to use interactively and which to program and delegate to lower levels in the organization. Interactive controls are those that business managers use actively to monitor and intervene in ongoing decision activities of subordinates. The distinguishing feature of interactive controls is that top managers get personally involved with these controls and signal the importance of these controls to other members of the organization. Over time Simons (1987 ${ }^{\mathrm{a}}$, $\left.1987^{b}, 1988,1990,1991,1995^{b}\right)$ developed a comprehensive set of characteristics of a management control system that describes how managers control strategy using four basic levers of control:

- beliefs systems;

- boundary systems;

- diagnostic control systems; and

- interactive control systems.

These four levers are used to explain how managers apply management control in empowered organizations that operate in highly competitive markets. They are represented in figure 2.1 and described subsequently. 


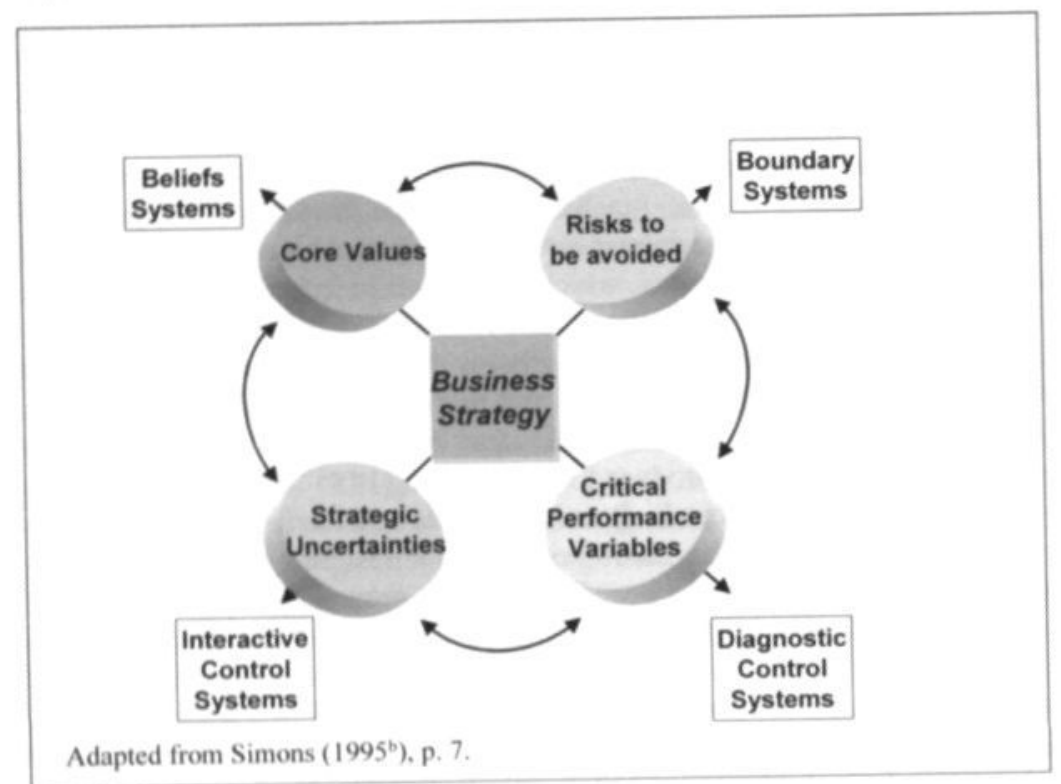

Beliefs systems and boundary systems demarcate the scope in the search for opportunities in strategy definition. They are the borders that the organization sets itself and its employees in the search for new possibilities. Beliefs systems are used to instill an overall sense of purpose and direction into the organization: corporate mission statements, presidential credos and ethical principles are elements of these systems.

Boundary systems define which risks the organization finds unacceptable and therefore wants to avoid. Boundary systems consist of norms that are laid down in codes of conduct, behavior codes and also in laws and government regulations.

Diagnostic control systems are the cornerstone of traditional management control. They are the systems that are used to ensure predictable goal achievement. These are the formal information systems that managers use to monitor organizational outcomes and correct deviations from predetermined standards of performance (Simons $1995^{\mathrm{b}}$ ). This clearly relates to the cybernetic mechanism described before. For the design of effective diagnostic controls, it is essential that goals are set at levels which are perceived to be realistic and challenging, but also specific and fair (Simons $1995^{\mathrm{b}}$ ). 
Interactive control systems are information systems that managers use to involve themselves regularly and personally in the decision activities of their subordinates, with the objective of guiding experimentation and learning that are necessary for new autonomous strategic initiatives to emerge and be tested in the organization (Simons 1995 ${ }^{\mathrm{b}}$ ). These are needed to enable the organization to adapt its strategies in view of uncertainties and the need for strategic renewal. A study by Euske et al. (1993, p. 275) observed that: 'when faced with a crisis, organizations abandoned both their formal and informal control mechanisms to exert specific, high intensity forms of control...'. In the case of crisis, interactive control systems apparently become so important that they override all other control systems.

Simons presents an overall characterization of management control that can be used to capture the multi-faceted nature of the concept. We will later use this model as a starting-point for the development of our own tool to measure and describe management control systems.

\subsection{Strategy}

Strategy is about setting long-term goals for an organization and defining ways to achieve these goals. It is a future-oriented concept. Most definitions of strategy include the process or actions that are used to realize the goals, since strategy not only defines the final objective but also the road to get there.

Corporate strategy deals with portfolio choices of companies: the businesses an organization should be active in, and how to change the composition of the portfolio through acquisitions, internal diversification and divestments. Corporate strategy also addresses the most appropriate way to control the businesses in a portfolio (Goold \& Campbell 1987, Goold \& Quinn 1990 and Goold et al. 1994, Nilsson 2000). Business strategy deals with the way businesses compete in their market, how businesses position themselves in relation to competition. The majority of the research into the contingency relation between management control and strategy has focused on business strategy.

Various classifications have been developed to describe business strategy. For our work those that have been used in contingency studies are the most relevant. In these studies organizations are grouped on the basis of characteristics of business strategy. One of the best-known classifications is Porter's (1980) description of three generic competitive strategies: cost leadership, differentiation and focus. His classification is summarized in figure 2.2. 


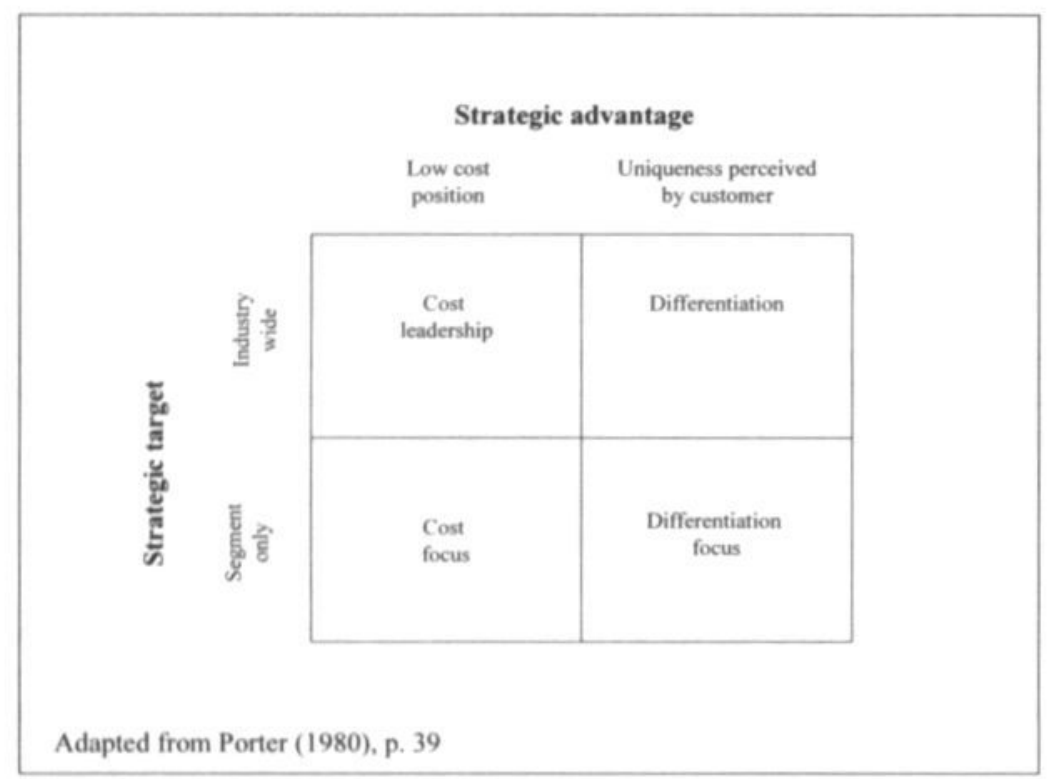

Porter described strategies that were developed from an analysis of the underlying structure of competition in industries. The choice of the appropriate strategy should allow 'positioning a business to maximize the value of the capabilities that distinguish it from competitors' (Porter 1980, p. 47). The strategies are easy to understand and therefore appealing. However, two conceptual weaknesses of the model need to be recognized. The strategies are not collectively exhaustive. Stuck-in-the- middle strategies, which Porter disqualifies as not being successful anyway, are excluded. Also, the model does not leave room to distinguish between broadscope companies that use different competitive strategies in different product market combinations and those that do not (Chrisman et al. 1988).

Miles and Snow (1978) developed a frequently used classification of strategies. They recognized three successful types of business strategies, which they called: defender, prospector and analyzer. A fourth type, reactor strategies, was also identified but was deemed to be unsuccessful and therefore received limited attention both in the original work of Miles and Snow and in some of the subsequent empirical work that was based on their typology. The classification was developed from three perspectives: the product portfolio of the business, the required efficiency level, and the necessary structure. The characteristics are summarized in table 2.3 . 
Table 2.3 Types of organizational behavior according to Miles and Snow

\begin{tabular}{|l|l|l|l|}
\hline Type & Product-market domain & Efficiency & Technology and structure \\
\hline Defenders & Narrow & High & Stable \\
\hline Prospectors & Wide and open. & Medium & Flexible \\
\hline Analyzers & Various & $\begin{array}{l}\text { High in one domain. } \\
\text { Medium in a second domain. }\end{array}$ & $\begin{array}{l}\text { Standardized in one domain. } \\
\text { Flexible in the second domain. }\end{array}$ \\
\hline Reactors & $\begin{array}{l}\text { No consistent strategy } \\
\text { structure relationship. }\end{array}$ & & \\
\hline
\end{tabular}

Adapted from Miles and Snow (1978).

When we contrast the two archetypes - defenders and prospectors - we find that defenders compete in a narrow product market domain and excel in cost leadership, while prospectors develop new market opportunities, thus requiring a wider scope and a more innovative approach. The typology is based on the level of uncertainty that organizations face. Both the external market and the internal structure are less stable and understood for prospectors; they need to cope with a higher level of uncertainty. Analyzers combine the characteristics of prospectors and defenders. In the views developed by Miles and Snow that does not mean that they have a combined strategy but that these organizations serve different product market combinations that allow them to apply both distinctive strategy types in the same organization. Empirical validation of the model has been provided in a number of studies (Snow \& Hrebiniak 1980, Hambrick 1983).

Studying the strategic mission of organizations, Gupta and Govindarajan (1984), (also Govindarajan \& Gupta 1985) singled out four types of strategic mission: build, hold, harvest, and divest. These are seen to be a continuum with, at the one end, businesses that want to increase market share and expand following a build strategy, and at the other end, businesses that concentrate on maximizing short-term earnings and cash flows following a harvest or divest strategy. In this classification the group of companies that is applying a stuck-in-the middle strategy is clearly included with the hold mission. The distinction builds on the tradeoff between expansion, which often pressures short-term income and cash flows, and shortterm performance maximization.

Having listed these three classifications, which all have been used at some stage in contingency research into the relation between strategy and management control systems, the question arises: To what extent are these classifications overlapping or mutually exclusive? It is recommended to see the variables as aspects of business strategies that should be integrated to fully describe the strategy of a business (Langfield-Smith 1997). Strategy can thus be described along three dimensions that do justice to the complexity of the construct: positioning. mission, and typology. Describing the strategy of a business is selecting a spot for the business in the three-dimensional object that is shown in figure 2.3. For our analysis in chapter 7 we will address all three dimensions in accordance with the recommendations of Langfield-Smith. 
Figure 2.3 Strategy in three aspects

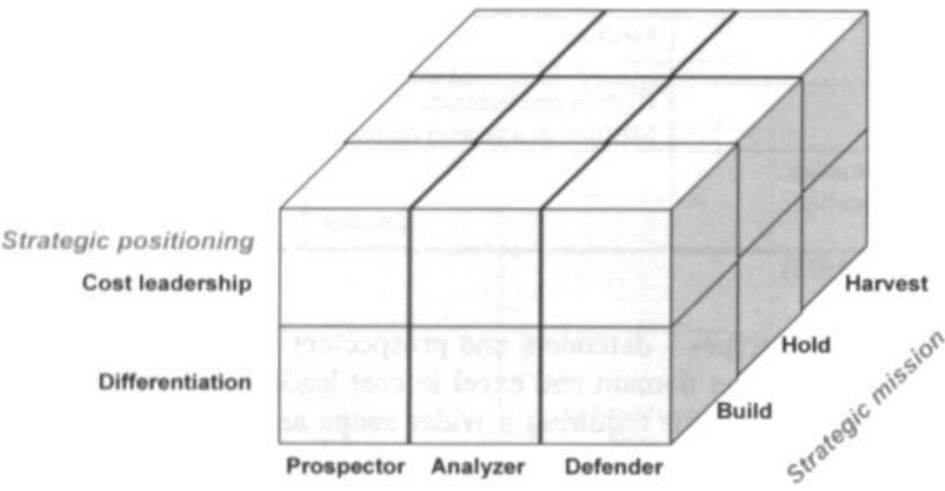

Strategic typologies

From Langfield-Smith (1997)

Strategy development is not a simple-to-describe process that organizations execute in their boardroom. The determination of an organization's strategy is ultimately the responsibility of the board of management. A standard roadmap for the process is not available. Early strategy writers paid limited attention to the process and viewed strategy creation as a "creative act" (Andrews as quoted in Mintzberg et al. 1998). One of the most important insights into strategy development was provided by Mintzberg (1978), who recognized that, in addition to intended strategies that are formally decided upon, there are strategies that emerge without being planned. These emerging strategies can be seen as organic responses of the organization to signals from its environment. Organizational strategy can be empirically measured, though whether one measures intended or emergent strategies it is impossible to say. The main importance for management control is that sufficient room needs to be available for emerging strategies to develop.

\subsection{Summary and conclusions}

The growing attention for shareholder value creation both in management accounting research and in business management led to the development of value-based management as a set of tools to help companies to maximize their value for shareholders. The question whether the application of these tools has indeed led to increased creation of shareholder value is one of the key questions for this dissertation. 
Management control theory has developed over time from a cybernetic model into a richer, multifaceted concept that addresses various aspects of management with the ultimate goal of guiding the decisions and actions of members of an organization towards the realization of the organization's objectives. Various approaches have been developed to describe management control systems, e.g. the four levers of control as defined by Simons (1995 $\left.{ }^{b}\right)$. These will be used to determine characteristics of management control systems and to test whether certain characteristics influence the creation of value for shareholders.

The existence of a contingency relation between management control system design and business strategy has been established empirically in a number of studies. Different strategy classifications have been used in these studies, which hinders the integration of the outcome of the different streams of research. We will use these classifications of business strategy to investigate the relation between strategy and management control systems design and whether this relation influences shareholder value creation. 



\section{Shareholder value creation and management control: empirical evidence}

\subsection{Introduction}

A considerable body of empirical research in management accounting deals with the design of management control systems. For the purpose of this dissertation an all-inclusive overview of these studies is not necessary. We will concentrate on the work that has been performed in relation to value-based management and will cover that extensively in view of the current lack of overview articles in this area (with the exception of chapter 3 of Arnold \& Davies 2000).

Three types of value-based management related research can be distinguished: 1) general surveys of VBM practice, often performed by management consultants, 2) empirical verification of the association between value-based performance measures and stock returns, and 3 ) investigations into the relation between value creation and management control system design characteristics.

The first stream of research is exploratory. The second group of studies deals with research questions similar to those we will address in chapter 5 and is therefore directly relevant to this dissertation. The third, to date rather limited, group of studies that deals with the relation between value creation and management control system design is relevant to chapter 6 .

In addition, contingency research into the relationship between management control systems design and strategy is relevant to our study. A large body of empirical material is available on the relation between (business) strategy and management control system design, including high-quality overview articles providing a critical assessment of the field (Dent 1990, Langfield-Smith 1997, Chenhall 2003). We will refer to these articles and only summarize the conclusions of empirical work that is directly related to the hypotheses that will be tested in chapter 7. We will investigate in that chapter whether the recommendations from these studies with regard to the alignment of management control systems and strategy contribute to the explanation of shareholder value creation. 


\subsection{Value-based management practice and shareholder value creation}

\subsection{Value-based management practice}

The first publications on value-based management (VBM) had a normative character (Rappaport 1986, Stewart 1991). Case studies of successes of VBM were often used to support the new management concept. From the early days, academics and management consultants advocating the use of VBM produced a generally positive stream of publications in which different methods of VBM were advocated (Rappaport 1986, Stewart 1991, McTaggart et al. 1994, Lewis Thomas 1994, Copeland et al. 1995, Black et al. 1998, Donovan et al. 1998, Knight 1998, Nichols 1998). Various management accounting bodies also contributed to the literature on the subject (IMA 1997, IFAC 1999 , IFAC 1999 ${ }^{\mathrm{b}}$ ). Different value-based performance measures like Shareholder Value Added (SVA), Cash Flow Return on Investment (CFROI), Economic Value Added (EVA), Economic Profit (EP) and Total Shareholder Return (TSR) were introduced. The literature is full of claims about the benefits that can be expected from the introduction of value-based management. This can be illustrated with a reference to Stewart who claimed that:

'EVA's most important advantage, however, is mat it is the om' performance measure to tie directly to intrinsic market value of a company. It is the fuel that lights up a premium in stock market value of any company.

(Stewart 1991, p. 119)

Descriptive research into the extent and nature of VBM adoption by companies in various countries has been conducted in the past, usually by management consultants that used these studies to support their endeavors to promote VBM to their customers. The results were not published in refereed academic journals but in research reports of the consultants. It is remarkable, in view of their weak methodological foundations, that these reports find their way into subsequent academic papers (Otley 1999, Ittner \& Larcker 2000).

An overview of these surveys is provided in table 3.1. The most important conclusions of the surveys will be summarized after the overview.

Table 3.1 Research into value-based management practice (VBM)

\begin{tabular}{|l|l|l|l|l|}
\hline Study & Research question & Research design & Response & Major conclusions \\
\hline $\begin{array}{l}\text { KPMG Consulting } \\
1996\end{array}$ & $\begin{array}{l}\text { How many organi- } \\
\text { zations manage for } \\
\text { value, how they } \\
\text { implement the } \\
\text { concept and what } \\
\text { the results are. }\end{array}$ & $\begin{array}{l}\text { Postal questionnaire of } \\
\text { European directors and } \\
\text { executives of "top or- } \\
\text { ganizations in Europe". } \\
\text { Timeframe 1994. }\end{array}$ & $\begin{array}{l}\text { 468 replies } \\
\text { from an un- } \\
\text { disclosed } \\
\text { sample. }\end{array}$ & $\begin{array}{l}\text { 70\% of the re- } \\
\text { spondents are } \\
\text { aware of VBM but } \\
\text { only 35\% claim to } \\
\text { use it. }\end{array}$ \\
\hline Mills et al. 1996 & $\begin{array}{l}\text { Determine use of } \\
\text { analysis in valua- } \\
\text { tion of businesses } \\
\text { for acquisition or } \\
\text { divestment. }\end{array}$ & $\begin{array}{l}\text { Telephone/mail survey } \\
\text { (with additional inter- } \\
\text { views) of 250 listed UK } \\
\text { companies. } \\
\text { Finance Director was } \\
\text { target. Timeframe } \\
1994 / 5 .\end{array}$ & $\begin{array}{l}40.4 \%(101 \\
\text { companies). }\end{array}$ & $\begin{array}{l}61.4 \% \text { of respon- } \\
\text { dents claimed to } \\
\text { use SVA (=VBM) }\end{array}$ \\
\hline
\end{tabular}




\begin{tabular}{|c|c|c|c|c|}
\hline Study & Research question & Research design & Response & Major conclusions \\
\hline $\begin{array}{l}\text { PA Consulting } \\
1997\end{array}$ & $\begin{array}{l}\text { Gather opinions on } \\
\text { the issue of man- } \\
\text { aging for share- } \\
\text { holder value. }\end{array}$ & $\begin{array}{l}\text { Mail survey of Chair- } \\
\text { men, CEOs and Finance } \\
\text { Directors of (large) } \\
\text { listed UK and Irish } \\
\text { companies. } \\
\text { Results were tied to TSR } \\
\text { performance of respon- } \\
\text { dents. } \\
\text { Timeframe } 1996 .\end{array}$ & $\begin{array}{l}132 \text { replies } \\
\text { from an un- } \\
\text { disclosed } \\
\text { sample. }\end{array}$ & $\begin{array}{l}96 \% \text { of companies } \\
\text { defined share- } \\
\text { holder value as key } \\
\text { objective. How- } \\
\text { ever many compa- } \\
\text { nies failed to trans- } \\
\text { late this into ac- } \\
\text { tions. }\end{array}$ \\
\hline $\begin{array}{l}\text { Buhr \& Desjardins } \\
1998\end{array}$ & $\begin{array}{l}\text { Investigate current } \\
\text { practices with re- } \\
\text { gard to use and } \\
\text { measurement of } \\
\text { shareholder value. }\end{array}$ & $\begin{array}{l}\text { Mail survey among fi- } \\
\text { nancial executives of } \\
\text { 1,298 Canadian compa- } \\
\text { nies (of which } 1,063 \\
\text { were listed). } \\
\text { Timeframe spring } 1997 \text {. }\end{array}$ & $\begin{array}{l}13 \%(168 \\
\text { companies }) \\
\text { No response } \\
\text { bias ob- } \\
\text { served. }\end{array}$ & $\begin{array}{l}50 \% \text { of listed } \\
\text { companies use } \\
\text { value-based per- } \\
\text { formance measures } \\
\text { (EVA or CFROI). }\end{array}$ \\
\hline $\begin{array}{l}\text { PA Consulting } \\
1998^{*}\end{array}$ & $\begin{array}{l}\text { Discover where } \\
\text { US businesses } \\
\text { were in the transi- } \\
\text { tion from VBM } \\
\text { theory to practice. }\end{array}$ & $\begin{array}{l}\text { Mail survey of Chair- } \\
\text { men, CEOs and Finance } \\
\text { Directors of } 1000 \text { (large) } \\
\text { listed US companies. } \\
\text { Results were tied to TSR } \\
\text { performance of respon- } \\
\text { dents. } \\
\text { Timerfarm t59s. }\end{array}$ & $\begin{array}{l}\text { Response not } \\
\text { disclosed. }\end{array}$ & $\begin{array}{l}88 \% \text { of companies } \\
\text { defined share- } \\
\text { holder value crea- } \\
\text { tion as a key objec- } \\
\text { tive. For the rest } \\
\text { similar conclusions } \\
\text { as the earlier UK } \\
\text { sarvoy. }\end{array}$ \\
\hline $\begin{array}{l}\text { PA Consulting } \\
1998^{\mathrm{b}}\end{array}$ & $\begin{array}{l}\text { Discover how } \\
\text { Benelux busi- } \\
\text { nesses thought } \\
\text { about "How we } \\
\text { should manage for } \\
\text { shareholder value". }\end{array}$ & $\begin{array}{l}\text { Mail survey of Chair- } \\
\text { men, CEOs and Finance } \\
\text { Directors of all listed } \\
\text { companies in the Bene- } \\
\text { lux countries. } \\
\text { Results were tied to TSR } \\
\text { performance of respon- } \\
\text { dents. } \\
\text { Timeframe } 1998 \text {. }\end{array}$ & $\begin{array}{l}91 \text { replies } \\
\text { from an un- } \\
\text { disclosed } \\
\text { sample. }\end{array}$ & $\begin{array}{l}76 \% \text { of companies } \\
\text { defined share- } \\
\text { holder value crea- } \\
\text { tion as a key objec- } \\
\text { tive. For the rest } \\
\text { similar conclusions } \\
\text { as the earlier UK } \\
\text { survey. }\end{array}$ \\
\hline $\begin{array}{l}\text { KPMG Consulting } \\
1999\end{array}$ & $\begin{array}{l}\text { Gain a comprehen- } \\
\text { sive understanding } \\
\text { of the application } \\
\text { of VBM in top } \\
\text { European organi- } \\
\text { zations and the } \\
\text { extent to which it } \\
\text { has changed over } \\
\text { the past five years. }\end{array}$ & $\begin{array}{l}\text { Telephone interviews of } \\
\text { directors and executives } \\
\text { of leading European } \\
\text { companies. } \\
\text { Timeframe } 1998 .\end{array}$ & $\begin{array}{l}435 \text { replies } \\
\text { from an un- } \\
\text { disclosed } \\
\text { sample. }\end{array}$ & $\begin{array}{l}64 \% \text { of organiza- } \\
\text { tions claim to use } \\
\text { VBM. Adoption } \\
\text { levels differ across } \\
\text { countries and in- } \\
\text { dustries. } 33 \% \text { of } \\
\text { respondents linked } \\
\text { executive remu- } \\
\text { neration to VBM. }\end{array}$ \\
\hline $\begin{array}{l}\text { Boston Consulting } \\
\text { Group } 1999\end{array}$ & $\begin{array}{l}\text { To ascertain how } \\
\text { the best companies } \\
\text { achieved superior } \\
\text { performance in } \\
\text { terms of average } \\
\text { annual TSR. }\end{array}$ & $\begin{array}{l}\text { Study of } 5,316 \text { large } \\
\text { quoted companies from } \\
\text { around the world. TSR } \\
\text { performance was ana- } \\
\text { lyzed in relation to coun- } \\
\text { try, industry and internal } \\
\text { proxies for TSR. } \\
\text { Timeframe 1993 - } 1998 \text {. }\end{array}$ & $\begin{array}{l}\text { Approx. } \\
80 \% \text { of the } \\
\text { total market } \\
\text { capitalization } \\
\text { of the } \\
\text { world's stock } \\
\text { markets in- } \\
\text { cluded. }\end{array}$ & $\begin{array}{l}\text { Three levers for } \\
\text { value creation } \\
\text { identified: cash } \\
\text { flow margin, asset } \\
\text { productivity and } \\
\text { gross investments. } \\
\text { Growth industries } \\
\text { were found to cre- } \\
\text { ate more value } \\
\text { than restructuring } \\
\text { ones. }\end{array}$ \\
\hline
\end{tabular}




\begin{tabular}{|l|l|l|l|l|}
\hline Study & Research question & Research design & Response & Major conclusions \\
\hline $\begin{array}{l}\text { Francis \& } \\
\text { Minchington 2000 }\end{array}$ & $\begin{array}{l}\text { Examine the nature } \\
\text { and prevalence of } \\
\text { value-based per- } \\
\text { formance measures } \\
\text { used at divisional } \\
\text { levels. }\end{array}$ & $\begin{array}{l}\text { Postal questionnaire } \\
\text { among a random sample } \\
\text { of 2,331 members of } \\
\text { CIMA in the UK. } \\
\text { Timeframe not dis- } \\
\text { closed. }\end{array}$ & $\begin{array}{l}258 \text { replies } \\
(11.1 \%) .\end{array}$ & $\begin{array}{l}\text { Traditional per- } \\
\text { formance measures } \\
\text { are still dominant } \\
\text { in practice. Low } \\
\text { awareness of } \\
\text { value-based per- } \\
\text { formance meas- } \\
\text { ures. }\end{array}$ \\
\hline $\begin{array}{l}\text { PA Consulting } \\
2001\end{array}$ & $\begin{array}{l}\text { Explore the extent } \\
\text { to which there are } \\
\text { demonstrable } \\
\text { benefits from } \\
\text { adopting VBM. }\end{array}$ & $\begin{array}{l}\text { Survey of Chairmen, } \\
\text { Chief Executives and } \\
\text { Finance Directors of } \\
\text { leading listed companies } \\
\text { across the world. } \\
\text { Timeframe 1997 - 2001. }\end{array}$ & $\begin{array}{l}\text { Population } \\
\text { not dis- } \\
\text { closed. }\end{array}$ & $\begin{array}{l}91 \% \text { claim to be } \\
\text { in favor of manag- } \\
\text { ing for shareholder } \\
\text { value. }\end{array}$ \\
\hline $\begin{array}{l}\text { Haspeslach et al. } \\
2001\end{array}$ & $\begin{array}{l}\text { Find out what dis- } \\
\text { tinguishes success- } \\
\text { ful and less suc- } \\
\text { cessful users of } \\
\text { VBM. }\end{array}$ & $\begin{array}{l}\text { Survey of 1,826 large } \\
\text { companies in North } \\
\text { America, Europe and } \\
\text { Asia. Self-perceived } \\
\text { success was validated } \\
\text { against actual TSR per- } \\
\text { formance. } \\
\text { Timeframe 1999 - 2001. }\end{array}$ & $\begin{array}{l}271 \text { replies } \\
(14.5 \%), \text { of } \\
\text { which 117 } \\
\text { had actually } \\
\text { adopted } \\
\text { VBM. }\end{array}$ & $\begin{array}{l}43 \% \text { of respon- } \\
\text { dents had actually } \\
\text { adopted VBM. } \\
5 \text { features identi- } \\
\text { fied that distin- } \\
\text { guished successful } \\
\text { VBM adopters. }\end{array}$ \\
\hline
\end{tabular}

CFROI $=$ Cash Flow Return on Investments, EVA $=$ Economic Value Added, SVA = Shareholder Value Added, TSR $=$ Total Shareholder Return.

These studies demonstrate that the importance of shareholder value creation is widely recognized and that VBM appears to be actively applied in various countries across the world.

The research performed by PA Consulting is notable due to the fact that it combined responses from business managers with their companies' performance in the stock market (measured in terms of TSR). This made it possible to draw conclusions with regard to the apparent success of the implementation of value-based management by these companies. It appeared that knowledge and recognition of the importance of shareholder value creation was already widespread in the UK and Ireland in 1996, a conclusion that is remarkable when we compare it to the findings of Francis and Minchington (2000) four years later. They found a low awareness of value-based performance measures in the UK, which appears to be in contrast to the findings of PA Consultants. This may be caused by response bias in the sample selected by PA Consultants. 
In the PA study many companies admitted that they failed (in up to $28 \%$ of the cases) to translate their understanding of the importance of shareholder value creation into appropriate management processes and actions. The research showed that companies that translated VBM into processes and actions benefited most from the introduction of value-based management and outperformed the market TSR by $5 \%$ annually over the 1993 - 1996 period. Companies that paid high attention to bonuses and had low basic salaries demonstrated the best performance in terms of shareholder value creation. These conclusions were also obtained from similar surveys in the US and in the Benelux countries, conducted in 1998. Although the trends that were observed were largely the same, some interesting details surface when we compare the results of the three Surveys conducted by PA Consultants $\left(1997,1998^{\mathrm{a}}\right.$ and $\left.1998^{\mathrm{b}}\right)$. Most prominently, UK managers appeared to be more VBM-minded in 1996 than their US colleagues' two years later. This is contrary to the general perception that the US is the cradle of VBM, and that US corporations were the early adopters of the concept. In view of the fact that all three surveys used the same questions a comparison of the scores is interesting, it is provided in table 3.2 .

Table 3.2 Three studies by PA Consultants compared

\begin{tabular}{|c|c|c|c|}
\hline Questions & $\begin{array}{c}U K \\
I 996 \\
\end{array}$ & $\begin{array}{c}U S \\
I 998 \\
\end{array}$ & $\begin{array}{c}\text { Benelux } \\
1998 \\
\end{array}$ \\
\hline Managing for shareholder value is key objective & $96 \%$ & $88 \%$ & $76 \%$ \\
\hline Principles have not been translated into requisite actions & $50 \%$ & $42 \%$ & $48 \%$ \\
\hline TSR out-performance for companies that fully employ VBM (annual surplus & & & \\
\hline TSR compared to market average) & $+5 \%$ & $+9 \%$ & $+7 \%$ \\
\hline Effect of agreeing on VBM-based bonus system on annual TSR performance & $+32 \%$ & $+14 \%$ & $+2 \%$ \\
\hline Effect of a VBM-based planning approach on annual TSR & $+29 \%$ & n.a. & $+8 \%$ \\
\hline
\end{tabular}

Based on the outcome of these surveys, PA Consultants concluded that companies are able to improve shareholder value creation by concentrating on two quick-hit areas, namely compensation and business planning. Companies that applied VBM concepts in these two areas were more successful in creating shareholder value than their peers. It was also concluded that additional benefits were to be obtained by those companies that applied VBM in full, meaning that a set of VBM principles was agreed to by senior management (beliefs systems), processes were installed that ensured that the principles were communicated and understood throughout the organization and that it was ensured that actions in the organization were fully congruent with VBM principles. In a follow-up study published in 2001 the conclusions drawn by PA Consulting remained more or less the same. The level of support had not grown, but this could not be expected in view of the high adoption level that was found initially. 
That VBM needs to be applied throughout the organization, in all management processes, was also recognized in the studies performed by KPMG. In fact they concluded that 'the more broadly and deeply VBM is used, the greater the perceived benefits are to the organization' (KPMG Consulting 1996, p. 5). The most interesting feature of the KPMG study was the fact that it was replicated 4 years later in order to be able to determine the trend in VBM adoption in Europe. The number of companies actually applying VBM nearly doubled from $35 \%$ in 1994 to $64 \%$ in 1998. These figures need to be interpreted with caution in view of the fact that the country and industry composition of the survey response was not the same in both surveys, e.g. the first survey had a larger participation from the UK and the Netherlands compared to the second survey. In the second survey KPMG Consulting (1999) found that only $33 \%$ of the respondents linked value-based performance to executive remuneration (an increase from $20 \%$ in the previous study). This is in contrast with the advice of PA Consulting, identifying remuneration as one of the quick hit areas.

The work of the Boston Consulting Group, often referred to in the financial press, provides a limited contribution to our understanding of value-based management. It lacks insight into the intent of the management of the companies involved and is not based on the testing of hypotheses that are derived from a model for value-based management. The studies report TSR performance of companies over a certain period, but do not offer a fundamental explanation of this performance.

Thu uss of atalu hased nerformance measures was addressed in manv of the surveys listed above. Contrary to VBM theory, traditional accounting measures still play an important role in all companies that were investigated. Buhr and Desjardins (1998) included Return on Equity (ROE) and Return on Net Assets (RONA) among their shareholder value metrics and found that these are used by $86 \%$ and $57 \%$ of the listed companies in their sample. Only $45 \%$ of these companies claimed to use economic profit (a residual income concept) and $33 \%$ cash flow return on investments (CFROI). For the UK, similar results were found by Francis and Minchington (2000). $31 \%$ percent of their respondents used some kind of economic profit measure (EVA, SVA or RI). Also KPMG (1999) found that many companies subscribe to the VBM concept but a large group still refers to accounting-based performance measures for executive remuneration and only one-third actually applies shareholder value added or economic profit for this purpose. Perhaps even more striking is the fact that Francis and Minchington (2000) found that $26 \%$ of the members of the Chartered Institute of Management Accountants (CIMA) in the UK, who responded to their survey, were not aware of EVA.

The adoption of value-based performance measures is increasing but traditional accountingbased measures appear to remain dominant. Francis and Minchington (2000) offer a number of explanations for this (s)low adoption: lack of awareness, difficulty to translate to lower levels of the organization, and cost and effort related to accounting adjustments. 
The research by Haspeslagh et al. (2001) is interesting because it focused on successful VBM adopters and tried to identify the explanation for their success. Starting from the observation that 'half the companies that adopted a VBM metric have met with mediocre success' (p. 66), the authors were interested in the drivers of success in VBM implementations. They identified the five main elements as: an explicit commitment to shareholder value, extensive training, incentive systems tied to VBM performance, willingness to make organizational changes, and broad and inclusive changes introduced to company processes. Successful companies were found to avoid accounting complexity, identify value drivers, integrate budgeting with strategic planning and execute heavy investments in information technology. Successful companies were selected on the basis of their own perception and on the basis of their TSR performance. This contributes to the internal validity of the study. On a global scale, actual application of VBM still remains limited to $43 \%$ of the respondents, which is considerably lower than the $64 \%$ adoption found by KMPG Consulting (1999).

All in all, these studies provide some insight into the application of VBM in organizations across the world. Interpretation of the results of the studies is hampered by the fact that full statistical analysis is not disclosed; internal validity is either lacking or only demonstrated superficially (PA Consulting 1997, 1998, 2001 and Haspeslagh et al. 2001). The reliability of the findings is therefore difficult to determine. Still, it can be concluded that a sizeable group of companies across the world actually employs value-based management with different degrees of success and with differences in the actual implementation. The surveys produced so far provide some, but only limited, insight into the determinants of success and the differences in application. Case studies can add to our understanding of management practice and are a second source for empirical data. To date, only a limited number of these studies are available (Arnold \& Davies 2000, p. 51, mention 3 studies).

As was described before, the actual application of value-based performance measures is not as widespread as would be expected on the basis of the universal critique of accounting-based performance measures by VBM theorists. Understanding whether this critique is indeed justified and whether value-based performance measures are more reliable predictors of future stock returns is the subject of research that we will address next.

\subsubsection{Value-based management and shareholder value creation}

A cornerstone of VBM implementation is of course the measurement of value. The measure to be used should not be based on accounting conventions according to most authors (e.g. Rappaport 1986, Stewart 1991, Copeland et al. 1996). These authors do not provide proof of the claimed superiority of value-based performance measures over traditional accountingbased performance measures. This has been the subject of a number of empirical studies that were published over the last 7 years. In table 3.3 an overview of these studies is provided. Subsequently the most important conclusions are summarized. 


\section{Chapter 3}

Table 3.3 Research into the association between value-based performance measures and stock returns

\begin{tabular}{|c|c|c|c|c|}
\hline Study & Research question & Research design & $\begin{array}{l}\text { Measurement } \\
\text { method }\end{array}$ & $\begin{array}{l}\text { Major conclu- } \\
\text { sions }\end{array}$ \\
\hline O'Byrne 1996 & $\begin{array}{l}\text { Show that EVA pro- } \\
\text { vides the operating } \\
\text { performance measure } \\
\text { that is consistent with } \\
\text { DCF and provides } \\
\text { valuation multiples } \\
\text { that are highly predic- } \\
\text { tive. }\end{array}$ & $\begin{array}{l}\text { Stock market data } \\
\text { for companies in the } \\
1993 \text { Stern Stewart } \\
\text { Performance } 1000 . \\
\text { Outliers excluded. } \\
\text { Remaining sample } \\
\text { of } 6,551 \text { company } \\
\text { years for the period } \\
1983 \text { - } 1993 \text {. }\end{array}$ & $\begin{array}{l}\text { Regression of } \\
\text { market value } \\
\text { against perform- } \\
\text { ance measures } \\
\text { (EVA, earnings } \\
\text { and free cash } \\
\text { flows). Adjust- } \\
\text { ments to the re- } \\
\text { gression model for } \\
\text { positive EVA and } \\
\text { capital employed. }\end{array}$ & $\begin{array}{l}\text { Changes in EVA } \\
\text { explain more of } \\
\text { the variation in } \\
10 \text { - year stock } \\
\text { returns than } \\
\text { changes in earn- } \\
\text { ings. EVA pro- } \\
\text { vides a better } \\
\text { predictor once an } \\
\text { adjusted regres- } \\
\text { sion model is } \\
\text { used. }\end{array}$ \\
\hline $\begin{array}{l}\text { Bacidore et al. } \\
1997\end{array}$ & $\begin{array}{l}\text { Empirical analysis of } \\
\text { the ability of EVA to } \\
\text { predict abnormal re- } \\
\text { turns. In addition, Re- } \\
\text { fined Economic Value } \\
\text { Added (REVA) is } \\
\text { introduced and the } \\
\text { same question is in- } \\
\text { vestigated. }\end{array}$ & $\begin{array}{l}\text { Random sample } \\
\text { from the Stern } \\
\text { Stewart } 1000 \text { data- } \\
\text { base for the period } \\
1982 \text { - } 1992 \text {. } \\
600 \text { firms selected. }\end{array}$ & $\begin{array}{l}\text { Regression analy- } \\
\text { sis of abnormal } \\
\text { returns on combi- } \\
\text { nations of EVA } \\
\text { and REVA meas- } \\
\text { ures. }\end{array}$ & $\begin{array}{l}\text { Both EVA and } \\
\text { REVA are posi- } \\
\text { tively related to } \\
\text { abnormal returns. } \\
\text { REVA statisti- } \\
\text { cally outperforms } \\
\text { EVA as predictor } \\
\text { of shareholder } \\
\text { value creation. }\end{array}$ \\
\hline $\begin{array}{l}\text { Biddle et al. } \\
1997\end{array}$ & $\begin{array}{l}\text { To test whether EVA } \\
\text { is more highly associ- } \\
\text { ated with stock return } \\
\text { and firm values than } \\
\text { accrual earnings. }\end{array}$ & $\begin{array}{l}\text { Relative informa- } \\
\text { tion content tests. } \\
\text { Period } \\
\text { June } 1983 \text { - May } \\
1994.219 \text { US firms } \\
\text { with outliers ex- } \\
\text { cluded providing } \\
6,174 \text { firm-year } \\
\text { observations. EVA } \\
\text { data from Stern } \\
\text { Stewart database. }\end{array}$ & $\begin{array}{l}\text { Measurement of } \\
\text { abnormal or unex- } \\
\text { pected returns as a } \\
\text { function of a given } \\
\text { (accounting) per- } \\
\text { formance measure } \\
\text { (cash flow, earn- } \\
\text { ings, RI or EVA). } \\
\text { Regression of } \\
\text { stock market re- } \\
\text { turns on each per- } \\
\text { formance metric. }\end{array}$ & $\begin{array}{l}\text { In the explana- } \\
\text { tion of stock re- } \\
\text { turns, earnings } \\
\text { outperform RI, } \\
\text { RI outperforms } \\
\text { EVA and EVA } \\
\text { outperforms cash } \\
\text { flow from opera- } \\
\text { tions. }\end{array}$ \\
\hline $\begin{array}{l}\text { Chen \& Dodd } \\
1997\end{array}$ & $\begin{array}{l}\text { Is the correlation be- } \\
\text { tween EVA and stock } \\
\text { returns as perfect as } \\
\text { claimed by EVA ad- } \\
\text { vocates, how does } \\
\text { EVA compare to ac- } \\
\text { counting profits and } \\
\text { does EVA provide } \\
\text { more information than } \\
\text { RI? }\end{array}$ & $\begin{array}{l}\text { Companies selected } \\
\text { from the } 1992 \text { Stern } \\
\text { Stewart } 1000 \text { data- } \\
\text { base. Period } 1983 \text { - } \\
1992 \text {. } 566 \text { US firms } \\
\text { selected as usable } \\
\text { sample, perform- } \\
\text { ance measures cal- } \\
\text { culated as 10-year } \\
\text { averages. }\end{array}$ & $\begin{array}{l}\text { Regression analy- } \\
\text { sis for various per- } \\
\text { formance meas- } \\
\text { ures with annual- } \\
\text { ized TSR as de- } \\
\text { pendent variable. } \\
\text { Incremental in- } \\
\text { formation content } \\
\text { analyzed. }\end{array}$ & $\begin{array}{l}\text { EVA variables } \\
\text { are related to } \\
\text { stock returns but } \\
\text { far from perfect. } \\
\text { EVA adds infor- } \\
\text { mation value } \\
\text { beyond account- } \\
\text { ing measures. RI } \\
\text { brings the same } \\
\text { benefits as EVA } \\
\text { at lower costs. }\end{array}$ \\
\hline $\begin{array}{l}\text { Biddle et al. } \\
1999\end{array}$ & $\begin{array}{l}\text { 1. As Biddle et al. } \\
1997 \text { and } \\
\text { 2. Determine whether } \\
\text { residual income based } \\
\text { compensation plans } \\
\text { motivate managers to } \\
\text { take actions consistent } \\
\text { with increasing share- } \\
\text { holder value. }\end{array}$ & $\begin{array}{l}\text { 1. As Biddle et al. } \\
1997 \text { and } \\
\text { 2. Based on } \\
\text { Wallace } 1997 \text {. } \\
\text { Refer to paragraph } \\
\text { 3.4. }\end{array}$ & $\begin{array}{l}\text { 1. As Biddle et al. } \\
1997 \text { and } \\
\text { 2. Based on } \\
\text { Wallace } 1997 \text {. }\end{array}$ & $\begin{array}{l}\text { 1. As Biddle et } \\
\text { al. } 1997 \text { and } \\
\text { 2. Managers } \\
\text { respond to } \\
\text { RI-based } \\
\text { incentives. }\end{array}$ \\
\hline
\end{tabular}




\begin{tabular}{|c|c|c|c|c|}
\hline Study & Research question & Research design & $\begin{array}{l}\text { Measurement } \\
\text { method }\end{array}$ & $\begin{array}{l}\text { Major conclu- } \\
\text { sions }\end{array}$ \\
\hline $\begin{array}{l}\text { Stark \& } \\
\text { Thomas } 1998\end{array}$ & $\begin{array}{l}\text { Empirically investi- } \\
\text { gate the cross- } \\
\text { sectional links be- } \\
\text { tween RI measures of } \\
\text { performance and mar- } \\
\text { ket value. }\end{array}$ & $\begin{array}{l}\text { Financial data for } \\
\text { UK firms for the } \\
\text { period } 1990 \text { - } 1994 \text {. } \\
\text { Sample cleaned for } \\
\text { extreme observa- } \\
\text { tions and financial } \\
\text { institutions. } 3,576 \\
\text { firm year observa- } \\
\text { tions available. }\end{array}$ & $\begin{array}{l}\text { Simple linear re- } \\
\text { gression of market } \\
\text { value against earn- } \\
\text { ings and RI. With } \\
\text { corrections for } \\
\text { R\&D expenditures } \\
\text { and firm size } \\
\text { (book value). }\end{array}$ & $\begin{array}{l}\text { RI has a stronger } \\
\text { association with } \\
\text { market value, in } \\
\text { conjunction with } \\
\text { R\&D expendi- } \\
\text { tures and opening } \\
\text { and closing book } \\
\text { value than earn- } \\
\text { ings in conjunc- } \\
\text { tion with R\&D } \\
\text { expenditures and } \\
\text { closing book } \\
\text { value. }\end{array}$ \\
\hline $\begin{array}{l}\text { Chen \& Dodd } \\
2001\end{array}$ & $\begin{array}{l}\text { Determine relative and } \\
\text { incremental informa- } \\
\text { tion content of RI and } \\
\text { EVA over operating } \\
\text { income. }\end{array}$ & $\begin{array}{l}\text { Companies selected } \\
\text { from the } 1992 \text { Stern } \\
\text { Stewart } 1000 \text { data- } \\
\text { base. Period } 1983 \text { - } \\
1992 \text {. Outliers were } \\
\text { eliminated. The } \\
\text { final data set con- } \\
\text { sisted of } 6,683 \text { firm } \\
\text { years. }\end{array}$ & $\begin{array}{l}\text { Simple linear re- } \\
\text { gression of annual } \\
\text { stock returns } \\
\text { against operating } \\
\text { income, RI and } \\
\text { EVA. Both pooled } \\
\text { cross-sectional and } \\
\text { intertemporal (all } \\
\text { years) sample and } \\
\text { individual year } \\
\text { cross-sectional } \\
\text { sample. }\end{array}$ & $\begin{array}{l}\text { Data do not sup- } \\
\text { port the assertion } \\
\text { that EVA is the } \\
\text { best measure for } \\
\text { valuation pur- } \\
\text { poses. OI has the } \\
\text { highest informa- } \\
\text { tion content fol- } \\
\text { lowed by RI and } \\
\text { than EVA. RI } \\
\text { measures contain } \\
\text { significant in- } \\
\text { cremental infor- } \\
\text { mation content } \\
\text { compared to OI. }\end{array}$ \\
\hline
\end{tabular}

DCF $=$ Discounted Cash Flow, EVA $=$ Economic Value Added, REVA $=$ Refined Economic Value Added, $\mathrm{RI}=$ Residual Income, $\mathrm{OI}=$ Operating Income, $\mathrm{TSR}=$ Total Shareholder Return.

The first study (O'Byrne 1996) on the relation between EVA and market value found strong support for the new performance measure. This support in favor of EVA was only available when two additional variables were added to the original regression models. Without these two variables the explanatory power of earnings (Net Operating Profit After Tax (NOPAT)) and EVA were about the same. One variable that was added differentiated between companies with positive and negative EVA on the grounds that 'investors typically capitalize positive EVA at more than its perpetuity value' and 'the expectation of a turnaround implies that negative EVA should be valued at less than its perpetuity value' (O'Byrne 1996, p. 121). To adjust for differences in size, total assets was added as another variable in the regression model. The last adjustment is regularly applied and theoretically supported (see e.g. Cools \& Van Praag $2000^{\mathrm{a}}$ ). However, neither a theoretical model nor other empirical results support the arguments for the first adjustment. Subsequent work by Biddle et al. (1997 and 1999) clearly raised doubts with regard to the purported superiority of EVA over traditional accounting based performance measures. Perhaps the final conclusion in this area is provided by Chen and Dodd (2001), who used the most important conclusions of previous work to direct their research questions. They came to the conclusion that EVA has value relevance but that it ranks only third after operating income and residual income in this respect. In addition they found that residual income had significant incremental value relevance (Biddle et al. 1995 ) over operating income, which was only marginally the case for EVA. 
All in all, this leads Chen and Dodd (2001) to the suggestion that the benefits of introducing EVA may not be large enough to justify the extra cost involved in comparison to simple residual income without adjustments to financial statements. The proposed refinements to the EVA model and the introduction of Refined Economic Value Added (REVA), as proposed by Bacidore et al. (1997), have to be judged against the above considerations. They propose to base the measurement of the capital base on market values instead of (adjusted) book values, which is in line with modern finance theory. Their analysis shows that REVA outperforms EVA as a predictor of shareholder value creation. However, the analysis only compared these two performance measures and did not include either residual income or traditional accounting earnings.

Outside the US only limited research into the relation between value-based performance measures and market value has been published. A notable exception is the study of Stark and Thomas (1998), who found additional information content in residual income performance measures in comparison to earnings, for companies listed on the London Stock Exchange. Their results are in line with the conclusions of Chen and Dodd (2001). However, EVA was not addressed in this study and therefore the question whether the increased complexity of EVA performance measures, compared to straightforward residual income measures, offers additional information content was not dealt with.

To summarize, the empirical evidence available today provides an answer to the following question raised by O' Hanlon and Peasnell (1998, p. 441): 'It is necessarily true that the present value of expected future EVA's, together with current book value, is related to current market value; but it is an open question whether current EVA is more closely correlated with share price than current reported earnings numbers'. So far the answer must be that this is not the case. One may therefore question whether EVA adds any value as a tool of management. As many have observed (Zimmerman 1997, O'Hanlon \& Peasnell 1998 and Biddle et al. 1999), the best performance measure is one that provides managers with an incentive to take actions that increase the value of the firm. That question has not been addressed in the studies discussed so far.

\subsection{The relation between management control system design and value creation}

Numerous empirical studies into the design of management control systems have been published to date. Early studies (e.g. Merchant $1985^{\mathrm{b}}$, Simons $1987^{\mathrm{b}}$ ) sought to explain economic success by certain management control characteristics in combination with the strategy of the business concerned. They are part of the extensive body of contingency-based studies into management control system design (an overview is provided in Chenhall 2003). From our research focus, studies that attempt to explain shareholder value creation by management control system characteristics are the most relevant. Returning to Anthony's statement that 'the central function of a management control system is motivation' (1965, p. 113), the answer to the question whether EVA as a performance measure induces managers to take actions that increase the value of the firm can be understood as studying the importance of EVA as a tool for management control. This has been investigated by Wallace $(1997,1998)$ and Hogan and Lewis (1999), and promoted in the VBM literature (Stewart 1991, Goldberg 1999, Rappaport 1999). The results of the empirical work are summarized in the following table. 
Table 3.4 Research into the relation between shareholder value creation and (aspects of) management control

\begin{tabular}{|c|c|c|c|c|}
\hline Study & $\begin{array}{l}\text { Research ques- } \\
\text { tion }\end{array}$ & Research design & $\begin{array}{l}\text { Measurement } \\
\text { method }\end{array}$ & Major conclusions \\
\hline Wallace 1997 & $\begin{array}{l}\text { Determine } \\
\text { whether compen- } \\
\text { sation plans } \\
\text { based on residual } \\
\text { income change } \\
\text { managers' behav- } \\
\text { ior. }\end{array}$ & $\begin{array}{l}\text { Sample of } 40 \text { US } \\
\text { firms that adopted } \\
\text { compensation con- } \\
\text { tracts with residual } \\
\text { income-based per- } \\
\text { formance measures, } \\
\text { compared to a } \\
\text { matched-pairs con- } \\
\text { trol sample. } \\
\text { Information ob- } \\
\text { tained from public } \\
\text { databases. } \\
\text { Timeframe } 1984 \text { - } \\
\text { 1994. }\end{array}$ & $\begin{array}{l}\text { Interrupted time- } \\
\text { series design. } \\
\text { Changes in man- } \\
\text { agement actions } \\
\text { between pre- and } \\
\text { post-adoption } \\
\text { periods investi- } \\
\text { gated using OL.S } \\
\text { regressions with } \\
\text { two control vari- } \\
\text { ables. Investing. } \\
\text { financing and } \\
\text { operating deci- } \\
\text { sions were stud- } \\
\text { ied. }\end{array}$ & $\begin{array}{l}\text { Relative to the con- } \\
\text { trol group, firms that } \\
\text { adopted RI- per- } \\
\text { formance measures } \\
\text { decreased invest- } \\
\text { ments, increased } \\
\text { share repurchases } \\
\text { and used assets more } \\
\text { intensively. Weak } \\
\text { evidence was found } \\
\text { for a positive capital } \\
\text { market response to } \\
\text { the adoption of RI- } \\
\text { based compensation } \\
\text { plans. }\end{array}$ \\
\hline Wallace 1998 & $\begin{array}{l}\text { Compare deci- } \\
\text { sions made and } \\
\text { actions taken in } \\
\text { relation to the } \\
\text { adoption of } \\
\text { EVA-type per- } \\
\text { formance meas- } \\
\text { ures. }\end{array}$ & $\begin{array}{l}\text { Same sample as } \\
\text { Wallace } 1997 \text { but } \\
\text { now a questionnaire } \\
\text { was used to collect } \\
\text { additional informa- } \\
\text { tion. } \\
14(35 \%) \text { com- } \\
\text { pleted question- } \\
\text { naires received. }\end{array}$ & $\begin{array}{l}\text { Changes in deci- } \\
\text { sions as a result of } \\
\text { the adoption of an } \\
\text { EVA framework } \\
\text { were investigated } \\
\text { on the basis of the } \\
\text { perception of the } \\
\text { responding man- } \\
\text { agers. The results } \\
\text { were compared } \\
\text { with the earlier } \\
\text { findings of Wal- } \\
\text { lace } 1997 \text {. }\end{array}$ & $\begin{array}{l}\text { Consistent with Wal- } \\
\text { lace ( } 1997) \text {, respon- } \\
\text { dents appear to be } \\
\text { concerned not only } \\
\text { with bottom-line } \\
\text { earnings. This is es- } \\
\text { pecially true for } \\
\text { firms that have more } \\
\text { fully embraced EVA } \\
\text { and included it in } \\
\text { management com- } \\
\text { pensation. }\end{array}$ \\
\hline $\begin{array}{l}\text { Hogan \& Lewis } \\
1999\end{array}$ & $\begin{array}{l}\text { Examine whether } \\
\text { compensation } \\
\text { plans based on } \\
\text { economic profits } \\
\text { do in fact pro- } \\
\text { duce better in- } \\
\text { vestment deci- } \\
\text { sions. }\end{array}$ & $\begin{array}{l}\text { Sample of } 5 \text { I US } \\
\text { firms that adopted } \\
\text { economic profit } \\
\text { plans between } 1986 \\
\text { and } 1994 \text {. } \\
\text { A matched sample } \\
\text { of non-adopting } \\
\text { comparison firms } \\
\text { was developed on } \\
\text { the basis of indus- } \\
\text { try, size and operat- } \\
\text { ing performance. } \\
\text { Information ob- } \\
\text { tained from public } \\
\text { databases. }\end{array}$ & $\begin{array}{l}\text { Interrupted time } \\
\text { series design. } \\
\text { Long-run stock } \\
\text { return and operat- } \\
\text { ing performance } \\
\text { compared over } 4 \\
\text { year-periods prior } \\
\text { to and following } \\
\text { adoption of EP } \\
\text { plans. Long run } \\
\text { stock returns in- } \\
\text { vestigated using } \\
\text { the procedure of } \\
\text { Loughran and } \\
\text { Ritter (1995). }\end{array}$ & $\begin{array}{l}\text { Significant im- } \\
\text { provements in oper- } \\
\text { ating performance, } \\
\text { subsequent to adop- } \\
\text { tion are found but } \\
\text { control sample of } \\
\text { non-adopting } \\
\text { matched firms shows } \\
\text { similar improve- } \\
\text { ments. They con- } \\
\text { clude that EP plans } \\
\text { do not provide a new } \\
\text { and different way to } \\
\text { motivate managers. }\end{array}$ \\
\hline
\end{tabular}

$\mathrm{EP}=$ Economic Profit, EVA $=$ Economic Value Added, $\mathrm{RI}=$ Residual Income. 
To date, the research investigating the relation between management control systems and shareholder value creation is limited and narrowly focused. The studies mentioned all took incentive systems that applied VBM performance measures as a distinguishing feature and compared the results of firms that adopted these incentive systems with a matched group of non-adopters. The focus on incentive systems can be explained, on the one hand, by the strong advocacy of value-based incentives in the VBM literature, and on the other hand by the research design. Both Wallace (1997) and Hogan and Lewis (1999) use publicly available information and therefore have limited access to characteristics of management control systems. Incentive plans could be studied due to the disclosure requirement on these plans under US Generally Accepted Accounting Principles. The only study that attempted to obtain richer data from an additional questionnaire was Wallace (1998). Interpretation of that study is hampered by the limited number of responses that were received (14 questionnaires were received back from the 40 firms that were investigated in Wallace 1997).

The results of these studies show some startling contrasts that warrant further investigation. All conclude that the adoption of value-based performance measures leads to managerial decisions that can be expected to improve shareholder value. Investments are decreased, shares are repurchased, assets are used more intensively (Wallace 1997) and operating performance improves (Hogan \& Lewis 1999). Further scrutiny of the results raises doubts, however. The theoretical argument to support the contention that lower investments are beneficial for shareholders is weak. Where investment opportunities exist that have a higher return than the cost of capital, increased investments are beneficial for shareholders, which is in contrast with the behavior found by Wallace $(1997,1998)$. Furthermore, the performance improvement that was found by Hogan and Lewis (1999) was similar for firms adopting value-based performance measures and for the matched sample of non-adopters, raising doubt as to the causality. The contrast between the studies is remarkable in this area and leads the authors to divergent conclusions. Hogan \& Lewis (1999) conclude from their work that 'economic profit plans are no better than traditional plans that provide a blend of earnings-based bonuses and stock-based compensation in terms of their ability to create shareholder wealth'. Wallace (1998) concludes that 'EVA performance measures appear to help align the interest of management with those of the firm's shareholders'. 
An explanation for the conflicting results may be that the scope of the research is too limited to come to a clear conclusion with regard to the effect of implementing VBM. As was stated in chapter 2, introducing value-based management involves more than the simple introduction of value-based incentive systems. Haspeslach et al. (2001) find that value-based incentives are only one of the five main elements that distinguish companies that successfully implemented a VBM culture. By concentrating on incentives only, the above studies are unable to determine whether companies that were selected actually implemented a VBM culture or only a new incentive system, which may explain the conflicting conclusions. It is only possible to solve this issue when other research methods are used. The creation of a VBM culture and the introduction of VBM in all elements of management control are not captured in publicly available information. Either case studies or surveys need to be used to enhance the information that is publicly available. We therefore argue that further research into the relation between management control and shareholder value creation needs to apply a mixed research design that uses both publicly available information, with regard to operating and stock market performance, and insight into the design characteristics of management control as perceived and intended by the companies' management. In addition, this research needs to take into account that a number of contingency factors have been identified to influence the design of management control systems. Business strategy is an important factor in this respect and we will address this field of research next.

\subsection{Alignment of management control systems, strategy and value creation}

Contrary to the previous paragraphs, the discussion of the empirical research into the relationship between management control systems and business strategy will be limited to the discussion of the most important findings of a selected group of studies. Only the studies that produced results that have direct relevance to the research questions in chapter 7 are presented here.

Excellent review articles (Dent 1990, Chapman 1997, Langfield-Smith 1997, Chenhall 2003) have been published covering the complete field of research into (specific aspects of) management control systems and their relationship with strategy. That this relationship warrants further research is a conclusion that is confirmed in this literature. Langfield-Smith (1997, p. 207) writes 'that our knowledge of the relationship between management control systems and strategy is limited'. In line with the recommendations of Langfield-Smith, strategy can be approached as a multifaceted concept that comprises strategic positioning, strategic typology and strategic mission (see also section 2.4 of this dissertation). 
The basic notion of contingency theory is that management control systems should be modified in accordance with the business strategy of the firm. This notion has been tested empirically in a number of studies. Simons $\left(1987^{\mathrm{b}}\right)$ investigated differences in accounting control systems between prospector and defender firms and found evidence of differentiation between the two. Notably, he found that defenders appear to use their control systems less intensively than prospectors. That Simons finds differences is a confirmation of the expected contingency relationship. The directions of the differences are surprising in view of the fact that they are in contrast with the findings of Miles and Snow (1978) and Porter (1980). Both Dent (1990, p. 13) and Langfield-Smith (1997, p. 218) suggest that the scope of Simons' study - it only investigated differences in accounting control systems - may be too limited to properly describe the management control systems in all their facets and therefore capture the relevant differences. Dent's (1990, p. 13) conclusion in this respect is still valid today: 'Broader strategic and operational planning activities and non-financial performance measurement are not dealt with in any depth. Little, beyond hypothesis, is known of how these systems are actually used and what significance they are afforded in each type' (of strategy). Still some correlation between areas of management control and strategy has been established.

Both Miles and Snow (1978) and Porter (1980) came to the conclusion that defender/cost leadership strategies require strong reliance on cost controls. Early work by Khandwalla (1972) found that the type of competition in an industry was relevant to control and that more intense competition resulted in greater reliance on formal control systems. Strategy as such was not the object of this study and could therefore not be used to explain the observed differences. Looking at two different strategic types, entrepreneurial and conservative firms, the first resembling prospectors and the second defenders, Miller and Friessen (1982) found that the strategic type influenced how management controls were used. In entrepreneurial firms they were used to curb innovative excess, whereas in conservative firms they were used to indicate opportunities and areas where innovation was required. In an exploratory study Merchant $\left(1985^{b}\right)$ found differences in the level of discretionary decision-making between firms that followed a rapid growth strategy and firms that followed other strategies. This can be interpreted as an indication that empowerment may be related to strategy.

The direct question whether a management control system that is properly aligned to strategy produces better economic results has not been tested to date, no doubt because an overall model of management control systems is not available. Various studies have approached this question for a limited area of management controls, most notably incentive systems. Results in this area are fairly consistent. Firms following defender/harvest type strategies were found to benefit from reward systems that are based on objective performance criteria (Govindarajan \& Gupta 1985, Simons $1987^{\mathrm{b}}$, Govindarajan 1988). Firms following prospector/build strategies were found to rely on subjective, behavior-oriented, long-run performance evaluation criteria. This is in line with the higher uncertainty that can be expected from these strategies (Govindarajan \& Gupta 1985, Govindarajan 1988, Govindarajan \& Fisher 1990). Studying accounting information systems, Abernethy and Guthrie (1994) found that broad scope information systems were more effective in prospector firms than in defender firms. In their study of the relation between control systems, resource sharing and strategy, Govindarajan and Fisher (1990) found that output control and high resource sharing were more effective for low-cost strategies and behavior control and high resource sharing for differentiation strategies. They also found that low cost strategies were associated with a high level of resource sharing whereas differentiation strategies were associated with a wider range of levels of resource sharing (Govindarajan \& Fisher 1990, p. 279). 


\section{An overview of the empirical studies discussed above is provided in table 3.5 .}

Table 3.5 Research into the relation between management control systems and strategy

\begin{tabular}{|c|c|c|c|c|}
\hline Study & Research question & Research design & Measurement method & $\begin{array}{l}\text { Major conclu- } \\
\text { sions }\end{array}$ \\
\hline $\begin{array}{l}\text { Merchant } \\
1985^{\circ}\end{array}$ & $\begin{array}{l}\text { Explore how discre- } \\
\text { tionary program } \\
\text { decisions are con- } \\
\text { trolled in decentral- } \\
\text { ized firms. }\end{array}$ & $\begin{array}{l}\text { Questionnaire } \\
\text { survey among } \\
\text { profit center man- } \\
\text { agers of one US } \\
\text { firm. } 59 \text { responses } \\
(95 \%) \text { were ana- } \\
\text { lyzed. }\end{array}$ & $\begin{array}{l}\text { Sirategy was measured } \\
\text { using firm's own ter- } \\
\text { minology (harvest, } \\
\text { maintain, selective } \\
\text { growth, rapid growth). } \\
\text { Five different controls } \\
\text { over discretionary pro- } \\
\text { gram decisions were } \\
\text { measured (income tar- } \\
\text { gets, budget expense } \\
\text { targets, headcount con- } \\
\text { trols, procedural con- } \\
\text { trols and meetings). } \\
\text { Economic performance } \\
\text { measured from manag- } \\
\text { ers' perception. }\end{array}$ & $\begin{array}{l}\text { Decisions are } \\
\text { influenced by } \\
\text { controls. Effects } \\
\text { of controls vary } \\
\text { with characteris- } \\
\text { tics of profit cen- } \\
\text { ter situation like } \\
\text { strategy and re- } \\
\text { cent perform- } \\
\text { ance. } \\
\text { Controls were } \\
\text { perceived to have } \\
\text { a stronger effect } \\
\text { on decision- } \\
\text { making in profit } \\
\text { centers that were } \\
\text { planning to grow } \\
\text { more rapidly. }\end{array}$ \\
\hline $\begin{array}{l}\text { Govindarajan \& } \\
\text { Gupta } 1985\end{array}$ & $\begin{array}{l}\text { Examine linkages } \\
\text { between strategy. } \\
\text { incentive bonus } \\
\text { systems and effec- } \\
\text { tiveness at SBU } \\
\text { level within } 8 \text { di- } \\
\text { versified firms. }\end{array}$ & $\begin{array}{l}\text { Questionnaire } \\
\text { survey among } \\
\text { SBU general } \\
\text { managers with } 58 \\
\text { usable responses } \\
(85 \%) \text {. Out of } \\
\text { this group } 46 \\
\text { SBU's with bonus } \\
\text { entitlement of } \\
\text { more than } 20 \% \\
\text { of basic salary } \\
\text { were investigated. }\end{array}$ & $\begin{array}{l}\text { Strategy measured in } \\
\text { terms of mission } \\
\text { (build, hold, harvest } \\
\text { and divest) using one } \\
\text { single question. } \\
\text { Controls measured in } \\
\text { terms of importance of } \\
\text { performance criteria for } \\
\text { bonus determination } \\
\text { and reliance on formal } \\
\text { versus subjective crite- } \\
\text { ria. } \\
\text { Economic performance } \\
\text { measured by compari- } \\
\text { son of actual perform- } \\
\text { ance and a priori ex- } \\
\text { pectations of managers } \\
\text { (effectiveness index). }\end{array}$ & $\begin{array}{l}\text { Reliance on long- } \\
\text { run criteria and } \\
\text { subjective ap- } \\
\text { proaches to bo- } \\
\text { nus determination } \\
\text { are beneficial for } \\
\text { build strategies } \\
\text { and detrimental } \\
\text { in case of harvest } \\
\text { strategies. } \\
\text { The relationship } \\
\text { between reliance } \\
\text { on short-run cri- } \\
\text { teria and effec- } \\
\text { tiveness is virtu- } \\
\text { ally independent } \\
\text { of strategy. }\end{array}$ \\
\hline
\end{tabular}




\begin{tabular}{|c|c|c|c|c|}
\hline Study & Research question & Research design & Measurement method & $\begin{array}{l}\text { Major conclu- } \\
\text { sions }\end{array}$ \\
\hline Simons $1987^{\circ}$ & $\begin{array}{l}\text { Investigation of the } \\
\text { relationship be- } \\
\text { tween business } \\
\text { strategy and ac- } \\
\text { counting based per- } \\
\text { formance control } \\
\text { systems. }\end{array}$ & $\begin{array}{l}\text { Questionnaire } \\
\text { developed from } \\
\text { interviews and } \\
\text { previous work } \\
\text { was distributed } \\
\text { among senior } \\
\text { managers of } 261 \\
\text { Canadian manu- } \\
\text { facturing firms. } \\
\text { Data from } 76 \\
\text { Prospector and } \\
\text { Defender firms } \\
\text { were used for the } \\
\text { analysis. }\end{array}$ & $\begin{array}{l}\text { Strategy type (prospec- } \\
\text { tor and defender only) } \\
\text { measured on the basis } \\
\text { of expert ratings cross- } \\
\text { validated against man- } \\
\text { agers' self-typing. } \\
\text { Control system attrib- } \\
\text { utes were measured } \\
\text { through } 33 \text { questions } \\
\text { that were grouped with } \\
\text { factor analysis into } 10 \\
\text { groups (tights budget } \\
\text { goals, external scan- } \\
\text { ning, reporting fre- } \\
\text { quencies and others). } \\
\text { Industry dynamism } \\
\text { was used as control } \\
\text { variable. } \\
\text { Economic performance } \\
\text { measured as mean ROI } \\
\text { over three years. }\end{array}$ & $\begin{array}{l}\text { Firms following } \\
\text { different strate- } \\
\text { gies employ ac- } \\
\text { counting control } \\
\text { systems in differ- } \\
\text { ent ways. } \\
\text { High performing } \\
\text { prospectors at- } \\
\text { tach great impor- } \\
\text { tance to forecast } \\
\text { data, tight budget } \\
\text { goals and moni- } \\
\text { toring of outputs. } \\
\text { Defenders, par- } \\
\text { ticularly large } \\
\text { ones, use their } \\
\text { control system } \\
\text { less intensively. } \\
\text { Negative rela- } \\
\text { tions were found } \\
\text { between the per- } \\
\text { formance of these } \\
\text { defenders and } \\
\text { tight budget goals } \\
\text { and output moni- } \\
\text { toring. Defenders } \\
\text { emphasized bo- } \\
\text { nus remuneration } \\
\text { based on budget } \\
\text { targets. }\end{array}$ \\
\hline $\begin{array}{l}\text { Govindarajan } \\
1988\end{array}$ & $\begin{array}{l}\text { Matching adminis- } \\
\text { trative mechanisms } \\
\text { with strategy is } \\
\text { likely to be associ- } \\
\text { ated with superior } \\
\text { performance. }\end{array}$ & $\begin{array}{l}\text { Data were col- } \\
\text { lected from SBU } \\
\text { general managers } \\
\text { of } 24 \text { US firms. A } \\
\text { questionnaire was } \\
\text { used for data col- } \\
\text { lection. } 121 \text { ( } 84 \\
\% \text { ) usable replies } \\
\text { were analyzed } \\
\text { and validated } \\
\text { against responses } \\
\text { of superior man- } \\
\text { agers }(\mathrm{N}=75) \text {. }\end{array}$ & $\begin{array}{l}\text { Strategy was measured } \\
\text { in terms of Porter's } \\
\text { definitions of position } \\
\text { (cost leader or differ- } \\
\text { entiator). } \\
\text { Three administrative } \\
\text { mechanisms were iden- } \\
\text { tified: budget evalua- } \\
\text { tion style, decentraliza- } \\
\text { tion and locus of con- } \\
\text { trol. } \\
\text { Economic performance } \\
\text { was measured using the } \\
\text { effectiveness index } \\
\text { described by } \\
\text { Govindarajan \& Gupta } \\
1985 \text {. }\end{array}$ & $\begin{array}{l}\text { High managerial } \\
\text { internal locus of } \\
\text { control and low } \\
\text { emphasis on } \\
\text { meeting a budget } \\
\text { are associated } \\
\text { with high per- } \\
\text { formance for } \\
\text { differentiators. } \\
\text { The expected } \\
\text { interaction be- } \\
\text { tween SBU strat- } \\
\text { egy, decentraliza- } \\
\text { tion and effec- } \\
\text { tiveness could } \\
\text { not be confirmed. }\end{array}$ \\
\hline
\end{tabular}




\begin{tabular}{|c|c|c|c|c|}
\hline$\overline{\text { Study }}$ & Research question & Research design & Measurement method & $\begin{array}{l}\text { Major conclu- } \\
\text { sions }\end{array}$ \\
\hline $\begin{array}{l}\text { Govindarajan \& } \\
\text { Fisher } 1990\end{array}$ & $\begin{array}{l}\text { Investigation of the } \\
\text { relationships among } \\
\text { control systems, } \\
\text { resource sharing. } \\
\text { and competitive } \\
\text { strategies and their } \\
\text { interactive effects } \\
\text { on SBU perform- } \\
\text { ance. }\end{array}$ & $\begin{array}{l}\text { Data collected } \\
\text { from SBU general } \\
\text { mangers of } 24 \text { US } \\
\text { firms. } 121 \text { ( } 84 \%) \\
\text { usable responses } \\
\text { were obtained. }\end{array}$ & $\begin{array}{l}\text { Strategy was measured } \\
\text { in terms of Porter's } \\
\text { definitions of position } \\
\text { (cost leader or differ- } \\
\text { entiator). } \\
\text { Output and behavior } \\
\text { controls were sepa- } \\
\text { rated. In addition re- } \\
\text { source sharing between } \\
\text { SBU's was measured. } \\
\text { Economic performance } \\
\text { was measured using the } \\
\text { effectiveness index as } \\
\text { described for } \\
\text { Govindarajan \& Gupta } \\
1985 \text {. }\end{array}$ & $\begin{array}{l}\text { Output control } \\
\text { combined with } \\
\text { high resource } \\
\text { sharing is associ- } \\
\text { ated with in- } \\
\text { creased effec- } \\
\text { tiveness for low- } \\
\text { cost SBUs. } \\
\text { For differentia- } \\
\text { tion SBUs with } \\
\text { high (low) re- } \\
\text { source sharing. } \\
\text { behavior (output) } \\
\text { control is associ- } \\
\text { ated with in- } \\
\text { creased effec- } \\
\text { tiveness. The } \\
\text { highest effective- } \\
\text { ness for differen- } \\
\text { tiation SBUs re- } \\
\text { sults when be- } \\
\text { havior controls } \\
\text { are combined } \\
\text { with high re- } \\
\text { source sharing. }\end{array}$ \\
\hline $\begin{array}{l}\text { Abernethy \& } \\
\text { Guthrie } 1994\end{array}$ & $\begin{array}{l}\text { To examine the } \\
\text { differences in de- } \\
\text { sign of management } \\
\text { information sys- } \\
\text { tems in firms adopt- } \\
\text { ing different strate- } \\
\text { gic priorities. }\end{array}$ & $\begin{array}{l}\text { A sample of } 49 \\
\text { business unit gen- } \\
\text { eral managers } \\
\text { from two compa- } \\
\text { nies based in Aus- } \\
\text { tralia was used. } \\
\text { Questionnaires } \\
\text { were used for data } \\
\text { collection. }\end{array}$ & $\begin{array}{l}\text { Strategy type (prospec- } \\
\text { tor and defender only) } \\
\text { measured on the basis } \\
\text { of expert ratings cross- } \\
\text { validated against man- } \\
\text { agers' self-typing. } \\
\text { Information was stud- } \\
\text { ied in terms of focus } \\
\text { (in- or external), quan- } \\
\text { tification and time ho- } \\
\text { rizon. On this basis } \\
\text { narrow (internal, his- } \\
\text { torical, financial) scope } \\
\text { and broad (external, } \\
\text { future oriented and } \\
\text { non-financial) scope } \\
\text { information systems } \\
\text { were distinguished. } \\
\text { Economic performance } \\
\text { was measured using the } \\
\text { effectiveness index } \\
\text { (Govindarajan \& Gupta } \\
\text { 1985). }\end{array}$ & $\begin{array}{l}\text { Effectiveness of } \\
\text { business units is } \\
\text { dependent on the } \\
\text { match between } \\
\text { the design of in- } \\
\text { formation sys- } \\
\text { tems and the stra- } \\
\text { tegic posture. } \\
\text { Broad-scope in- } \\
\text { formation sys- } \\
\text { tems are more } \\
\text { effective for } \\
\text { prospectors. }\end{array}$ \\
\hline
\end{tabular}

ROI $=$ Return on Investment, $\mathrm{SBU}=$ Strategic Business Unit 
For our research the key question remains whether management control systems that are properly aligned to strategy explain economic success. From our research perspective success will be defined in terms of shareholder value creation. Contrary to earlier studies an attempt will be made to use an overall model of management control to investigate the answer to this question.

\subsection{Summary and conclusions}

A considerable body of literature on the application of value-based management has been produced that provides insight into practices around the world and shows that the recognition of shareholder value creation as an important objective is widespread and that companies have actively implemented VBM in recent history. Most studies in this area have been produced by consultants and lack a strong conceptual foundation and empirical validation. They only provide limited understanding of the basic advantages obtained from applying VBM. The association between stock returns and value-based performance measures has been investigated in more detail resulting in the insight that value-based performance measures indeed provide additional value relevance but do not outperform traditional accounting based performance measures in this respect. This raises the question whether application of these value-based performance measures can contribute to improved creation of value for shareholders, which will be investigated in chapter 5 .

The impact of certain management controls on the creation of value for shareholders has received only limited attention in empirical work to date. Furthermore, this attention has been focused on a specific aspect of management control, namely incentive systems. There is evidence that incentive systems using value-based performance measures influence managerial behavior, though it remains unclear whether this results in improved creation of value for the shareholder. In chapter 6 the relation between management control and shareholder value creation will be investigated further.

Empirical research into the aspects of management control systems and their relationship with strategy has shown that control system tightness, reliance on cost controls, empowerment and the use of objective or subjective performance evaluation criteria are contingent on the strategy pursued by a business. In these studies different dimensions of strategy have been used as point of departure: positioning, typology and mission. The understanding of the causal relationship between strategy and management control remains limited and conclusive evidence of a beneficial impact on economic performance of certain management controls for specific strategies is missing. In chapter 7 we will attempt to obtain a better understanding of this relationship when we investigate whether management control systems that are aligned to strategy explain the creation of value for shareholders. 


\section{Research method and sample}

\subsection{Introduction}

The hypotheses that we want to test all relate to the relationship between shareholder value creation and the design of management control systems.

In the previous chapter it already became clear that this research would benefit from an approach that uses publicly available information with respect to the financial performance of organizations, and information from those organizations themselves with respect to the design and use of their management control system. This latter information should also provide insight into how VBM was applied by these organizations.

To gather the required information it was decided to use a questionnaire that would be mailed to the CFOs of all companies listed on the Amsterdam Exchanges at the end of the year 2000. The questionnaire was not anonymous and therefore the results of the companies that participated could be related to the performance of their shares on the Amsterdam market and to publicly available information about these companies.

This chapter describes the target audience, the design of the research instrument, the testing of the research instrument, the execution of the survey, the response received and the tests that have been performed to determine whether response bias was present. It was clear from the outset that target respondents were not an easy audience that could be expected to provide a high response rate. Typically the CFOs of listed companies have very limited time for responding to questionnaires. 


\subsection{The target audience}

It was decided to limit the scope of the investigation to Dutch companies listed on the Amsterdam Exchanges. Using a wider geographical sample would no doubt be interesting but it would also make interpretation of the final outcome of the investigation much more difficult. It has been established that management control systems differ between countries and cultures (Daniel \& Reitsperger 1992, Chow et al. 1999, Wijerwardena \& De Zoysa 1999), and these differences would create difficulty in judging any outcome of a survey that was spread over more than one country.

A second reason for limiting the research to the Netherlands is simply practical: the companies concerned are more easily contacted, the cost of contacting them is limited, and they can be expected to know the Universiteit Maastricht and will therefore be more likely to respond than foreign companies. Based on these considerations, it was decided to conduct the research among the companies that were listed in Amsterdam as at the end of 2000.

A list was obtained from the Amsterdam Exchanges that contained all the companies listed as at December 20,2000. In view of the fact that no new listings or de-listings occurred between the moment that the list was compiled and the end of the year, this group was taken as the starting point.

In accordance with the decision to research the management control systems of Dutch companies, six listed companies were removed from the list because they were essentially foreign. These were companies that have a large majority of their activities outside the Netherlands and have an operational head office that is also located abroad. In addition, 11 financial institutions were removed from the list in view of the limited comparability of these organizations to the remainder of the listed companies. Finally, two companies were removed from the list due to the fact that they went into receivership early in 2001 , which made it impossible to obtain responses from these companies. After these eliminations a group of 169 companies remained that was invited to co-operate in the research. In Appendix 1, 'Target audience and response', an overview is provided of the companies listed as at the end of 2000 , the names of the companies that were eliminated with the reason for their elimination and the final audience for the survey. The build-up of the target audience is summarized in table 4.1

Table 4.1 Target Audience

\begin{tabular}{lc}
\hline & Number of Companies \\
\hline Total number of companies listed per the end of 2000 & 188 \\
Excluded foreign companies & -6 \\
Excluded financial institutions & -11 \\
Bankruptcies early 2001 & -2 \\
Target audience & 169 \\
\hline
\end{tabular}


To ensure that the replies to the questionnaire referred to the management control system of the whole organization and not to individual businesses or subsidiaries of the listed companies, it was decided to send the instrument to the CFO/Finance Director (henceforth referred to as CFO) of the companies. In line with Dillman's $(1978,2000)$ recommendations, the covering letter should preferably be addressed to the CFO personally. This made it necessary to obtain a file with the names of the CFOs. Such a file was not available and needed to be assembled as part of the research. Based on the 'Jaarboek van Nederlandse Ondernemingen 2000' (Tijd Beursmedia 2000), a provisional and incomplete list was prepared. In a number of cases missing names could be added from internet-searches. All companies were contacted in January/February 2001, either to verify the name and address details of the CFO, or to obtain his or her name in case this was not yet available. Ultimately, it was possible to identify the CFO for 168 out of the 169 companies that were to be mailed. Only for Emba Techniek NV was it not possible to obtain information, and it had to be decided to address all correspondence to 'the Finance Director'.

\subsection{The research instruments}

\subsubsection{Management control system characteristics}

An instrument that captures the overall composition of the management control system of an organization is not readily available.

A two-step approach was used to develop the instrument to capture the management control system design. Based on a review of the relevant literature and empirical work, a list of 15 elements was developed, which were expected to provide a total description of the management control system of an organization. The list was grouped along the lines of the four levers of control developed by Simons $\left(1994,1995^{\mathrm{a}}, 1995^{\mathrm{b}}\right)$, to be able to relate the results of subsequent fieldwork to these levers. The list of topics in itself was generic and was expected to include all relevant aspects of management control. 
An expert panel was subsequently used to validate and order the list. The expert panel consisted of 13 professors teaching management accounting at Dutch universities, who were asked to express their opinion on the 15 elements of management control system design, in a questionnaire that contained a provisional ordering of these elements along the levers of control. They were asked to select 9 characteristics that they found the most important to describe management control systems. Definitions of all 15 elements were provided to avoid interpretation differences. The instrument was sent by e-mail to all participants on June 27, 2000. E-mail was selected in view of the speed and ease of access to the recipients. The initial response was 4 returned reply forms and one reply indicating disagreement with the proposed ranking. The last respondent was interviewed on July 13 to better understand his opinion. On July 17 a fax-reminder was sent to 8 participants. Subsequently 2 additional replies were received. In view of the summer holiday, the next reminder was only sent on August 29. In the interim period, the chance of contacting the respondents was considered to be too low. The complete questionnaire with an appropriate final request was sent to the 6 participants that had not yet replied by August. One additional reply was received after that. On September 15 the missing respondents were contacted by phone. Two could be reached. One explained that he felt unable to respond because he did not agree with the design of the questionnaire. He explained his views in a 30-minute telephone interview. The other participant requested a new copy of the instrument and replied by September 27. An additional reply was received on October 10.

All in all, this resulted in 9 replies and 2 additional interviews. One respondent returned the reply form with a selection of the elements he found important without ranking them as he

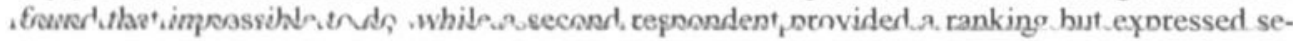
rious reservations with regard to its validity. This was not a major concern because the ranking in itself was of secondary importance. The prime reason to consult the expert panel was to select the most relevant areas to be covered in the research instrument and to obtain input on any areas that might be missing in the provisional list. Missing elements were not identified, and a consensus among the members of the expert panel emerged on 10 elements. These are presented in table 4.2 , including an allocation to the levers of control. The table lists the number of respondents that selected a characteristic as important and their percentage out of the total group of 9 respondents. The allocation to the levers of control was not used in the subsequent development of the research instrument. Separate research questions were developed for all 10 characteristics.

Table 4.2 Summary of expert panel questionnaire

\begin{tabular}{|c|c|c|c|}
\hline Lever of control & MCS Characteristics & $\begin{array}{l}\text { Number of } \\
\text { responses }\end{array}$ & Percentage \\
\hline \multirow[t]{3}{*}{ Beliefs systems } & Company culture & 9 & $100 \%$ \\
\hline & Management style & 8 & $89 \%$ \\
\hline & Mission statement or credo & 5 & $55 \%$ \\
\hline \multirow[t]{3}{*}{ Boundary systems } & Codes of conduct & 8 & $89 \%$ \\
\hline & Internal controls & 7 & $78 \%$ \\
\hline & Organizational structure & 5 & $55 \%$ \\
\hline Diagnostic control & Balanced scorecard and non-financial & & \\
\hline \multirow[t]{3}{*}{ Systems } & performance measures & 6 & $67 \%$ \\
\hline & Budgeting system & 6 & $67 \%$ \\
\hline & Cost and variance analysis & 6 & $67 \%$ \\
\hline $\begin{array}{l}\text { Diagnostic control or } \\
\text { belief system " }\end{array}$ & Incentive system & 6 & $67 \%$ \\
\hline
\end{tabular}

1) The replies with regard to incentives were mixed; three times they were mentioned as diagnostic controls and also three times as beliefs systems. 
In the table only three out of the four levers of control are mentioned because interactive control systems were excluded from the questionnaire (with an explanation in the accompanying letter). The reason for this exclusion was that interactive controls can be any type of control; it is the interactive use of these controls by management that distinguishes them, not the type of control itself.

For the above 10 management control system characteristics, research questions were developed. Based on the input from the expert panel one element, balanced scorecards and nonfinancial performance measures was split into two elements: importance attached to financial performance measures and importance attached to non-financial performance measures. In addition to general questions asking the CFOs to indicate the importance they attached to these characteristics of management control systems, support questions were developed to obtain further insight into how management control actually worked.

The CFOs were asked to rank the importance of all 11 characteristics on a 7 - point Likertlike scale that was anchored at three points (not important - average importance - very important).

\subsubsection{Role of accounting information and level of delegation}

Additional questions were included to measure the role of accounting information and the level of delegation to be able to obtain a richer understanding of the way that management control was performed by the companies in the sample. For these two elements existing research instruments were used. The role of accounting information was measured in accordance with the instrument developed by Abernethy and Brownell (1997) and the level of delegation in accordance with Chow et al. (1999). These measures were not used for the research that is discussed in this dissertation and remain available for future work.

\subsubsection{Application of value-based management}

To obtain insight into the application of value-based management, a second part of the questionnaire was developed. As already described in paragraph 3.2, various surveys are available in this area. It was decided to replicate the research of Buhr and Desjardins (1998) as far as possible. The reasons for this choice were: 1) it is one of the few independent surveys addressing VBM practice, 2) the full research instrument has been published, 3) responses have been published in detail, and 4) the responses represented a broad cross-section of companies in a certain country (although both listed and unlisted companies were included, an aspect that differs from our research design). Using these questions would allow us to validate the results obtained for the Netherlands. 


\subsubsection{Business strategy}

The three strategy dimensions that we needed to investigate have been previously researched and established research instruments are available. The questions have been based on Snow and Hrebeniak (1980) for strategic type, Govindarajan and Gupta (1985) for strategic mission and Govindarajan (1988) for strategic positioning. In addition, the degree of diversity in the portfolio of an organization was asked for, using an instrument developed by Christie et al. (2003). The reason for this additional question was the fact that the questionnaire would be addressed to the CFOs of the companies. Therefore, the replies to the strategy questions would not necessarily reflect the individual business strategies of business units in multidivisional firms. The instruments to be used to research strategy have been used before at the strategic business unit level. To be able to analyze whether the replies received deviate from previous studies as a result of this difference in vantage point (group level or strategic business unit level), portfolio diversity was measured.

\subsubsection{The overall questionnaire}

The questionnaire comprising the various research instruments that was ultimately used is summarized in Appendix 2. Cross-references, relating those questions that were replications back to the original research, have also been included in that appendix. An overview of the research questions and the constructs they measure, including references to the origin of replicated questions, is provided in table 4.3. The order of the individual questions in the questionnaire was determined on the basis of the recommendations of Dillman $(1978,2000)$.

Table 4.3 Overview of the research questions

\begin{tabular}{|c|c|}
\hline Subject & Question number \\
\hline General introduction & 1 \\
\hline Application of value-based management & $5^{\prime \prime}, 33^{\prime \prime}, 34$ \\
\hline $\begin{array}{l}\text { Background information on value-based manage- } \\
\text { ment }\end{array}$ & $\begin{array}{l}18^{\prime \prime}, 19^{\prime \prime}, 35,40^{\prime \prime}, 41,42^{\prime \prime}, 43^{\prime \prime}, 44^{\prime \prime}, 45^{\prime \prime}, 46^{\prime \prime}, \\
47^{\circ *}, 48^{* *}\end{array}$ \\
\hline Management control system characteristics & $2,6,12,15,16,17,25,26,29,36$ \\
\hline Background on management style & 27,28 \\
\hline Role of accounting information & $4^{\circ}$ \\
\hline Level of decentralization & $37^{m+1}$ \\
\hline $\begin{array}{l}\text { Additional information on management control sys- } \\
\text { tem }\end{array}$ & $\begin{array}{l}3,7,8,9,10,11,13,14,20,21,22,23,24,30,31, \\
32^{\circ}, 38,39\end{array}$ \\
\hline Business strategy & $49^{1}, 50^{m}, 51^{m+1}, 52^{m m}$ \\
\hline
\end{tabular}

- Abernethy \& Brownell 1997

* Buhr \& Desjardins 1998

** Chow et al. 1999

\# Govindarajan \& Gupta 1985

H\# Snow \& Hrebiniak 1980

\#\#\# Govindarajan 1988

\#\#\#\# Christic et al. 2003 
The questionnaire was not translated into Dutch. The consideration underlying the decision to opt for an English language instrument was twofold. A number of CFOs of listed companies in the Netherlands were in fact not Dutch and could not be expected to be familiar with the language. This would mean that either two versions of the instrument were needed or that part of the target audience could not be reached. A second consideration was that translation of a number typical VBM terms is impossible. For example, there is no Dutch translation for EVA and introducing one would simply cause confusion. Furthermore, use of an English language instrument would facilitate replication of the research in other countries. Due to the open character of the Dutch economy it could be anticipated that all CFOs would be able to answer an English language instrument. In view of the fact that questions came from various sources, including a number that were developed by the researcher, a translator was asked to review the draft instrument, and his recommendations were incorporated in the questionnaire before field testing.

\subsection{Testing the questionnaire}

The questionnaire was reviewed and commented upon by an experienced accounting researcher at Maastricht University. Simultaneously, all questions in the instrument were checked against the recommendations from Dillman's Tailored Design Method (Dillman 2000). In view of Dillman's (p. 92) advice to start a questionnaire with a first question that applies to everyone, is easy to answer, short, not open-ended and interesting; the first question was added to the instrument. It was not directly needed for the subsequent analysis but was simply meant to give the respondents an easy start into the questionnaire.

On the basis of these inputs a second draft of the questionnaire was produced for a test in the field. For this purpose three business controllers, working at the Product Division or Business Unit level in Royal Philips Electronics N.V., were invited to fill out the questionnaire in the presence of the researcher. They were subsequently interviewed to obtain insight into areas of unclarity or interpretation difficulties they had when they answered the questions. Interview protocols were written to keep track of their comments. In addition, the time they needed was established. In view of the fact that these controllers were responsible for businesses that - individually - were at least of the size of a medium-sized company listed in Amsterdam, they were assumed to be a good proxy for the target audience. Some questions could not be answered directly by the respondents because their business had no traded shares. They were asked to answer these questions as if they were the CFO of Royal Philips Electronics NV, to ensure that the complete instrument was actually tested. Based on the input from these tests, the wording of a number of questions was altered to make them more-clear and less open to interpretation.

The graphic design of the instrument was developed using experience with previous accounting research instruments developed at Maastricht University, and the recommendations of Dillman's Total Design Method (1978) and Tailored Design Method (2000). In the end 275 copies of a booklet of twenty-four A4-format pages were printed on high-quality paper. 


\subsection{Distribution and follow-up}

From the outset it was clear that the target audience would be a challenge with regard to the response that could be expected. CFOs tend to have a busy schedule and are not necessarily strong advocates of academic research. In addition, it is known that they are inundated with surveys and requests for research co-operation. In view of this, the execution of the research was carefully planned and, to the extent possible, the recommendations of the Total/Tailored Design Method (TDM) were followed. It was decided to apply various communication formats to contact the target audience (letter, postcard, telephone-calls, e-mail messages). The total process of conducting the survey consisted of six steps that were taken in accordance with the TDM. As a first conclusion, it can be stated that the target audience is considerably more difficult to elicit a response from than the populations that Dillman usually addresses. Although Dillman states that 'repeated tests of this one-size-fits-all approach [the TDM] showed that response rates of $70 \%$ could be produced consistently for general public populations, and higher rates were feasible for more specialized populations..........the method has consistently produced higher response rates than are traditionally expected from mail surveys', rigorous application of all his recommendations resulted in 68 returned questionnaires from the total of 169 that were mailed-out, a response rate of $40.2 \%$. The questionnaire was not anonymous, a factor that was considered beforehand to potentially reduce the willingness of some CFOs to participate. This last aspect was not confirmed in the execution of the survey. In 32 cases the CFO responded at some stage that he or she would not participate in the survey, in all these cases the reason mentioned was either lack of time or a company policy not to participate in surveys. Sensitivity of the information as such was not given as a reason for not responding. In the later phase of the survey, CFOs were called or e-mailed with a final request for co-operation. In these contacts, sensitivity of the information was never mentioned as an objection either.

It needs to be recognized that in 10 cases the response rate was positively influenced by the fact that the CFOs had an additional incentive to respond because they either knew the researcher personally or because they were asked by a member of their company's Supervisory Board to participate in the project. Out of these 10 companies, 8 have responded. An overview of the target audience and the response is presented in Appendix 1.

The total process of conducting the survey consisted of six steps. A letter explaining the purpose of the research and announcing the survey was sent to all participants on March 9, 2001. This letter and all subsequent letters were personally addressed to the CFO and signed by hand.

The survey was mailed with a second letter to the participants on March 16. The mail-out package contained the letter, the printed questionnaire, a stamped self-addressed return envelope and a mini-coinset of the Netherlands, as a token of appreciation. Based on the TDM, a small gift was used to encourage the response. The choice of a gift was not obvious. Money that is often given in the US, was felt to be inappropriate with respect to the target audience, while gifts like a pen were not expected to attract sufficient attention. The coinset provided a suitable in-between solution in this respect. 
Three weeks after sending the package, on April 6, a postcard was sent to all recipients thanking them for returning the questionnaire or reminding them to do so. This card was also signed by hand and addressed to the CFOs personally. In view of the TDM advice to vary the form of communication, a postcard was preferred to a letter in this case. Those who had not replied by April 20 received a new letter on that date with a new questionnaire and a new self-addressed return envelope. In this case the return envelope was not stamped, and a postage paid ('antwoordnummer') envelope was used instead. On June 1, a last effort was made to increase the response. All companies that had not responded by that date were called, with the objective of reminding the CFO once more of the questionnaire. As was expected, only a limited number of CFOs could be contacted in person either on that day or at an agreed time in the subsequent week. For the others, e-mail addresses were obtained. They received an email on June 5 reminding them of the survey and once again asking for a reply. In 6 cases this resulted in a request to re-submit the questionnaire, which was promptly dealt with (together with a postage paid return envelope). In June and early July the last replies were received which, in the end, resulted in 68 questionnaires that were returned, $40.2 \%$ of the target audience. Although $40.2 \%$ is not high in relation to the standards applied by Dillmann (1978, 2000 ), it certainly compares favorably with other survey research in the Netherlands that addressed a similar audience. In his research into capital budgeting practices Verbeeten (2001) obtained a response of $26.9 \%$ from the CFOs of 704 large organizations he addressed, Herst et al. (1998) obtained a $21 \%$ response to their inquiry into investment decision-making. The response rate also compares favorably to the studies into value-based management practice quoted in chapter 3.

While the survey was being conducted, the questionnaires that were returned were registered in the software that was going to be used for the statistical analysis, SPSS. This revealed five cases where the respondent had not filled out one or more pages of the questionnaire. On May 1, these five respondents were asked by fax to complete their input with the missing information. All five replied to the request. Although it is suggested that missing data can be an indication of inappropriateness of the instrument for the recipient (Hartmann 1997, Moers 2001), it can be assumed that this was not applicable in these instances. The recipients had clearly missed one or more pages and, due to the fact that the instruments covered a number of areas, they could not be expected to spot their mistake easily, while filling out the questionnaire. Based on this consideration it was decided to include their additional replies in the subsequent analysis.

\subsection{Response: representativeness and bias}

\subsubsection{Representativeness}

With 68 returned questionnaires available for analysis, the replies represented slightly more than $40 \%$ of the relevant Amsterdam market. The representativeness of the response group for the total population needed analysis. In addition, due to the fact that the response was below $100 \%$, it needed to be established whether non-response bias was present. Various analyses were performed to determine the match between the response group and the market. 
An industry comparison was performed comparing the response group to the target audience; the total group of companies listed on the Amsterdam Exchanges at the end of 2000 excluding financial institutions and foreign companies. All companies in the target audience were ranked into 12 industry categories, as distinguished in the 'Handboek Nederlandse Beursfondsen 1999' (Het Financieele Dagblad 1999). The resulting distribution is provided in table 4.4 and figure 4.1 .

Table 4.4 Industry distribution of target audience and response group

\begin{tabular}{|c|c|c|c|c|}
\hline \multirow[t]{2}{*}{ Industry } & \multicolumn{2}{|c|}{ Target audience } & \multicolumn{2}{|c|}{ Response group } \\
\hline & Number & $\%$ & Number & $\%$ \\
\hline 1. Information technology/software & 29 & $17 \%$ & 10 & $15 \%$ \\
\hline 2. Services & 13 & $8 \%$ & 6 & $9 \%$ \\
\hline 3. Retail & 8 & $5 \%$ & 4 & $6 \%$ \\
\hline 4. Metal and capital goods & 18 & $11 \%$ & 8 & $12 \%$ \\
\hline 5. Construction & 16 & $9 \%$ & 6 & $9 \%$ \\
\hline 6. Wholesale & 15 & $9 \%$ & 5 & $7 \%$ \\
\hline 7. Media and entertainment & 9 & $5 \%$ & 4 & $6 \%$ \\
\hline 8. Transport & 8 & $5 \%$ & 5 & $7 \%$ \\
\hline 9. Paper/textiles/plastics & 15 & $9 \%$ & 4 & $6 \%$ \\
\hline 10. Food and beverages & 8 & $5 \%$ & 4 & $6 \%$ \\
\hline 11. Electronics/hardware & 19 & $11 \%$ & 5 & $7 \%$ \\
\hline 12. Chemicals/energy/pharmaceuticals & 11 & $6 \%$ & 7 & $10 \%$ \\
\hline Total & 169 & $100 \%$ & 68 & $100 \%$ \\
\hline
\end{tabular}

Figure 4.1 Industry distribution of target audience and response group (in \%).

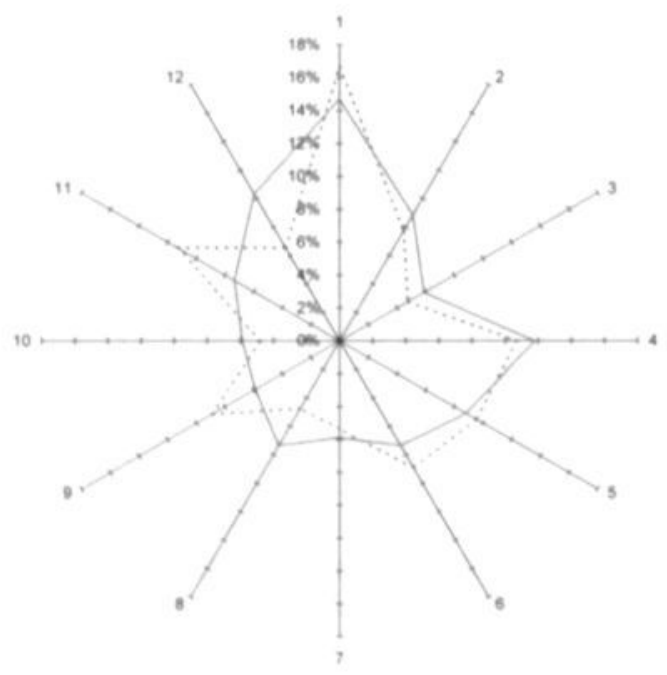


The table and graph clearly show that the response group covers all industries. The distribution of the response group over the individual industry categories closely mirrors the distribution that was found for the market as a whole. From this analysis we concluded that the response group provides a fair representation of the industry distribution of the total market and is representative in this respect.

To determine the extent to which the response group was a fair reflection of the total population of companies listed on the Amsterdam Exchanges as at the end of 2000 we also analyzed whether size and economic characteristics of companies in both groups were similar. For this purpose a number of accounting characteristics of both groups were compared. The information was obtained from Reach and completed with information from the annual reports of companies that were not (or no longer) available in Reach. The comparison was based on the annual reports for 2000 . For companies that had an accounting year that differed from the calendar year, the annual report for the year that was closed during the calendar year 2000 was used. In 3 cases annual reports for 2000 could not be obtained because the company either went bankrupt early in $\mathbf{2 0 0 1}$ or was taken over by, or merged with, another company. In these cases the 1999 figures were used. In view of the limited number of companies concerned, it is assumed that this does not distort the results. After these 3 companies were removed from the target audience, the comparison led to virtually the same results, which confirms that assumption. The means and averages of a number of accounting measures that reflect both size and profitability of both groups were compared. The information is provided in table 4.5

Table 4.5 Comparison of accounting information for response group and the target group for 2000

\begin{tabular}{lcccc}
\hline Accounting measures & \multicolumn{2}{c}{ Median } & \multicolumn{2}{c}{ Average } \\
\hline Size & Target & Response & Target & Response \\
\hline Sales (NLG 1,0 million) & 664 & 1,749 & 6,057 & 11,975 \\
Total Assets (NLG 1,0 million) & 500 & 965 & 5,262 & 8,394 \\
Equity (NLG 1,0 million) & 175 & 242 & 1,916 & 3,370 \\
Number of employees (1.000) & 1,649 & 3,958 & 13,081 & 25,969 \\
& & & & \\
Return & 19 & 57 & 340 & 727 \\
\hline Net income (NLG 1,0 million) & $17 \%$ & $17 \%$ & $13 \%$ & $17 \%$ \\
Return on average equity & $8 \%$ & $8 \%$ & $8 \%$ & $7 \%$ \\
Return on total assets & & & & \\
& & & & \\
\hline
\end{tabular}

\footnotetext{
' Reach is a database owned by Elsevier Publishers. It includes accounting information of Dutch companies.
} 
From the comparison between the response group and the target audience, it can be concluded that the companies that responded were larger in all size aspects than the average/median of the total market. In that respect the response group may not be a fair representation of the total group of companies listed as at the end of 2000 . In view of the fact that Philips Electronics, Royal Dutch and Unilever were all included in the response group, there is a likelihood that the comparison is strongly biased by the presence of these three large multinationals. Excluding the three biggest companies from both the target audience and the response group leads to results that are in line with those presented in the table above. The conclusion remains that large companies are over-represented in the response group, even when we exclude the big three from the comparison. What is important is that any conclusion that we will draw in the remainder of this dissertation may be biased towards the practices of larger listed companies. Where appropriate, we will use size of the organizations involved as a control variable in our analysis to determine whether there are indications that the results are influenced by size. Annual sales will be used as a proxy for company size, among other reasons because this is an area where the observed differences between the response group and the target audience are the largest.

Table 4.5 shows that the response group does represent the target audience in terms of accounting returns. For both accounting performance measures the median and average performance of the response group is similar to that of the market over 2000. Again, in absolute profit amounts, the response group has a higher profitability but in relative terms the performances of both groups are very alike. For these return measures the exclusion of Philips Electronics, Royal Dutch and Unilever from the comparison did not lead to different conclusions.

It should be noted that the response group contains a number of companies that obtained a listing during the years $1997-2000$, the period that will be covered in this dissertation. For these companies a complete set of accounting information is available but obviously capital market based data like shareholder returns are only available for the period that the company was listed. In the analysis in the next chapters the number of companies that were analyzed $(\mathrm{N})$ is always mentioned in view of the fact that this number may be lower than 68 in a number of cases, due to the absence of the required data.

\subsubsection{Response bias analysis}

Since the response to the survey was not $100 \%$, we had to take into consideration that response bias might be present in the empirical data that were obtained. A number of possible approaches to test for non-response bias are available. Additional information can be obtained with regard to the companies that did not respond to the questionnaire or responses of the early and late respondents for the variables that are critical for the study can be compared (Wallace \& Mellor 1988, Brownell 1995). The first possibility has been used to some extent in the preceding part, where we compared the accounting and return characteristics of the respondents to those of the full target audience. This showed that large companies, in terms of accounting measures of size, were over-represented in the response group. Any conclusions we draw are therefore more likely to apply to larger companies than to small listed companies. Attitude towards value creation and design of management control systems cannot be derived from the analysis presented before. Obtaining additional information in this respect would only be possible through interviews or a second questionnaire, which was not feasible. Companies that had not responded in the first place could not be expected to invest the time in a second attempt to obtain the relevant information. 
Therefore the second approach was used, and the mean scores of the first 27 and last 28 respondents, on the relevant variables, were compared. As the responses were collected in batches, splitting the response group at the mean, a method often applied for these comparisons, was not exactly possible. Instead the group of 13 companies whose replies were received between the first and the last group were removed from the comparison. When no significant differences are found between the early and late respondents this suggests the absence of non-response bias, based on the assumption that the replies from late respondents approximate to those of non-respondents and therefore, if these are not significantly different from the early respondents, the same can be expected to apply for non-respondents. This approach is especially relevant in our research design in view of the fact that, for a number of companies that replied late, the response level was improved by having Supervisory Board members or other senior managers of companies, who were personally known to the researcher, ask the CFO to participate in the survey. It can be argued that these companies would not have participated if this action had not been taken and therefore that they represent the non-respondents. The mean scores on the important research variables for the first and last respondents are listed in the following table, together with the result of an independent samples t-test for the differences in the respective means.

Table 4.6 Test for non-response bias (t-test)

\begin{tabular}{lcccc}
\hline Variable & First 27 & Last 28 & t-value & Sign. \\
\hline Importance of financial performance measures & 6.04 & 5.86 & 0.828 & 0.411 \\
Importance of non-financial performance measures & 5.22 & 5.39 & -0.553 & 0.583 \\
Importance of budgeting & 6.26 & 6.18 & 0.983 & 0.330 \\
Importance of codes of conduct & 4.48 & 4.64 & -0.437 & 0.664 \\
Importance of company culture & 5.37 & 5.39 & -0.071 & 0.944 \\
Importance of cost and variance analysis & 5.15 & 5.54 & -1.100 & 0.276 \\
Importance of incentives & 5.56 & 5.44 & 0.389 & 0.699 \\
Importance of internal controls & 5.48 & 5.82 & -1.341 & 0.186 \\
Importance of management style & 5.30 & 5.75 & -1.653 & 0.104 \\
Importance of mission statement & 4.22 & 4.26 & -0.097 & 0.923 \\
Importance of organizational structure & 5.70 & 5.82 & -0.418 & 0.678 \\
Decentralization & 39.68 & 42.65 & -1.628 & 0.110 \\
Mission & 0.11 & 0.14 & -0.407 & 0.686 \\
Strategy type & 2.59 & 2.30 & 1.087 & 0.282 \\
Positioning & 4.65 & 4.64 & 0.110 & 0.991 \\
Relatedness & 2.59 & 3.00 & -1.522 & 0.134 \\
Value-based management (yes/no) & 1.52 & 1.43 & 0.658 & 0.513 \\
\hline
\end{tabular}

The t-test that was performed confirms that equal variances are present in both groups, and therefore there is no indication for non-response bias in the replies that were received. The 11 questions asking the CFOs for the importance they attached to certain aspects of management control were asked for the end of the year 2000 and 4 years earlier. The replies as at the end of the year 2000 are reported in table 4.5. Similar results were obtained when the replies for 4 years earlier were analyzed. These tests corroborate anecdotal evidence that was collected during the execution of the survey. At various stages information was obtained from the companies that did not cooperate with respect to their motives for not doing so. The reasons mentioned were either a company policy not to spend time on research like this or a lack of time. These reasons were not related to the opinion of the CFOs with regard to the subject of our investigation. 


\section{Chapter 4}

\subsection{Summary and conclusions}

In this study value-based management, management control systems and company strategy are investigated for companies listed on the Amsterdam Stock Exchange as at the end of the year 2000. A questionnaire was developed and submitted to the CFOs of these companies during the spring of 2001. The questionnaire was pre-tested before actual use. Part of the instrument was newly developed for this study and part of it was based on previous work by other researchers. Dillman's $(1978,2000)$ Tailored/Total Design Method was applied for the preparation and execution of the field study.

Out of the 169 companies listed in Amsterdam at the end of 2000, 68 returned the questionnaire. The $40.2 \%$ response rate compares favorably with other management accounting research directed at similar audiences. The industry distribution in the response group matched that of the total market. In terms of size the respondents were larger than the average of the companies listed as at the end of 2000. In terms of accounting return, the performance of the response group was in line with the total market.

The presence of response bias was investigated. There were no significant differences between the replies from early and late respondents. It could therefore be concluded that a bias from non-response was not present in the empirical material. 


\section{Value creation as central goal: does a value-based management focus create value?}

\subsection{Introduction}

Many management-consulting firms are advising clients to apply value-based management (VBM, see section 3.2). From research by PA Consulting (1998) discussed in chapter 3, we know that these developments have not gone unnoticed by Dutch companies. Anecdotal evidence of the adoption of value-based management as a key strategic objective is available for Dutch companies. Royal Philips Electronics NV and Heijmans NV are two examples of companies that have publicly stated that they introduced value-based management and have confirmed this in their respective annual reports.

What benefits Dutch companies obtain from VBM application has not been investigated empirically. This issue will be addressed in this chapter. To do this we develop and test hypotheses that build on research questions proposed by Ittner and Larcker (1998, p. 211) and others.

The stock market performance of companies that responded to the survey distributed among companies listed on the Amsterdam Exchanges as at the end of the year 2000 is investigated to determine whether there is evidence that the adoption of value-based management by a company actually contributes to the creation of shareholder value. Creation of shareholder value is measured in terms of Relative Total Shareholder Return (RTSR) realized.

In this chapter we first develop a number of hypotheses starting from the assumptions that are the theoretical basis of value-based management concepts. After that, the empirical material used and the variables measured will be described. The hypotheses will be tested and the results will be discussed. The chapter is concluded with a summary of the findings and some suggestions for future research. 


\subsection{Previous research and the development of hypotheses}

The primary purpose of applying value-based management as a managerial approach is the creation of long-term shareholder wealth as was already explained in chapters 2 and 3 . The systems, strategy, analytical techniques, performance measurement and culture of a firm that applies VBM have shareholder wealth creation as their guiding objective (Arnold et al. 2000, p. 9). Applying value-based management is more than using a value-based performance metric to measure value creation. It also includes singling out value creation and realization as key corporate objectives and translating these into company values and decision-making processes. Companies that apply VBM are expected to use value-based performance measures internally and to have selected and communicated value creation as a key corporate objective internally.

Underlying our research in this chapter is the intuition that, when value-based management leads to the desired result, the companies that apply it will have a better stock market performance (value created) than their peers who have not (yet) introduced value-based management.

Performance in this respect can be measured on three levels: 1) actual stock market performance that benefits from the outcome of better decisions taken by management as a consequence of value-based management, 2) improvement in accounting based performance measures, and 3) self-reported perception of senior management with regard to the value-creating performance of their organizations.

Some evidence of superior stock market performance for companies that apply residual income-based compensation plans was found by Wallace (1998) and is also claimed to exist in a number of studies by management consultants discussed in section 3.2 .

Based upon the responses to the survey, we test whether there is evidence in the Netherlands of better stock market performance, improvements in accounting performance measures, and improvements in the reported perception of CFOs with respect to value creation, for companies that apply VBM.

We define companies that apply VBM as those that have selected value creation as a key corporate objective and use a value-based performance metric internally. In essence these companies have selected value creation as a central goal. We divide companies into those that have adopted VBM and those that have not (yet) done so. We will test the following hypothesis:

HI. RTSR of companies that adopted VBM is higher than RTSR of companies that have not adopted VBM.

Known factors that impact RTSR will be included in the analysis to control for influences that are not related to the adoption of VBM, notably firm size, price/book ratio and beta. These have been found to be relevant to the explanation of RTSR in the Amsterdam market in earlier research (Cools \& Van Praag 2000 ${ }^{\mathrm{a}}$ and ${ }^{c}$ ). 
Additionally, empirical work by Chen and Dodd $(1997,2001)$ demonstrated that traditional accounting performance measures can be a reliable proxy for value creation. To the extent that this is true, the assumed relationship between VBM adoption and organizational performance should also hold for traditional, accounting-based, performance measures.

We will test this for two accounting-based performance measures: Return on Equity (ROE) and Earnings per Share (EPS). This leads to two additional hypotheses that are related to HI but apply to accounting-based performance measures. These two additional hypotheses are:

H2. ROE of companies that adopted VBM is higher than ROE of companies that have not adopted $V B M$.

H3. EPS of companies that adopted VBM is higher than EPS of companies that have not adopted $V B M$.

To ensure that conclusions we arrived at were not affected by short-term performance fluctuations, the measurement period for RTSR and the accounting performance measures was the annual performance in the three-year period from the beginning of 1998 up to the end of 2000.

In addition to looking at stock market performance and performance in terms of accounting measures, the question can be asked how management judges the success of VBM implementation and whether they perceive it as contributing to the creation of value for shareholders. This is in line with earlier research of Buhr and Desjardins (1998, and also Desjardins 1998) in Canada. From the survey instrument we know the perception of management with regard to the success of their organization in creating value for its shareholders. It can be expected that CFOs of companies that introduced VBM, when they recognize this introduction as having been successful, will be more satisfied with the performance of their organization with regard to value creation than the CFOs of companies that have not done so. This is expressed in the following hypothesis:

H4: CFOs of companies that have adopted VBM are more satisfied with their organization's performance in 'creating shareholder value' than their colleagues in companies that have not adopted $V B M$.

\subsection{Data and measurement of variables}

\subsubsection{VBM adoption}

In the survey we conducted in early 2001 , we obtained detailed insight into the value-based management practices of 68 listed Dutch companies. As was already described in chapter 4 , the companies that replied were larger than the average of the market in terms of size. 
Companies were classified as applying VBM when they reported the use of value-based performance measures in question $5 \mathrm{~b}$ of the questionnaire and also stated that "creating shareholder value" was a key corporate objective in question 33b (see Appendix 2). These two questions were used to ensure that value creation was the explicitly communicated central goal internally (question 33b). We also asked whether this goal was communicated externally in question 33a, but that was not relevant to the classification. For the objective to be part of management control it needs to be communicated within the company, hence question 33b was used, and not 33a. To avoid including in the group of VBM adopters those companies that only paid lip service to the concept without actually applying it, the condition was added that value-based performance measures needed to be applied. This was reported in question $5 b$.

The year of introduction of value-based management was reported in question 34, permitting us to classify the respondents according to the year of introduction.

Our results show that 35 companies applied VBM by the end of 2000 representing $51.5 \%$ of the total of 68 . These companies indicated that they applied value-based performance measures in question $5 \mathrm{~b}$ and answered yes to question $33 \mathrm{~b}$. Our outcome is similar to the results obtained by Buhr and Desjardins (1998), who found that $50 \%$ of their sample of listed Canadian companies applied value-based performance measures. The level of VBM application in the Netherlands appears to be lower than what was found by Mills et al. (1996) for the UK $(61.4 \%)$ and KPMG Consulting (1999) for a cross-section of European companies (64\%) (oee chapter 3 ).

From information on the year of VBM introduction we can conclude that value-based management became popular in the Netherlands in the second half of the nineties, more than 10 years after Rappaport $(1986,1988)$ started to publish on the subject. Before 1996 adoption of VBM and actual implementation in the Netherlands must have been exceptional. For the 35 companies that introduced VBM an overview of the years of introduction is provided in table 5.1 .

Table 5.1 Year of VBM introduction

\begin{tabular}{lcc}
\hline Year of VBM introduction $(\boldsymbol{N}=35)$ & $\begin{array}{c}\text { Number of } \\
\text { companies }\end{array}$ & Percentage \\
\hline Before 1995 & 4 & $12 \%$ \\
1995 & 1 & $3 \%$ \\
1996 & 5 & $14 \%$ \\
1997 & 6 & $17 \%$ \\
1998 & 7 & $20 \%$ \\
1999 & 6 & $17 \%$ \\
Total & 6 & $17 \%$ \\
\hline
\end{tabular}


By way of digression, an interesting question is how many of the 68 companies actually stated to have selected shareholder value creation as a key corporate objective that has been communicated externally, in question 33a. This has frequently been measured in studies by management consultants. In the total response group 44 companies $(64.7 \%)$ mention the creation of shareholder value as a key corporate objective in external communications. This percentage appears to be lower than the recognition of shareholder value as a key objective found in other studies. The most striking difference is with the results obtained by PA Consulting $\left(1998^{\mathrm{b}}\right)$, who found a much higher acceptance of shareholder value as a key objective, for example $76 \%$ for the Benelux companies that participated in their 1998 study. In Canada the number of companies that mention creating shareholder value as a key corporate objective is $90 \%$ (Buhr \& Desjardins 1998). The only comparison for the Netherlands is available in Cools and Van Praag $\left(2000^{\mathrm{a}}\right.$, p. 11), who report that $28 \%$ of the companies, in their sample of 36 companies mention shareholder value as a company goal and steering objective in 1997 (compared to $11 \%$ in 1993). Our data suggest that the increase in the adoption of shareholder value targets, observed by Cools and Van Praag $\left(2000^{\mathrm{a}}\right)$, has continued over the subsequent 3 years.

From these first comparisons a tentative conclusion must be that value-based management is not as widely applied in the Netherlands as it is in the United Kingdom or Canada. With other European countries a comparison is more difficult due to the limited data available.

\subsubsection{Shareholder value creation: RTSR and accounting performance measures}

To measure the creation of shareholder value, RTSR was used as dependent variable. For the companies in the response group, share price and dividend information was obtained from Datastream to determine TSR (Total Shareholder Return). To determine company-specific wealth creation we correct for the general price movement of the Amsterdam Exchange, annual TSR was corrected for the changes in the CBS-herbeleggingsindex for non-financial companies (Centraal Bureau voor de Statistiek 1999, 2000) to arrive at RTSR per company. This index was used because it is expected to provide a suitable proxy for the general price movement of the stock exchange for the companies that responded. The AEX-index was not used as it is heavily biased towards large listed companies (Het Financieele Dagblad 1999) and therefore was not suitable for our purposes. Our approach is similar to that of Cools and Van Praag (2000 and c $)$, who used the total market (index) return to determine RTSR. 
Similarly to Cools and Van Praag, we applied the following formulas to determine RTSR:

\begin{tabular}{|c|c|c|c|}
\hline $\mathrm{TSR}_{\mathrm{i}}$ & $=$ & $\left(P_{t}-P_{0}+D_{t}\right) / P_{0}$ & (1) \\
\hline $\mathrm{TSR}_{\mathrm{m}}$ & $=$ & $\left(\mathrm{CBS}_{1}-\mathrm{CBS}_{0}\right) / \mathrm{CBS}_{0}$ & (2) \\
\hline RTSR & $=$ & $\left(\left(1+\mathrm{TSR}_{\mathrm{i}}\right) /\left(1+\mathrm{TSR}_{\mathrm{m}}\right)\right)-1$ & (3) \\
\hline $\mathrm{P}_{0}$ & $=$ & Share price end of year 0 & \\
\hline$P_{1}$ & $=$ & Share price end of year $t$ & \\
\hline$D_{1}$ & $=$ & Dividend paid in year $t$ & \\
\hline $\mathrm{CBS}_{0}$ & $=$ & $\begin{array}{l}\text { CBS-herbeleggingsindex fo } \\
\text { companies per the end of y }\end{array}$ & ancial \\
\hline $\mathrm{CBS}_{\mathrm{t}}$ & $=$ & $\begin{array}{l}\text { CBS-herbeleggingsindex fo } \\
\text { companies per the end of y }\end{array}$ & lancial \\
\hline TSR & $=$ & Total shareholder return of & \\
\hline & $=$ & Total shareholder return of & \\
\hline
\end{tabular}

Contrary to Cools and Van Praag $\left(2000^{\mathrm{a}}\right.$, and c $)$, we did not apply a 6 months' time lag in measuring RTSR. This was deemed not to be necessary in view of the fact that we are not measuring the announcement effect of the adoption of VBM on the share price but the reflection of improved performance in the share price. TSR data were obtained from Datastream.

Return on Equity (ROE) data were obtained from the Reach database and were based on the definition used by Reach. Earnings per Share (EPS) data were obtained from Datastream. Where necessary these two sources were supplemented with information from annual reports.

\subsubsection{CFO perception}

The other variable that is relevant to the analysis in this chapter is the perception of the CFOs with regard to their companies' performance in terms of value creation. This was measured in question 47 of the research instrument that allowed the CFOs to express their satisfaction with the performance of their company in creating shareholder value. This was scored on a fully anchored 5-point scale that ranged from very satisfied (1) to very dissatisfied (5). This question was a direct replication of the research of Buhr and Desjardins (1998) in Canada.

\subsubsection{Control variables}

From earlier studies (among others Cools \& Van Praag $2000^{\text {a. and }}{ }^{\text {c }}$ ) it is known that RTSR differences between firms are explained by company characteristics like size, relative risk and valuation. These characteristics are used as control variables. Company beta's (BETA) and market/book (MB) data were all obtained from Datastream. The market-to-book ratio is determined in Datastream by dividing the share price by the net tangible assets per share. This results in negative market-to-book ratios for some companies in certain years. These negative ratios were retained. 
Additional accounting information on the companies in the response group was available from Reach, the 'Handboek Nederlandse Beursfondsen' (Het Financieele Dagblad 1999 and 2001 ) and the 'Jaarboek van Nederlandse Ondernemingen 2000' (Tijd Beursmedia 2000). From these sources annual sales for the companies in our sample were obtained. For further analysis the natural logarithm of annual sales in the year 2000 was determined and coded LNSALES. This was used as a proxy for firm size in our further analysis. In view of the fact that the sales levels did not change substantially over the period under investigation, it was decided not to use the information for each individual year but to rely on the LNSALES for the year 2000 for all subsequent analysis. How the response group relates to the Amsterdam Stock Market in total has been discussed in section 4.6.

\subsection{Results}

\subsection{Descriptive results}

An overview of the mean and median values of the variables in the years that were analyzed is provided in table 5.2. For companies that were newly listed during the period under investigation, stock market prices are not available for all three years and therefore RTSR, MB and BETA are not available for all 68 companies in all years.

In view of the distinction between companies that apply value-based management and companies that do not, which will be used in our subsequent analysis, we also present the data for both groups separately in the table.

Table 5.2 Dependent and control variables

\begin{tabular}{|c|c|c|c|c|c|c|c|c|c|c|}
\hline \multirow[b]{2}{*}{ Year } & \multirow[b]{2}{*}{ Variable } & \multicolumn{3}{|c|}{ Apply VBM } & \multicolumn{3}{|c|}{ No-VBM } & \multicolumn{3}{|c|}{ Total } \\
\hline & & $N$ & Mean & Median & $N$ & Mean & Median & $N$ & Mean & Median \\
\hline \multirow[t]{7}{*}{2000} & RTSR & 35 & 0.44 & 0.48 & 30 & 0.30 & 0.29 & 65 & 0.38 & 0.39 \\
\hline & EPS (Euro) & 35 & 1.77 & 1.82 & 33 & 1.72 & 1.11 & 68 & 1.74 & 1.44 \\
\hline & ROE & 35 & 19.47 & 18.99 & 33 & 14.40 & 13.73 & 68 & 17.01 & 17.36 \\
\hline & CFO perc. & 35 & 2.91 & 3.00 & 33 & 3.15 & 3.00 & 68 & 3.03 & 3.00 \\
\hline & MB & 35 & 0.36 & 1.66 & 33 & 3.60 & 1.69 & 68 & 1.93 & 1.68 \\
\hline & BETA & 35 & 0.79 & 0.79 & 30 & 0.65 & 0.56 & 65 & 0.72 & 0.70 \\
\hline & LNSALES & 35 & 14.85 & 15.55 & 33 & 12.88 & 13.12 & 68 & 13.89 & 14.34 \\
\hline \multirow[t]{5}{*}{1999} & RTSR & 28 & -0.18 & -0.28 & 30 & -0.19 & -0.29 & 58 & -0.19 & -0.28 \\
\hline & EPS (Euro) & 29 & 1.32 & 1.06 & 39 & 1.63 & 1.32 & 68 & 1.50 & 1.19 \\
\hline & ROE & 29 & 23.67 & 19.13 & 39 & 20.83 & 16.06 & 68 & 22.04 & 18.21 \\
\hline & $\mathrm{MB}$ & 29 & 7.49 & 2.69 & 35 & 5.71 & 1.80 & 64 & 6.52 & 2.55 \\
\hline & BETA & 28 & 0.76 & 0.81 & 30 & 0.75 & 0.75 & 58 & 0.76 & 0.80 \\
\hline \multirow[t]{5}{*}{1998} & RTSR & 22 & -0.21 & -0.29 & 30 & -0.22 & -0.27 & 52 & -0.22 & -0.27 \\
\hline & EPS (Euro) & 23 & 1.39 & 1.43 & 45 & 1.75 & 1.16 & 68 & 1.63 & 1.17 \\
\hline & ROE & 23 & 26.49 & 19.73 & 45 & 37.75 & 21.06 & 68 & 33.94 & 21.02 \\
\hline & MB & 23 & 5.16 & 2.41 & 35 & 6.84 & 2.93 & 58 & 6.17 & 2.75 \\
\hline & BETA & 22 & 0.76 & 0.81 & 30 & 0.56 & 0.66 & 52 & 0.64 & 0.71 \\
\hline
\end{tabular}

The results we obtained on the satisfaction of CFOs with their organization's performance in term of value creation was a replication of the research by Buhr and Desjardins (1998), which allowed us to compare the scores obtained in the Netherlands with the results that were found among listed Canadian companies. Further validation of the measurement was not possible as it was only measured in one question using a single scale. The level of satisfaction is reported in the next table. 
Table 5.3 Satisfaction of CFOs with their organization's performance in creating shareholder value

\begin{tabular}{lcccc}
\hline & \multicolumn{2}{c}{$\begin{array}{c}\text { CF } \text { of listed Dutch } \\
\text { companies }\end{array}$} & $\begin{array}{c}\text { Canadian companies (Buhr } \\
\text { \& Desjardins, 1998) }\end{array}$ \\
\cline { 2 - 5 } & Number & $\%$ & Number & $\%$ \\
\hline Very satisfied & 12 & $17.6 \%$ & 36 & $32.5 \%$ \\
Somewhat satisfied & 17 & $25.0 \%$ & 30 & $27.0 \%$ \\
Neither satisfied nor dissatisfied & 12 & $17.6 \%$ & 9 & $8.1 \%$ \\
Somewhat dissatisfied & 11 & $16.2 \%$ & 20 & $18.0 \%$ \\
Very dissatisfied & 16 & $23.5 \%$ & 14 & $12.6 \%$ \\
No response & & & 2 & $1.8 \%$ \\
& & & 111 & $100.0 \%$ \\
\hline Total & 68 & $100.0 \%$ & & \\
\hline
\end{tabular}

Clearly, satisfaction of the Dutch CFOs was lower than that of their Canadian colleagues two years earlier. Unfortunately an in-depth analysis of this difference is impossible. A tentative explanation could be the disappointing performance of the stock market in the year 2000 . After a number of years of strong growth, the year 2000 was the first to see a reversal of the trend, with the CBS all-share index actually dropping. This may have influenced the perception of the CFOs and therefore their ranking. The Canadian survey was done in the middle of the bull market in the second half of the nineties, which possibly explains a more positive judgment.

\subsubsection{Univariate results and comments}

\subsubsection{Hypothesis I}

The dependent variable of interest for our first hypothesis is RTSR for the years 1998, 1999 and 2000. The response group was divided into two subgroups for further analysis: those companies that used VBM and those that had not implemented VBM by the respective year. As can be seen in table 5.4, the companies that applied VBM had a higher RTSR in all three years compared to the group of companies that did not apply VBM. However the difference in the years 1998 and 1999 is very small, and only in 2000 a notable advantage appears to be present.

To determine whether the differences between the two groups were significant, both parametric and non-parametric tests were performed. As the expected direction of the relationship is known, 1-tailed significance levels could be applied for the tests.

Table 5.4 Test of the difference in RTSR between companies that applied VBM and companies that did not (t-test)

\begin{tabular}{|c|c|c|c|c|c|}
\hline Year & $\begin{array}{c}\text { Average } \\
\text { RTSR } \\
\text { VBM }\end{array}$ & $\begin{array}{c}\text { Average } \\
\text { RSTR } \\
\text { No-VBM }\end{array}$ & $D f$ & t-value & $\underset{\text { (1-tailed) }}{\text { Sign. }}$ \\
\hline 2000 & 0.4404 & 0.3031 & 63 & 1.080 & 0.142 \\
\hline 1999 & -0.1840 & -0.1883 & 56 & 0.038 & 0.485 \\
\hline 1998 & -0.2124 & -0.2211 & 50 & 0.113 & 0.455 \\
\hline
\end{tabular}

For the non-parametric analysis the Mann-Whitney test was used, which resulted in outcomes that were similar to those reported above for the t-test. 
The number of cases analyzed was lower than the total number of respondents as a consequence of the fact that some companies were only listed for part of the relevant period. In fact, three companies were only introduced on the Amsterdam market during 2000 and consequently no RTSR for these three could be established.

In all three years the group of companies that adopted VBM did show a better performance than the companies that did not do so, but the differences between the two groups were not significant. Therefore we have to reject hypothesis $\mathrm{Hl}$. There is no significant difference in terms of RTSR between the two groups of companies in any of the three years that were investigated.

A possible explanation for the fact that $\mathrm{HI}$ cannot be confirmed may be that the success of VBM does not appear immediately on adoption. It is possible that a certain learning period is required before the benefits of VBM actually occur. To determine whether this is the case we performed the same analysis discussed above with a one and two-year time lag between VBM adoption and RTSR measurement. In other words, we compared the RTSR in the year 2000 for the companies that had adopted VBM in 1999 with that of the companies that had not yet adopted VBM (one-year lag). Similarly we compared RTSR in 2000 for the companies that had adopted VBM in 1998 with the companies that had not done so (2-year lag). Both t-tests and Mann-Whitney tests were performed, but these did not confirm the existence of significant differences. Consequently, hypothesis $\mathrm{HI}$ has to be rejected also on the basis of the lagged comparison.

\subsubsection{Hypothesis 2}

In section 5.2, two additional hypotheses were developed that are related to $\mathrm{H} 1$ but use accounting-based performance measures instead of market based performance. These measures have not been corrected for the influence of the average performance of the market: we compare the absolute measures per company. As before, both a t-test and a Mann-Whitney test were performed.

From table 5.2 we know that the adopters of value-based management outperformed nonadopters in terms of ROE in 2000 and 1999, which is in accordance with hypothesis H2. However, in 1998 the non-adopters clearly achieved higher ROE, which is contrary to our expectations. The results of the tests that were performed to determine the significance of the observed differences are reported in table 5.5.

Table 5.5 Test of the difference in ROE between companies that applied VBM and companies that did not (t-test)

\begin{tabular}{|c|c|c|c|c|c|}
\hline & $\begin{array}{c}\text { Average } \\
\text { ROE } \\
\text { VBM }\end{array}$ & $\begin{array}{c}\text { Average } \\
\text { ROE } \\
\text { No-VBM }\end{array}$ & $D f$ & t-value & $\begin{array}{c}\text { Sign. } \\
\text { (I-tailed })\end{array}$ \\
\hline 2000 & 19.4669 & 14.4085 & 66 & 0.542 & 0.296 \\
\hline 1999 & 23.6655 & 20.8338 & 66 & 0.366 & 0.358 \\
\hline 1998 & 26.4878 & 37.7484 & 66 & -0.597 & 0.276 \\
\hline
\end{tabular}

Again the differences are not significant between both groups in all three years, which was also the case for the Mann-Whitney test, and therefore we have to reject hypothesis $\mathrm{H} 2$.

Additional analysis comparing ROE for companies that had adopted VBM 1 or 2 years prior to the year of measurement and those that had not adopted VBM produced similar results. 


\subsubsection{Hypothesis 3}

EPS performance of the companies in the response group contradicts the assumption in hypothesis $\mathrm{H} 3$ in two out of three years, where EPS of VBM companies are actually below those of non-VBM companies. Only in 2000 are the expected higher EPS actually observed. The significance levels for the observed differences are reported in the table below.

Table 5.6 Test of the difference in EPS between companies that applied VBM and companies that did not (t-test).

\begin{tabular}{lccccc}
\hline & EPS & EPS & Df & t-value & $\begin{array}{c}\text { Sign. } \\
\text { (I-tailed })\end{array}$ \\
\hline 2000 & $\boldsymbol{V B M}$ & $\mathbf{N o - V \boldsymbol { B } M}$ & & & $\mathbf{0 . 0 2 3}$ \\
1999 & $\mathbf{1 . 7 6 6}$ & $\mathbf{1 . 7 2 0}$ & $\mathbf{6 6}$ & $\mathbf{0 . 0 9 5}$ & 0.224 \\
1998 & 1.323 & 1.627 & 66 & -0.763 & 0.139 \\
\hline
\end{tabular}

Significant effects are in bold.

Although we find a significant and directionally correct relationship between EPS and VBM adoption in the year 2000 in the parametric analysis, this is not confirmed by the nonparametric test (Mann-Whitney test). The observed differences in 1999 and 1998 were directionally incorrect, although not significant, which further supports that we have to reject hypothesis $\mathrm{H} 3$ for our sample. This conclusion was reconfirmed when we analyzed the performance 1 and 2 years after VBM introduction, to take possible learning requirements into acrerun.

\subsubsection{Hypothesis 4}

In order to learn how satisfied CFOs of the companies in the response group were with respect to the value creation within their own organization, $\mathrm{H} 4$ stated that CFOs of VBM companies are more satisfied with the value creation of their companies than CFOs of non-VBM companies. In view of the fact that a positive relation between the adoption of VBM and a superior market performance could not be established from our empirical material, the relevance of this research question is increased. If the CFOs actually realize that the expected positive relation does not hold, it is unlikely that there is confirmation for $\mathrm{H} 4$ in our sample. The response group was split between companies that actually applied VBM by the end of 2000 and companies that did not. CFOs were asked to rate their satisfaction with the valuebased performance of their organization on an anchored 5-point scale that ranged from very satisfied to very dissatisfied with neither satisfied nor dissatisfied as a midpoint. The scores were recoded on a scale of 1 (= very satisfied) to 5 (= very dissatisfied) to ease interpretation. These scores represent ordinal measures, and therefore non-parametric statistics were used for the interpretation of these scores. The scores of the two groups concerned are compared in table 5.7. 
Table 5.7 CFO's satisfaction with their organization's performance in creating shareholder value (measured at the end of 2000)

\begin{tabular}{lcccc}
\hline & \multicolumn{2}{c}{ VBM companies } & \multicolumn{2}{c}{ No-VBM } \\
\hline & Number & $\%$ & Number & $\%$ \\
\hline Very satisfied & 9 & $25.7 \%$ & 3 & $9.1 \%$ \\
Somewhat satisfied & 8 & $22.9 \%$ & 9 & $27.3 \%$ \\
Neither satisfied nor dissatisfied & 3 & $8.6 \%$ & 9 & $27.3 \%$ \\
Somewhat dissatisfied & 7 & $20.0 \%$ & 4 & $12.1 \%$ \\
Very dissatisfied & 8 & $22.9 \%$ & 8 & $24.2 \%$ \\
No response & - & & & \\
& & & & \\
Total & 35 & $100.0 \%$ & 33 & $100.0 \%$ \\
Mean score & 2.91 & & 3.15 & 1.33 \\
SD & 1.56 & & & \\
\hline
\end{tabular}

From the table it is clear that the dispersion of the answers is much greater for the VBM companies. On average the CFOs of these companies appear to be more satisfied with the performance of their companies in terms of shareholder value creation. The Mann-Whitney test that was performed confirmed this conclusion. It showed that the mean rank for VBM companies was actually, but not significantly, better than that of non-VBM companies.

Table 5.8 Test of the difference in CFO's satisfaction with companies performance in shareholder value creation (Mann-Whitney test)

\begin{tabular}{lccccc}
\hline VBM & No-VBM & N & z-value & $\begin{array}{c}\text { Sign. } \\
(\text { I-tailed })\end{array}$ \\
\hline 2000 & 32.74 & 36.36 & 68 & -0.772 & 0.220 \\
\hline
\end{tabular}

A further analysis of the responses from companies that adopted VBM between 1998 and 2000 showed that their CFOs were less satisfied with the performance of these companies than their colleagues in companies that had not adopted VBM at all. When we removed this group from our analysis, the ranking of the remaining two groups confirmed hypothesis $\mathrm{H} 4$, to the extent that the CFOs of the companies that adopted VBM before 1998 were more satisfied with the performance of their organization in terms of "creating shareholder value" than their colleagues in companies that did not apply VBM. The z-statistic was - 1.71 in this case and the one tailed significance 0.044 . This allows us to conclude that $\mathrm{H} 4$ is supported when we compare the opinions of CFOs in companies that adopted VBM before 1998 with the opinion of CFOs of companies that had not adopted VBM at all.

\subsubsection{Multivariate results}

The previous univariate analysis did not support the claims of the supporters of VBM that led us to expect a beneficial impact of application of VBM on the creation of value for shareholders. There was no significant difference in value creation, measured in terms of RTSR, between Dutch companies that applied value-based management and those that did not. As a last step, regression analysis was used to test for a relationship. It is known from earlier work by Cools and Van Praag $\left(2000^{\mathrm{a} \text {, and } \mathrm{c}}\right)$ for the Amsterdam market, and from various studies based on US data (e.g. Fama \& French 1992) that size of the company, BETA, and marketto-book ratios are relevant to the explanation of return differences between companies. Cools and Van Praag $\left(2000^{\mathrm{a}}\right)$ also tested for industry segment and diversification as explanatory variables for differences in stock returns, which proved to be insignificant for companies listed in Amsterdam. In the regression analysis we controlled the effect of VBM on value creation for the first three factors mentioned. 


\section{Chapter 5}

The regression analysis was only performed for RTSR and not for the accounting-based performance measures and CFO perception. Although the other performance measures and perception are of interest as well, they are not the prime objective for companies that introduce VBM. The ultimate goal of VBM adoption is the creation of value for shareholders and that is measured by RTSR. We have therefore limited our analysis to this dependent variable.

For the three years 1998,1999 and 2000 we estimated the following regression equation:

$$
\text { RTSR }_{1}=\beta_{0}+\beta_{1} \text { VBM }_{t}+\beta_{2} \text { LNSALES }+\beta_{3} \text { MB }_{t}+\beta_{4} \text { BETA }_{4}+\varepsilon
$$

The independent variables were defined as follows:

$\mathrm{VBM}_{\mathrm{t}}$ : dummy variable that equaled 1 for companies that applied VBM in year $\mathrm{t}$, otherwise the value was 0 .

LNSALES: the natural logarithm of the sales realized in the year 2000.

$\mathrm{MB}_{1}$ : the price book ratio for the year concerned as provided by Datastream.

BETA $_{4}$ : the monthly average of the share BETA for the year concerned as provided by Datastream.

Analysis of the correlation between the independent variables showed that multicollinearity did not pose a problem. To remain concise these results are not reported here.

The results of the regression analysis are presented in table 5.9. 
Table 5.9 Multivariate results with annual RTSR as dependent variable

RTSR 2000

\begin{tabular}{lccccc}
\hline \multicolumn{1}{c}{ Variable } & Expected sign & $\begin{array}{c}\text { Coefficient } \\
\text { value }\end{array}$ & Standard error & t-value & Sign. \\
\hline Constant & $(?)$ & 0.4214 & 0.306 & 1.376 & 0.174 \\
VBM & $(+)$ & 0.2003 & 0.125 & 1.606 & 0.113 \\
LNSALES & $(+)$ & 0.0097 & 0.022 & 0.436 & 0.664 \\
MB & $(+)$ & 0.0061 & 0.005 & $\mathbf{0 . 1 0 5}$ & 0.274 \\
BETA & $(2)$ & $\mathbf{- 0 . 4 1 3 6}$ & $\mathbf{0 . 1 1 4}$ & $\mathbf{0 . 0 0 1}$ \\
\hline
\end{tabular}

$\mathrm{R}^{2}=0.148, \mathrm{~N}=64,4 \mathrm{df}, \mathrm{F}=3.774$, Sign. two-tailed $=0.008$. Significant effects are in bold.

\section{RTSR 1999}

\begin{tabular}{lccccc}
\hline \multicolumn{1}{c}{ Variable } & Expected sign & $\begin{array}{c}\text { Coefficient } \\
\text { value }\end{array}$ & Standard error & t-value & Sign. \\
\hline Constant & $(?)$ & -0.2097 & 0.262 & -0.802 & 0.426 \\
VBM & $(+)$ & 0.0557 & 0.102 & 0.545 & 0.588 \\
LNSALES & $(+)$ & -0.0114 & 0.018 & -0.638 & 0.526 \\
MB & $(+)$ & 0.0056 & 0.004 & 1.534 & 0.131 \\
BETA & $(?)$ & 0.1344 & 0.118 & 1.134 & 0.262 \\
\hline
\end{tabular}

$\mathrm{R}^{2}=0.070, \mathrm{~N}=56,4 \mathrm{df}, \mathrm{F}=0.983$, Sign. two-tailed $=0.425$.

RTSR 1998

\begin{tabular}{lccccc}
\hline \multicolumn{1}{c}{ Variable } & Expected sign & $\begin{array}{c}\text { Coefficient } \\
\text { value }\end{array}$ & Standard error & t-value & Sign. \\
\hline Constant & $(?)$ & $-\mathbf{0 . 4 8 0 6}$ & $\mathbf{0 . 1 4 9}$ & $\mathbf{- 3 . 2 1 8}$ & $\mathbf{0 . 0 0 2}$ \\
VBM & $(+)$ & 0.0200 & 0.062 & 0.322 & 0.749 \\
LNSALES & $(+)$ & 0.0108 & 0.011 & 1.016 & 0.315 \\
MB & $(+)$ & $\mathbf{0 . 0 2 1 3}$ & $\mathbf{0 . 6 2 5}$ & $\mathbf{5 . 4 4 8}$ & $\mathbf{0 . 0 0 0}$ \\
BETA & $(?)$ & -0.0131 & 0.063 & -0.207 & 0.837 \\
\hline
\end{tabular}

$\mathrm{R}^{2}=0.377, \mathrm{~N}=50,4 \mathrm{df}, \mathrm{F}=8.577$, Sign. two-tailed $=0.000$. Significant effects are in bold.

For all three years it can be concluded that the adoption of VBM does not contribute significantly to the explanation of RTSR, which is similar to the outcome of the univariate tests in the previous section. These results do not confirm the assumed positive relationship between the adoption of VBM and the creation of shareholder value in terms of RTSR. Similar regression analyses were also performed for the relation between the RTSR and VBM adoption 1 or 2 years prior to the measurement of RTSR, which confirmed this observation. Hence, the univariate and multivariate analysis lead to the rejection of $\mathrm{HI}$.

\subsection{Summary and conclusions}

In this chapter we discussed our findings with regard to the impact, in our sample of 68 listed Dutch companies, of the application of value-based management on the creation of shareholder value in terms of RTSR and on certain accounting based performance measures. The first part of the chapter described the development of the hypotheses from value-based management theory and the variables that were used for the empirical study. In the second part of the chapter the testing of the hypotheses against the empirical material obtained from questionnaires and from external databases with stock price and annual report information was described. 
Slightly more than $50 \%$ of the companies in the response group actually applied VBM by the year 2000. This means that the adoption of VBM in the Netherlands was lower than in the major Anglo-Saxon economies (Canada, UK and US). Large companies were more than proportionally represented in the group of VBM adopters. All conclusions with respect to VBM in this chapter are therefore biased towards companies that are large in size, measured in financial terms.

The hypotheses that were tested did not provide confirmation of the expected beneficial impact of VBM on the stock market performance of the companies in the response group. The expected positive impact of VBM on RTSR (H1), ROE (H2) and EPS (H3) could not be found in the empirical material. A number of explanations are possible. It may be that companies did not properly apply VBM or that a certain learning period is needed before VBM application actually results in improved value creation. This last aspect was tested by the investigation of the performance 1 and 2 years after the adoption of VBM. Again no significant influence from VBM could be found. There was only partial evidence that the CFOs of VBM companies were more satisfied with the value-creating performance of their companies than the CFOs of non-VBM companies (H4). Therefore, both management perception and stock market performance do not provide conclusive confirmation that the VBM companies in the Netherlands actually realized superior returns for their shareholders as a result of applying VBM. A possible explanation of this can be that companies pay lip-service to the concept but do not apply it widely across all business processes to obtain a true VBM culture. A more straightforward conclusion can be that superior stock market performance does not depend on the adoption of VBM but on other factors. That possibility will be further investigated in the next two chapters.

An additional area for further investigation is the relation between value-based and accounting-based performance measures. Previous studies, suggest that accounting-based performance measures are a reliable proxy for value creation, which is an area that can be explored further. Furthermore, longitudal studies over a longer time frame may be needed to find an impact of VBM on stock market performance, certainly when learning and deployment require time before VBM becomes effective. In that respect it can be interesting to study the performance of the companies that had adopted VBM by the year 2000 in subsequent years. 


\section{Do management control system characteristics explain value creation?}

\section{1 Introduction}

In the preceding chapter we discussed the relation between selecting the creation of value for shareholders as an overall goal and the creation of Relative Total Shareholder Return (RTSR), for companies listed on the Amsterdam Exchanges. It was not possible to explain the creation of value by the application of value-based management. This leads to our next research question.

As was already stated in section 2.3 of this dissertation, management control systems are a tool to guide decisions by individual members of the organization towards the objectives of the organization. As mentioned in 5.3.1, the majority $(64.7 \%)$ of the companies that participated in our survey mentioned the creation of shareholder value as a key corporate objective. We may therefore expect that management control is used by these companies to direct individual members of the organization towards the creation of value. This assumption is further supported by the fact that the target audience for our enquiry comprised publicly listed companies that have a fiduciary duty to create value for their shareholders. In this chapter the question will be addressed whether differences in the importance ratings for selected management controls by CFOs provide an explanation for the creation of shareholder value.

Contingency theory suggests there is no universally applicable management control system; the choice of management controls must be based upon the circumstances a specific organization operates in and the environment that it operates in (see chapters 2 and 3). In accordance with contingency theory we should not expect to find one set of controls that is beneficial to all organizations. Depending on the circumstances and environment of organizations, certain controls can be expected to be more or less important. One of the contingency factors, company strategy, will be discussed in the next chapter. We exclude it from our analysis at this stage. Other contingency factors that have been found to impact management control system design are technology, competition, environmental uncertainty and size (Otley 1980, Chow et al. 1999, Chenhall 2003). 
The remainder of this chapter starts with the development of hypotheses that are derived from management control theory and previous research. The focus is on which management controls are judged to be important by the CFOs of the companies in our sample. Subsequently, the data that were obtained and their measurement will be discussed. The outcome of the tests of the hypotheses will be presented and a summary with main conclusions is provided at the end of the chapter.

\subsection{Previous research and the development of hypotheses}

As stated in chapter 2, management control is a multi-faceted concept that comprises many techniques and procedures that can be applied by organizations. The design of management control systems is highly contextual and situation-dependent. This makes it virtually impossible to define clear boundaries that determine what belongs to management control and what is outside the scope of this concept. As was explained in chapter 4, 11 elements of management control systems have been identified, based on the extant literature and an expert panel validation. These elements provide the cornerstone for the analysis in this chapter. In addition to the importance attached by management to each individual element, further information on the way in which the various controls were applied has been obtained. Exploratory factor analysis has been used to determine whether there are clusters of variables that best describe management control systems in the empirical material obtained.

The creation of value for shareholders, measured in terms of RTSR, is again used as the measure of success. The basic question that underlies the hypotheses is whether the creation of value for shareholders can be explained from the importance attached to (certain) management controls and from a focus on value-based management (VBM). For the first part of this investigation no distinction was made between companies that applied VBM and companies that did not do so. The management control systems of all respondents in our sample were investigated and related to the RTSR performance of the companies. The value relevance of management control systems is the overarching theme for our enquiry in this part.

We investigate what differences exist in the importance attached to various management controls between companies that were successful in creating value for their shareholders and companies that were not. VBM theory does not offer generally accepted recommendations with regard to the optimal design of a management control system, geared towards value realization. Therefore the investigation of this relationship cannot start from a preset assumption with regard to the type of controls that benefit value creation. Consequently the first hypothesis has an exploratory character and reads:

HI: MCS characteristics differ between companies that are more successful in creating value for their shareholders, measured in terms of RTSR, and companies that are less successful.

The combination of our enquiry in chapter 5 with the above research question leads to an additional area for research. If confirmation of hypothesis $\mathrm{Hl}$ is found, it can be expected that companies that apply value-based management attach high importance to certain controls that are associated with the creation of value. The companies that do so should be more successful in realizing value for their shareholders.

H2: MCS characteristics differ between companies that adopted VBM compared to companies that have not adopted VBM. 


\subsection{Data and measurement of variables}

\subsubsection{Management control system characteristics}

Detailed insight into the importance that CFOs attach to elements of management control, and into the application of various controls by listed companies in the Netherlands, was obtained through our survey. There is only limited information available about existing management control practices in the Netherlands (with the exception of the excellent but dated study of Hofstede (1970)). The only recent broad scope study on the subject was published by KPMG (Van Leeuwen \& Wemmenhove 1999). The drawback of that study is that it focuses on trends over time and less on the actual set-up of management control. The material that we collected provides insight into a number of developments that have received attention in literature and appear to be of practical relevance. We will discuss our findings with regard to the importance attached to various management controls first, to contribute to the understanding of management control as practiced in the Netherlands and of the data that will be used for our subsequent analysis.

To obtain an overall impression of the design of management control systems in the organizations under review, we used 11 purpose-developed questions that asked CFOs how important they found individual elements of control systems for management control in their company. The development of this set of questions has already been discussed in chapter 4 . The CFOs were asked to rate the importance of the different elements on a 7 - point Likert-like scale that was anchored at three points (not important - average importance - very important). Each question was twofold asking the CFO to rank both the current importance, which was explained to be as at the end of the year 2000 (the survey was conducted early 2001), and 4 years earlier, which was as at the end of 1996. The Cronbach alpha for both sets of 11 questions, describing the current importance and the importance 4 years earlier, was acceptable (Nunnally \& Bernstein 1994, p. 265, Chow et al. 1999, p. 452): with values of 0.71 (year 2000 ) and 0.82 (year 1996) respectively. The outcomes obtained on the 11 questions are listed below. 
Table 6.1 Importance of management control elements

\begin{tabular}{|c|c|c|c|c|c|c|}
\hline & $\begin{array}{r}\text { Mean } \\
2000\end{array}$ & $\begin{array}{c}\text { Median } \\
2000\end{array}$ & $\begin{array}{c}S D \\
2000\end{array}$ & $\begin{array}{r}\text { Mean } \\
1996\end{array}$ & $\begin{array}{c}\text { Median } \\
1996\end{array}$ & $\begin{array}{c}S D \\
1996\end{array}$ \\
\hline $\begin{array}{l}\text { Importance of financial performance measures } \\
\text { Question 2.a }\end{array}$ & $\begin{array}{c}5.99 \\
(\mathrm{~N}=68)\end{array}$ & 6.00 & 0.801 & $\begin{array}{c}5.39 \\
(\mathrm{~N}=67)\end{array}$ & 6.00 & 1.660 \\
\hline $\begin{array}{l}\text { Importance of non-financial performance measures } \\
\text { Question 2.b }\end{array}$ & $\begin{array}{c}5.29 \\
(\mathrm{~N}=68)\end{array}$ & 5.00 & 1.147 & $\begin{array}{c}3.97 \\
(\mathrm{~N}=67)\end{array}$ & 4.00 & 1.487 \\
\hline $\begin{array}{l}\text { Importance of budgeting } \\
\text { Question } 6\end{array}$ & $\begin{array}{c}6.18 \\
(\mathrm{~N}=68)\end{array}$ & 6.00 & 0.880 & $\begin{array}{c}5.62 \\
(\mathrm{~N}=67)\end{array}$ & 6.00 & 1.465 \\
\hline $\begin{array}{l}\text { Importance of codes of conduct } \\
\text { Question } 12\end{array}$ & $\begin{array}{c}4.63 \\
(\mathrm{~N}=68)\end{array}$ & 5.00 & 1.424 & $\begin{array}{c}4.00 \\
(\mathrm{~N}=67)\end{array}$ & 4.00 & 1.576 \\
\hline $\begin{array}{l}\text { Importance of company culture } \\
\text { Question } 15\end{array}$ & $\begin{array}{c}5.38 \\
(N=68)\end{array}$ & 6.00 & 1.159 & $\begin{array}{c}4.64 \\
(\mathrm{~N}=67)\end{array}$ & 4.00 & 1.377 \\
\hline $\begin{array}{l}\text { Importance of cost and variance analysis } \\
\text { Question } 16\end{array}$ & $\begin{array}{c}5.29 \\
(\mathrm{~N}=68)\end{array}$ & 6.00 & 1.305 & $\begin{array}{c}4.43 \\
(\mathrm{~N}=67)\end{array}$ & 5.00 & 1.559 \\
\hline $\begin{array}{l}\text { Importance of incentives } \\
\text { Question } 17\end{array}$ & $\begin{array}{c}5.54 \\
(N=67)\end{array}$ & 6.00 & 1.064 & $\begin{array}{c}4.71 \\
(\mathrm{~N}=66)\end{array}$ & 5.00 & 1.298 \\
\hline $\begin{array}{l}\text { Importance of internal controls } \\
\text { Question } 25\end{array}$ & $\begin{array}{c}5.62 \\
(\mathrm{~N}=68)\end{array}$ & 6.00 & 0.993 & $\begin{array}{c}4.90 \\
(\mathrm{~N}=67)\end{array}$ & 5.00 & 1.269 \\
\hline $\begin{array}{l}\text { Importance of management style } \\
\text { Question } 26\end{array}$ & $\begin{array}{c}5.57 \\
(\mathrm{~N}=68)\end{array}$ & 6.00 & 0.997 & $\begin{array}{c}5.18 \\
(\mathrm{~N}=67)\end{array}$ & 5.00 & 1.230 \\
\hline $\begin{array}{l}\text { Importance of mission statement } \\
\text { Question } 29\end{array}$ & $\begin{array}{c}4.31 \\
(\mathrm{~N}=67\end{array}$ & 4.00 & 1.500 & $\begin{array}{c}3.65 \\
(\mathrm{~N}=66)\end{array}$ & 4.00 & 1.409 \\
\hline $\begin{array}{l}\text { Importance of organizational structure } \\
\text { Ohexnion is }\end{array}$ & $\begin{array}{c}5.76 \\
(\mathrm{~V}=68)\end{array}$ & 6.00 & 1.038 & $\begin{array}{c}5.12 \\
\mathrm{ON}=6.7\end{array}$ & 5.00 & 1.462 \\
\hline
\end{tabular}

A general observation with regard to the table is that the three elements that CFOs found most important for management control were financial performance measures, budgeting and organizational structure. In this respect, organizational structure referred to the accountability in the organization and to the use of responsibility centers. Three cornerstones of traditional management control system design, as originally described by Anthony (1965, see also Chapter 2), were therefore still of predominant importance in the minds of the CFOs by the end of the year 2000. The most noticeable change over the preceding 4 years was the growing importance of non-financial performance measures. It is remarkable that the mean score for all variables is higher in 2000 compared to 4 years earlier, and that the standard deviations are lower in all but one case. A possible explanation for this occurrence can be that recollection of the recent past is stronger in people's minds, which leads to higher ratings (Dillman 2000).

For further analysis we used the mean score of the importance ranking for the 11 elements of management control per company. This variable provides a proxy for the description of the management control system in the 4-year period under investigation and can be related to the RTSR of the companies over the same period. Per company the scores for importance attached to each element of management control as at the end of the year 2000 and 4 years earlier were added and averaged. This new variable was used in the subsequent analysis. 
Table 6.2 Mean and median importance of management control elements based on 1996 and 2000 rankings

\begin{tabular}{|c|c|c|c|}
\hline & Mean & Median & $S D$ \\
\hline $\begin{array}{l}\text { Importance of financial performance measures } \\
\text { Question 2.a }\end{array}$ & $\begin{array}{c}5.69 \\
(\mathrm{~N}=68)\end{array}$ & 6.00 & 1.069 \\
\hline $\begin{array}{l}\text { Importance of non-financial performance measures } \\
\text { Question 2.b }\end{array}$ & $\begin{array}{c}4.65 \\
(\mathrm{~N}=68)\end{array}$ & 5.00 & 1.143 \\
\hline $\begin{array}{l}\text { Importance of budgeting } \\
\text { Question } 6\end{array}$ & $\begin{array}{c}5.89 \\
(\mathrm{~N}=68)\end{array}$ & 6.00 & 1.065 \\
\hline $\begin{array}{l}\text { Importance of codes of conduct } \\
\text { Question } 12\end{array}$ & $\begin{array}{c}4.32 \\
(\mathrm{~N}=68)\end{array}$ & 4.00 & 1.411 \\
\hline $\begin{array}{l}\text { Importance of company culture } \\
\text { Question } 15\end{array}$ & $\begin{array}{c}5.01 \\
(\mathrm{~N}=68)\end{array}$ & 5.00 & 1.165 \\
\hline $\begin{array}{l}\text { Importance of cost and variance analysis } \\
\text { Question } 16\end{array}$ & $\begin{array}{c}4.87 \\
(\mathrm{~N}=68)\end{array}$ & 5.00 & 1.329 \\
\hline $\begin{array}{l}\text { Importance of incentives } \\
\text { Question } 17\end{array}$ & $\begin{array}{c}5.12 \\
(\mathrm{~N}=67)\end{array}$ & 5.00 & 1.056 \\
\hline $\begin{array}{l}\text { Importance of internal controls } \\
\text { Question } 25\end{array}$ & $\begin{array}{c}5.26 \\
(\mathrm{~N}=68)\end{array}$ & 5.50 & 1.009 \\
\hline $\begin{array}{l}\text { Importance of management style } \\
\text { Question } 26\end{array}$ & $\begin{array}{c}5.38 \\
(\mathrm{~N}=68)\end{array}$ & 5.50 & 0.982 \\
\hline $\begin{array}{l}\text { Importance of mission statement } \\
\text { Question } 29\end{array}$ & $\begin{array}{c}3.99 \\
(N=67)\end{array}$ & 4.00 & 1.358 \\
\hline $\begin{array}{l}\text { Importance of organizational structure } \\
\text { Question } 36\end{array}$ & $\begin{array}{c}5.45 \\
(\mathrm{~N}=68) \\
\end{array}$ & 5.50 & 1.140 \\
\hline
\end{tabular}

Again financial performance measures, budgeting and organizational structure are the three most important elements of management control in the opinion of the CFOs that participated in our survey.

To enhance understanding of the importance attached to various elements of management control, factor analysis was employed on the mean scores for the importance of the 11 management control characteristics. The purpose of this enquiry was exploratory. The various characteristics were all part of the multi-facetted concept we call management control. Orthogonal factor analysis with varimax rotation and Kaiser normalization produced four factors with eigenvalues greater than 1 , which explained $64.9 \%$ of the total variance in the replies. The composition of the factors with the loading of the individual management control characteristics on the factors is presented in table 6.3.

Table 6.3 Factor analysis on importance attached to management control system elements

\begin{tabular}{|c|c|c|c|c|c|}
\hline Factor & Items loading $>0.5$ & Loading & Eigenvalue & $\begin{array}{c}\% \text { of } \\
\text { variance } \\
\text { explained }\end{array}$ & $\alpha^{\prime}$ \\
\hline \multirow[t]{3}{*}{1} & Financial performance measures & 0.823 & & & \\
\hline & Budgeting & 0.754 & & & \\
\hline & Organizational structure & 0.624 & 3.723 & $33.8 \%$ & 0.73 \\
\hline \multirow[t]{3}{*}{2} & Mission statement & 0.721 & & & \\
\hline & Non-financial performance measures & 0.686 & & & \\
\hline & Codes of conduct & 0.672 & 1.282 & $11.7 \%$ & 0.50 \\
\hline \multirow[t]{2}{*}{3} & Organizational structure & 0.619 & & & \\
\hline & Management style & 0.899 & 1.129 & $10.3 \%$ & 0.50 \\
\hline \multirow[t]{2}{*}{4} & Incentives & 0.795 & & & \\
\hline & Company culture & 0.509 & 1.002 & $9.1 \%$ & 0.34 \\
\hline
\end{tabular}

Cronbach alpha for the items comprising the respective factors. 
The Kaiser-Meyer-Olkin measure of sampling adequacy was above 0.6 , the Barlett test of sphericity was significant, and all 11 measures of sampling adequacy were above 0.5 . Thus the factorability of the items was confirmed (Coakes \& Steed 1999, p. 166). The low Cronbach alpha of factor 4 leads to caution with respect to the interpretation of this factor. The eigenvalue of factor 1 was above 3.0. This factor clearly dominated the other factors that had eigenvalues close to 1.0. Importance attached to internal controls and cost and variance analysis did not produce loadings in excess of 0.5 on any of the four factors. Therefore they are not included in the four factors. The earlier observation that traditional elements of management control are still regarded as very important by CFOs is confirmed by the factor analysis and by the high percentage of the total variance explained by factor 1 controls (financial performance measures, budgeting and organizational structure).

Although the factor analysis produced statistically relevant outcomes, the interpretation of the four factors that emerged was not very clear. What is clear from a first inspection is that there is no obvious relation between the factors and the levers of control as defined by Simons $\left(1994,1995^{\mathrm{a}}, 1995^{\mathrm{b}}, 1999^{\mathrm{a}}, 1999^{\mathrm{b}}\right)$ and described in section 4.3 . For instance, factor 1 comprises two elements that were categorized as diagnostic controls and one that was categorized as boundary system (organizational structure). The factor analysis appears to contradict Simon's conclusion that four distinct levers of control can be distinguished. However, an alternative interpretation is also possible. Executing management control can also be seen as a balancing act that encompasses applying a combination of controls that best suits a company (Simons $1995^{b}$, p. 128). In that respect each factor would represent a balanced set of complementing controls. How to relate these factors to the four levers of control defined by Simons is an area that warrants further investigation.

\subsubsection{Shareholder value creation}

Not the annual RTSR that was discussed in section 5.3.2, but cumulative RTSR for the four years $1997-2000$ was used for analyses in this chapter. This provides a performance measure that is aligned to the period covered by the importance scores for management control characteristics. Similarly to section 5.3.2, cumulative RTSR (coded RTSR 00-97 ) was determined, using the following formulas:

\begin{tabular}{|c|c|c|}
\hline \multicolumn{2}{|c|}{$\operatorname{TSR}_{i 00-97}=$} & $\left(P_{00}-P_{96}+D_{00-97}\right) / P_{96}$ \\
\hline \multicolumn{2}{|c|}{$\mathrm{TSR}_{\mathrm{m00-97}}=$} & $\left(\mathrm{CBS}_{00}-\mathrm{CBS}_{96}\right) / \mathrm{CBS}_{96}$ \\
\hline \multicolumn{2}{|c|}{$\operatorname{RTSR}_{00-97}=$} & $\left(\left(1+\right.\right.$ TSR $\left._{i 00-97}\right) /\left(1+\right.$ TSR $\left.\left._{m 00-97}\right)\right)-1$ \\
\hline $\mathrm{P}_{0}$ & $=$ & Share price end of year 0 \\
\hline$P_{t}$ & $=$ & Share price end of year $t$ \\
\hline & $=$ & Dividend paid in years \\
\hline $\mathrm{CBS}_{0}$ & $=$ & $\begin{array}{l}\text { CBS-herbeleggingsindex for non-financial } \\
\text { companies per the end of year } 0\end{array}$ \\
\hline $\mathrm{CBS}_{1}$ & $=$ & $\begin{array}{l}\text { CBS-herbeleggingsindex for non-financial } \\
\text { companies per the end of year } t\end{array}$ \\
\hline $\mathrm{TSR}_{\mathrm{i}}$ & $=$ & Total shareholder return of company i \\
\hline $\mathrm{SR}_{\mathrm{m}}$ & $=$ & Total shareholder return of the market \\
\hline
\end{tabular}


Only 47 companies that responded were actually listed over the full period of 4 years and RTSR $_{00-97}$ could only be determined for these companies. The dividends over the four years were added to determine $\mathrm{D}_{00-97}$. Alternative specifications of this measure were considered but not used in view of the fact that other researchers have found that such alternatives do not materially affect long-interval returns (O'Hanlon \& Pope 1999, p. 467). The values that were found are reported in the following table.

Table 6.4 RTSRo0-9?

\begin{tabular}{lccc}
\hline & Mean & Median & SD \\
\hline RTSR $_{00-97}$ & 0.0083 & -0.2786 & 1.252 \\
& $(\mathrm{~N}=47)$ & & \\
\hline
\end{tabular}

The differences between the mean and the median are unexpected. One would also assume a positive median when the mean performance exceeds the market. We found the opposite. A review of the data shows that three companies that had an outstanding performance in the period under review and realized a RTSR considerably exceeding $100 \%$, positively influenced the mean.

\subsubsection{Control variables}

In accordance with our focus on cumulative RTSR over the years $1997-2000$ in this chapter, the control variables used to measure relative risk and valuation - stock beta and market/book ratio - were aligned to the measurement period. For both measures the un-weighted average for the 4-year period was determined and coded $\mathrm{BETA}_{00-97}$ and $\mathrm{MB}_{00-97}$. As explained in chapter 5, the natural logarithm of annual sales for the year 2000, LNSALES, was used as a proxy for company size.

Having described the information that was obtained from the response group we now turn to testing the hypotheses that were developed.

\subsection{Results}

\subsubsection{Univariate results and comments}

\subsubsection{Hypothesis I}

To test hypothesis $\mathrm{Hl}$ we first split the response group in two on the basis of the median cumulative RTSR over the four-year period 1997 - 2000. This median RTSR $00-97$ showed a negative performance of $27.9 \%$ over the period. The resulting two groups of 24 companies with a performance equal to or above the median, and 23 with a performance below the median, were coded as companies successful in value creation, with RTSR $_{00-97}$ ranging from $27.9 \%$ to $+760.4 \%$, and companies not successful in creating value, with RTSR $00-97$ ranging between $-72.9 \%$ and -28.7 . 
When comparing the importance attached to the 11 elements of management control between

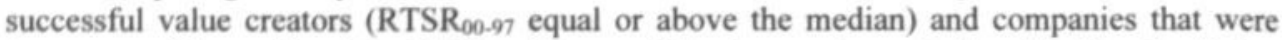
less successful, we found that CFOs of successful value creators attach a significantly higher importance to budgeting, company culture and internal controls compared to their colleagues

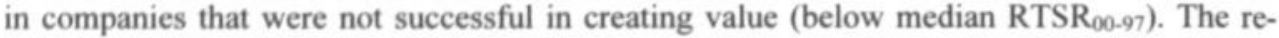
sults of the independent samples t-test, that was performed to determine whether significant differences existed between the two groups, are reported in the following table.

Table 6.5 Test of the difference in importance attached to elements of management control systems between companies with below median and equal or above median RTSR ( $t-t e s t, N=47$ )

\begin{tabular}{|c|c|c|c|c|}
\hline & $\begin{array}{c}\text { Below } \\
\text { median } \\
\text { RTSR }\end{array}$ & $\begin{array}{c}\text { Equal or } \\
\text { above } \\
\text { median } \\
\text { RTSR }\end{array}$ & t-value & $\begin{array}{c}\text { Sign. } \\
\text { (2-tailed) }\end{array}$ \\
\hline Mean importance of financial performance measures & 5.67 & 5.94 & -0.941 & 0.35 \\
\hline Mean importance of non-financial performance measures & 4.41 & 4.67 & -0.789 & 0.43 \\
\hline Mean importance of budgeting & 5.76 & 6.25 & -1.719 & 0.09 \\
\hline Mean importance of codes of conduct & 4.17 & 4.54 & -0.864 & 0.39 \\
\hline Mean importance of company culture & 4.54 & 5.13 & -1.871 & 0.07 \\
\hline Mean importance of cost and variance analysis & 4.78 & 4.98 & -0.503 & 0.62 \\
\hline Mean importance of incentives & 4.96 & 5.17 & -0.671 & 0.51 \\
\hline Mean importance of internal controls & 4.98 & 5.56 & -2.154 & 0.04 \\
\hline Mean importance of management style & 5.33 & 5.44 & -0.382 & 0.70 \\
\hline Mean importance of mission statement & 3.89 & 3.92 & -0.063 & 0.95 \\
\hline Mean importance of organizational structure & 5.43 & 5.65 & -0.694 & 0.49 \\
\hline
\end{tabular}

Significant values are in bold.

A conclusion that may be derived from the table above is that the item where the most significant difference existed between both groups of companies was the importance attached to internal controls. A similar pattern emerged when the non-parametric Mann-Whitney test was performed. In that case the two-tailed significance for both the importance of budgeting and the importance of internal controls moved above a significance level of 0.10 , but the difference in importance attached to company culture remained significant. Both tests confirm that there are significant differences in importance attached to certain management controls between companies that are successful in creating value for their shareholders and companies that are not. We find support for hypothesis $\mathrm{Hl}$ in our data.

It is also interesting to note that successful value creators attach a higher importance to management control in general, judging from the fact that they give a higher mean importance to all 11 elements, as can be read in table 6.5.

An alternative analysis on the basis of the four factors developed in section 6.3.1 produced significant differences on the score for factor 4 controls, as presented in table 6.6. This might be expected from the fact that company culture was part of that factor. 
Table 6.6 Test of the difference in importance attached to management control system factors between companies with below and equal or above median RTSR ( $t$-test, $\mathrm{N}=47$ )

\begin{tabular}{lcccc}
\hline & $\begin{array}{c}\text { Below } \\
\text { median } \\
\boldsymbol{R} \text { TSR }\end{array}$ & $\begin{array}{c}\text { Equal or } \\
\text { above } \\
\text { median } \\
\boldsymbol{R} \text { TSR }\end{array}$ & $\begin{array}{c}\text { A-value } \\
\text { (2-failed) }\end{array}$ \\
\hline Factor 1 & 5.62 & 5.94 & -1.439 & 0.16 \\
Factor 2 & 4.64 & 4.88 & -0.932 & 0.36 \\
Factor 3 & 5.38 & 5.54 & -0.645 & 0.52 \\
Factor 4 & $\mathbf{4 . 7 5}$ & $\mathbf{5 . 1 5}$ & $\mathbf{- 1 . 6 8 3}$ & $\mathbf{0 . 1 0}$ \\
\hline
\end{tabular}

Significant values are in bold.

Again this provides confirmation of hypothesis $\mathrm{Hl}$ and shows a higher importance for all four factors in value-creating companies.

That importance attached to company culture is a distinguishing feature for companies that are successful in value creation, can possibly be explained from the fact that the CFOs of the successful companies realize that culture and beliefs are important tools to ensure that all employees act in the interest of the company and, through that, also in the interest of the shareholders. It may indicate that these companies are able to create a value-based management culture as defined by Haspeslach et al. (2001). In this respect it is important to reiterate that the companies were not selected on the basis of their actual application of value-based management but on their performance. Some of the successful companies have not made the creation of value for their shareholders their central goal. However, they are managed in such a way that this objective is realized. It may be the case that VBM-principles are part of normal management behavior and that successful managers apply them unconsciously.

\subsubsection{Hypothesis 2}

To test the second hypothesis the importance attached to the 11 elements of management control was compared between companies applying value-based management and companies not doing so. For the companies that applied value-based management in the year 2000 , the importance attached to the various elements of management control as at the end of that year showed no significant differences, except for the importance attached to incentives and organizational structure. For this first element VBM companies rated the importance significantly higher than non-VBM companies $(t=1.922$, two-tailed significance $=0.059)$. This can probably be explained from the high importance that is generally attached to incentives in the literature on value-based management. The second element, importance of organizational structure, was also rated higher by VBM companies $(t=1.715$, two-tailed significance $=0.091$ ).

The scores for the four management control system factors were also compared between companies that applied VBM by the end of 2000 and companies that did not do so. No significant differences were found for any of the four factors using either the t-test or the MannWhitney test.

We therefore only find very weak evidence for hypothesis $\mathrm{H} 2$. 
A second approach to testing hypothesis $\mathrm{H} 2$ could also be used based upon our findings with respect hypothesis $\mathrm{H} 1$. We found that value creation is related to differences in management control focus and this means that companies trying to create value for their shareholders can work towards this objective by focusing on the appropriate management controls. To be able to judge whether this is actually done, we investigated the sample on the basis of two separate variables. The creation of value for shareholders in terms of RTSR $00-97$ and the application of VBM, in accordance with the criteria defined in the previous chapter. Again the companies that applied VBM in the year 2000 were distinguished from those that did not do so. Based on the results obtained in testing for hypothesis $\mathrm{H1}$, we can expect that companies applying VBM attach significantly more importance to budgeting, company culture and internal controls, respectively to factor 4 management controls.

To investigate this relationship, univariate analysis of the differences in mean scores for the respective importance rankings was performed. In all four cases no significant influence of the interaction term or of the application of VBM on the importance attached to the respective management controls could be found. The importance attached to each individual control was used as a dependent variable for this analysis and the adoption of VBM and the creation of value for shareholders were used to allocate companies to the 4 groups being compared (fixed factors). The importance attached to the respective management controls as at the end of the year 2000 was used for analysis to be in line with the measurement date for the application of value-based management. The relevant results are summarized in table 6.7.

Table 6.7 Univariate analysis of variance for importance attached to selected elements of management control with creation of $\mathrm{K} I \mathrm{SK}$ and appitcation of $\mathrm{VBM}$ as ixed tactors $(\mathrm{N}=4 /)$

\begin{tabular}{lcccccccc}
\hline Fixed factors & \multicolumn{2}{c}{$\begin{array}{c}\text { Importance of } \\
\text { budgeting }\end{array}$} & \multicolumn{2}{c}{$\begin{array}{c}\text { Importance of } \\
\text { company culture }\end{array}$} & $\begin{array}{c}\text { Importance of } \\
\text { internal controls }\end{array}$ & \multicolumn{2}{c}{$\begin{array}{c}\text { Importance of } \\
\text { factor 4 controls }\end{array}$} \\
\hline & $\mathrm{f}$ & Sig. & $\mathrm{f}$ & Sig. & $\mathrm{f}$ & $\mathrm{Sig}$ & $\mathrm{f}$ & Sig. \\
\hline Value creation & 0.986 & 0.33 & $\mathbf{3 . 2 7 0}$ & $\mathbf{0 . 0 8}$ & $\mathbf{6 . 1 2 3}$ & $\mathbf{0 . 0 2}$ & 1.694 & 0.20 \\
VBM year 2000 & 0.043 & 0.84 & 1.727 & 0.20 & 0.074 & 0.79 & 0.095 & 0.76 \\
Interaction term & 1.457 & 0.23 & 0.566 & 0.46 & 0.452 & $\mathbf{0 . 5 1}$ & 2.474 & 0.12 \\
\hline
\end{tabular}

Significant values are in bold.

These results are surprising. They suggest that the companies applying VBM fail to translate their adoption of value creation as an overriding goal into an appropriate focus in their management control system. From the fact that a high importance attached to these elements of management control is beneficial for value creation, we would expect to find a significant and positive interaction term. The absence of the expected relation may provide an explanation for the fact that no confirmation of a beneficial impact of the application of VBM on the creation of RTSR could be found in chapter 5 .

\subsubsection{Multivariate results for hypothesis I}

To be able to gain a richer understanding of the relationship between management control and value creation, linear regression analysis was performed, both for the mean importance rankings on the 11 elements of management control and for the 4 factors developed in section 6.3.1. Again, cumulative RTSR over the four-year period $1997-2000$ was used as a dependent variable. 


\subsubsection{Management control system elements}

To investigate the relation between the importance attached by the CFOs to the 11 elements of management control and the creation of value for shareholders, we estimated the following regression equation:

$\operatorname{RTSR}_{00-97}=\beta_{0}+\beta_{1 \ldots 11} \mathrm{IMPMC}_{1.11}+\beta_{12}$ LNSALES $+\beta_{13} \mathrm{MB}_{00-97}+\beta_{14} \mathrm{BETA}_{00-97}+\varepsilon$

The new independent variable was defined as:

IMPMC $_{1.11}$ : importance attached by the CFO to each of the 11 individual elements of management control (average of 2000 and 1996 scores)

The results of the regression analysis are presented in table 6.8 .

Table 6.8 Multivariate results with mean importance of control system elements as independent variables and cumulative RTSR as dependent variable

\begin{tabular}{|c|c|c|c|c|c|}
\hline Variable & $\begin{array}{l}\text { Expected } \\
\text { sign }\end{array}$ & $\begin{array}{c}\text { Coefficient } \\
\text { value }\end{array}$ & $\begin{array}{c}\text { Standard } \\
\text { error }\end{array}$ & t-value & Sign. \\
\hline Constant & (?) & -3.7276 & 1.556 & -2.395 & 0.024 \\
\hline $\begin{array}{l}\text { Mean importance of financial performance } \\
\text { measures }\end{array}$ & (?) & 0.5538 & 0.218 & 2.538 & 0.017 \\
\hline Mean importance of non-financial & & & & & \\
\hline performance measures & (?) & -0.0629 & 0.196 & -0.320 & 0.751 \\
\hline Mean importance of budgeting & (?) & 0.1653 & 0.224 & 0.738 & 0.467 \\
\hline Mean importance of codes of conduct & (?) & 0.1643 & 0.184 & 0.894 & 0.379 \\
\hline Mean importance of company culture & (?) & 0.2647 & 0.205 & 1.293 & 0.207 \\
\hline $\begin{array}{l}\text { Mean importance of cost and variance } \\
\text { analysis }\end{array}$ & (?) & -0.2170 & 0.127 & -1.714 & 0.098 \\
\hline Mean importance of incentives & (?) & -0.5348 & 0.162 & $-\mathbf{3 . 3 0 7}$ & 0.003 \\
\hline Mean importance of internal controls & (?) & 0.0307 & 0.214 & 0.143 & 0.887 \\
\hline Mean importance of management style & (?) & 0.0097 & 0.180 & 0.054 & 0.957 \\
\hline Mean importance of mission statement & (?) & -0.1008 & 0.131 & -0.772 & 0.446 \\
\hline Mean importance of organizational structure & (?) & -0.0519 & 0.181 & -0.287 & 0.776 \\
\hline LNSALES & $(+)$ & 0.0692 & 0.056 & 1.241 & 0.225 \\
\hline $\mathrm{MB}_{00-96}$ & $(+)$ & 0.0467 & 0.029 & 1.604 & 0.120 \\
\hline BETA $_{00-96}$ & (?) & 1.1437 & 0.436 & 2.623 & 0.014 \\
\hline
\end{tabular}

$\mathrm{R}^{2}=0.514, \mathrm{~N}=42,14 \mathrm{df}, \mathrm{F}=4.178$, Sign. two-tailed $=0.001$. Significant effects are in bold.

Again we find that systematic risk measured in terms of stock BETA is relevant to the explanation of cumulative RTSR differences across companies. Also, differences in importance attached to certain management controls are significant. This provides further confirmation for hypothesis H1. The controls that are relevant differ from those that were found in the previous section, which can be a consequence of the more refined analysis at this stage. That a focus on financial performance measures is significant can be a consequence of a focus on value-based performance measures like residual income. The significant, but negative, contribution of importance attached to incentives is contrary to the recommendations of the value-based management literature. Next, we present the results for the four management control system factors. 


\section{Chapter 6}

\subsubsection{Management control system factors}

The regression equation that was tested reads:

$$
\begin{aligned}
\text { RTSR }_{00-96}= & \beta_{0}+\beta_{1} \text { Factor } 1+\beta_{2} \text { Factor } 2+\beta_{3} \text { Factor } 3+\beta_{4} \text { Factor4 }+\beta_{5} \text { LNSALES }+ \\
& \beta_{6} \text { MB }_{00-96}+\beta_{7} \text { BETA }_{00-96}+\varepsilon
\end{aligned}
$$

And produced the following results:

Table 6.9 Multivariate results with control system factors as independent variables and RTSR as dependent variable

RTSR

\begin{tabular}{lccccc}
\hline \multicolumn{1}{c}{ Variable } & Expected sign & $\begin{array}{c}\text { Coefficient } \\
\text { value }\end{array}$ & Standard error & T-value & Sign. \\
\hline Constant & $(?)$ & $\mathbf{- 4 . 4 5 9 0}$ & $\mathbf{1 . 5 9 6}$ & $\mathbf{- 2 . 7 9 5}$ & $\mathbf{0 . 0 0 8}$ \\
Factor 1 & $(?)$ & $\mathbf{0 . 6 0 5 6}$ & $\mathbf{0 . 3 0 3}$ & $\mathbf{2 . 0 0 1}$ & $\mathbf{0 . 0 5 3}$ \\
Factor 2 & $(?)$ & 0.3325 & 0.245 & 1.359 & 0.183 \\
Factor 3 & $(?)$ & -0.1195 & 0.303 & -0.394 & 0.696 \\
Factor 4 & $(?)$ & -0.2217 & 0.241 & -0.919 & 0.364 \\
LNSALES & $(+)$ & 0.0268 & 0.058 & 0.458 & 0.650 \\
MB $_{00-96}$ & $(+)$ & $\mathbf{0 . 0 8 1 0}$ & $\mathbf{0 . 0 3 2}$ & $\mathbf{2 . 5 6 9}$ & $\mathbf{0 . 0 1 5}$ \\
BETA $_{0095}$ & $(?)$ & 0.6186 & 0.479 & 1.292 & 0.205 \\
\hline
\end{tabular}

$R^{2}=0.302, N=42,7 d f, F=3.600$, Sign. two-tailed $=0.005$. Significant effects are in bold.

In this case factor I controls and valuation in terms of the market-to-book ratio are relevant to the explanation of RTSR. Again this provides confirmation for H1. These results are in line with those obtained in the previous section. Factor 1 controls comprise financial performance measures, which were found to be significant in the previous section, together with budgeting and organizational structure. It would appear that attaching high importance to traditional management controls explains, part of, the realization of value for shareholders.

\subsection{Summary and conclusions}

To explain successful value creation from management control system characteristics was the purpose of this chapter. We tested 2 hypotheses, using empirical data provided by the CFOs of 68 Dutch companies listed on the Amsterdam Exchanges. The information obtained showed that Dutch CFOs focus on traditional management control concepts like budgeting, financial performance measures and responsibility centers.

Management control system characteristics were found to be different for companies that were successful in realizing value for their shareholders. Most notably, successful value creators attached greater importance to company culture, budgeting and internal controls. The importance of the three controls should not be judged in isolation. Factor analysis provided evidence that four different groups of controls could be identified. It produced four factors that together explained $61.5 \%$ of the variation in management control systems. Companies that were successful in creating value for their shareholders scored significantly higher on one of these factors, in comparison to companies that were less successful. An area for future research is the question whether and, if so, how the four factors that were found relate to the four levers of control defined by Simons $\left(1994,1995^{\mathrm{a}}, 1995^{\mathrm{b}}, 1999^{\mathrm{b}}\right)$. 
When control variables were introduced in the analysis, the primary conclusions were corroborated. It emerged that differences in importance attached to certain management controls contributed to the explanation of differences in the creation of shareholder value in terms of cumulative RTSR, notably differences in importance attached to financial performance measures and incentives. We established that characteristics of management control systems help to explain the creation of value for shareholders in Dutch listed companies $(\mathrm{H} 1)$ but that they only explain part of the differences between companies in value creation.

We also found that companies applying value-based management do not differentiate their management control system to place additional focus on those controls that appear to support value creation $(\mathrm{H} 2)$. A possible explanation for the apparent lack of success of value-based management implementations that was found in chapter 5 can therefore be that companies applying VBM fail to translate this into an appropriate focus in their management control system. 



\section{Does alignment of management control system and strategy explain shareholder value creation?}

\subsection{Introduction}

The suggestion that management control systems should be aligned explicitly with the strategy of a business to create competitive advantage and thus superior performance (LangfieldSmith 1997 , p. 207) has been voiced by various authors (Simons $1987^{\mathrm{b}}, 1990$, Govindarajan 1988, Dent 1990, Abernethy \& Guthrie 1994) and is acknowledged in today's textbooks on management control (Merchant 1998, Anthony \& Govindarajan 1998, Simons 1999 ${ }^{\mathrm{b}}$ ). This relationship is documented in contingency studies into the relation between organizational performance and the appropriate alignment between environment, strategy and internal structures (Gordon \& Narayanan 1984, Govindarajan \& Gupta 1985, Govindarajan 1988, Govindarajan \& Fisher 1990). To obtain a full understanding of the interaction between the creation of value for shareholders and a company's management control system, we have to address this contingent relationship.

In the preceding chapter we already found that certain characteristics of management control contribute to the explanation of value creation. Our objective in this chapter is to investigate whether the alignment of business strategy and management control system design supports value creation and therefore allows us to explain the difference in the creation of value for shareholders between companies better. We will also investigate whether a value creation focus in management control is associated with certain strategies. Successful performance will again be measured in terms of the relative total shareholder return (RTSR) generated by the companies in our sample. 
Over time, numerous ways to describe and distinguish company strategy have been proposed and tested empirically. In line with the recommendations of Langfield-Smith (1997), we treat strategy as a multifaceted concept and investigate three aspects of the concept in our research: strategic position, strategic typology and strategic mission. The notion of strategic positioning builds on Porter's (1980) distinction between cost leadership and differentiation strategies. Strategic typologies have been developed by Miles and Snow (1978), who introduced defender, prospector, analyzer and reactor strategies. The objectives of business strategies have led Gupta and Govindarajan (1984) to differentiate build, hold, harvest and divest missions. Information about these three aspects of strategy has been obtained from the companies that participated in our survey.

As was explained in chapter 2, a distinction is usually made between business strategy and corporate strategy. The latter concept addresses portfolio choices of companies and the relation between the head office and the strategic business units (SBUs). Business strategy describes how a business unit operates within its competitive environment. The three strategy concepts mentioned above all address business strategy. Because our target audience contained both single SBU firms and conglomerates, comprising large numbers of distinct SBUs, it was decided to focus on SBU strategy in the research instrument. This was the common denominator that applied to all companies in the target audience. The fact that the CFOs were requested to reply to the questionnaire could be expected to result in replies that described the "average" SBU strategy for multi-business firms and not necessarily the individual SBU strategies within these firms. This was an inevitable consequence of the research design. It is not uncommon for this type of research to obtain information from top management for the strategy classification, as top management can be expected to be most knowledgeable about strategies, market emphasis and planning processes, according to Shortell \& Zajac (1990). In this respect our research design is similar to earlier studies that obtained strategy classifications from self-typing by the CEO (Snow \& Hrebiniak 1980, Shortell \& Zajac 1990). To be able to identify whether certain strategy data were possibly impacted by portfolio diversity, this last aspect was measured separately, and used as a control variable.

In the next section we present the hypotheses that will be tested and explain their foundation in previous empirical work and literature. Subsequently, the empirical material used and the new variables introduced in this chapter will be described. Exploratory material is included that provides descriptive statistics of the variables that were reported by the 68 companies in our sample. The results of the tests of the hypotheses are subsequently presented. The last section of the chapter provides the main conclusions.

\subsection{Previous research and the development of hypotheses}

Similarly to Simons $\left(1987^{\mathrm{b}}\right)$, Abernethy and Guthrie (1994) and Chenhall and LangfieldSmith (1998), the first question in this section is whether management control systems differ between firms with different strategic priorities. Firms with control systems that are better aligned to their strategy are expected to have a superior performance in terms of RTSR. This question is interesting because Simons' conclusions in this area are still controversial (Dent 1990, p. 13, Gray 1990, Langfield-Smith 1997, p. 218). Notably his findings that highperforming prospectors attached high importance to controls like forecasting data, tight budget goals and careful monitoring of outputs, and gave little attention to cost control. Defenders, particularly large defenders, were found to use control systems less intensively. 
The conceptual model underlying the research in this chapter is shown in figure 7.1.

Figure 7.1 Conceptual model of the contingency relationship

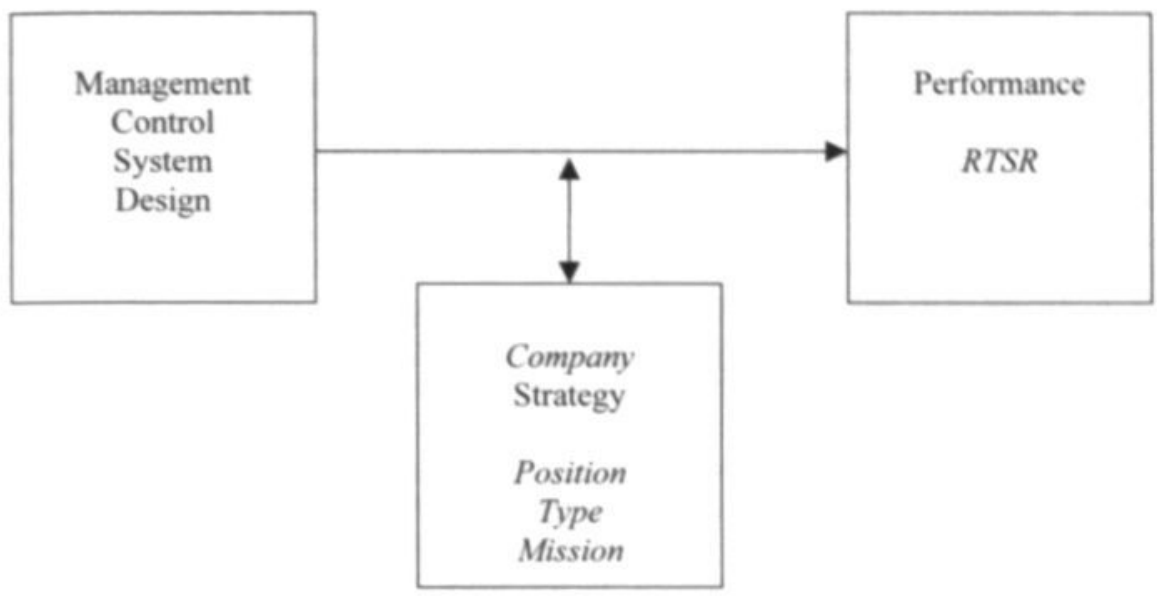

In characterizing management control system design both the value-based management (VBM) focus in management control (chapter 5) and characteristics of management control (chapter 6) will be used.

Three approaches to analyzing data under a contingency approach have been suggested by Van de Ven and Drazin (1985): the selection, interaction and systems approach. The selection and the interaction approach will be used in our analysis.

Prior research into the relation between strategy and management control system design was frequently based on the assumption that management control systems would be different between prospector and defender firms (Govindarajan \& Gupta 1985, Simons $1987^{\mathrm{b}}$, Govindarajan 1988, Abernethy \& Gunthrie 1994). Due to the fact that inconclusive evidence exists for the assumed differences and taking into account that similarities can be expected to exist between control system characteristics of defenders, hold missions and cost leaders on the one hand and prospectors, build missions and differentiators on the other (Langfield-Smith 1997, Ittner et al. 1997), we will first test whether this differentiation actually exists. The hypothesis to be tested reads:

H1: Management control system characteristics differ between companies with a differentiation (build, prospector) and a cost leader position (hold mission, defender type). 
An additional enquiry, that relates the research question of chapter 5 to strategy, was developed building on Lovata and Costigan (2002), who posited that the adoption of EVA as a performance measurement system is less likely for companies pursuing a prospector strategy than for companies pursuing a defender strategy. They derive this assumption from the notion that non-financial performance measures are more important for companies that pursue an innovation-oriented strategy (Ittner et al. 1997, p. 231). Lovata and Costigan find empirical support for their assumption. In line with their reasoning we can expect that a VBM focus in management control is more likely for cost leaders (hold missions, defender types) than for differentiators. As a next step in our analysis we will therefore test the following hypothesis.

H2: Adoption of VBM is higher in companies that pursue a cost leader position (hold mission, defender type) compared to companies that pursue a differentiation mission (build mission, prospector type).

Alignment between management control systems and strategy has been investigated in a number of empirical studies, as was already discussed in section 3.5. In summary it can be stated that strategies that entail a high level of uncertainty make certain management control characteristics desirable. This is illustrated by the work of Miles and Snow (1978) and Govindarajan (1988), who argued that prospector and build strategies encompassed a high degree of uncertainty and therefore warranted a lower focus on budget goals. Similarly Gupta (1987) stated that differentiation positions resulted in a higher degree of uncertainty, which is not supported by objective performance evaluation and reward systems. A contradiction in this respect is that Merchant $\left(1985^{b}\right)$ and Simons $\left(1987^{b}\right)$ found that the emphasis on accounting information was greater in companies adopung butia' or prospector strategies, wriereas Govindarajan (1988) found that such companies place lower emphasis on accounting information.

According to Simons $\left(1987^{\mathrm{b}}\right.$, p. 360$)$, the assumption in most accounting research into the relation between management control system characteristics and strategy is that control system design contributes to the successful operation and profitability of the company. Therefore it is usually assumed that control system attributes and economic performance are different for companies following different strategies. We measure economic performance by RTSR of the companies in our sample. Three different dimensions of the strategy construct were investigated and the assumed relation can thus be studied for strategic mission, type and positioning. The theoretical foundations for these relationships are still unclear (see also Dent 1990, Langfield-Smith 1997). Therefore it is premature to specify which differences are to be expected and which direction the differences will take. The assumed impact on performance from differences in control system attributes, in relation to business strategy, will be investigated by testing the following hypothesis, which is related to the research questions addressed in chapter 6:

H3: The relation between importance attached to certain management control system characteristics and economic performance, measured in terms of RTSR, is different for companies that pursue different strategies. 


\subsection{Data and measurement of variables}

\subsubsection{Strategy measurement}

In our survey we obtained information on three aspects of strategy. These were measured using established research questions that have been used successfully in previous empirical studies. In addition, we measured the degree of portfolio diversity of the companies in our sample. Due to the fact that the information obtained relates to the strategy of the companies as a whole, our measurements do not necessarily reflect individual business unit strategies. The three strategy dimensions were measured at the end of the year 2000. It is assumed that these provide an appropriate proxy for the strategy in earlier years also, because we expect strategy to be relatively stable over time. Previous research in this area usually focused on strategic business unit (SBU) strategies, making results not directly comparable to the information we obtained. To be able to explain possible deviations from previous studies, the additional measure for portfolio diversity was added.

To measure strategic mission, question 49 was included in our survey instrument. The question is a replication of the original research instrument used by Govindarajan and Gupta (1985) and has been used in many subsequent studies. The CFOs of the companies in our sample were asked to indicate the percentage of their company sales that was accounted for by products that represented a certain mission. Govindarajan and Gupta (1985) introduced a distinction between build, hold, harvest and divest missions. 61 companies provided information on their strategic mission, which is close to the number of observations used by Govindarajan and Gupta $(\mathrm{N}=58)$. Where they found that only $12(21 \%)$ companies reported

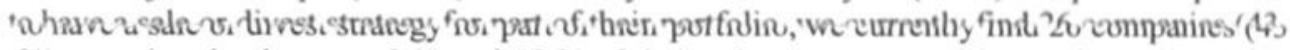
$\%$ ) reporting that between $2 \%$ and $55 \%$ of their sales are generated by products that are to be liquidated or sold (Govindarajan and Gupta found a range of between $2 \%$ and $13 \%$ ). In the response group 5 companies reported part or all of their sales as 'Others', a category that was also available in the original study but not used by respondents then. A review of the companies concerned shows that some new economy businesses and research ventures reported their sales in the category 'Others'. Because new economy and research are associated with build strategies it was decided to include the sales under that strategic mission for our analysis. In line with the original study, we developed a weighted average strategy index by coding the reported sales percentages with: +1 for build, 0 for hold, -1 for harvest and -2 for divest. Because sales for new economy activities were reported as 'Others', these were also coded +1 to reflect a build strategy. The overall measures obtained are presented in table 7.1 .

Table 7.1 Strategic mission

\begin{tabular}{lcccc}
\hline & Mean & SD & Minimum & Maximum \\
\hline Strategic mission, (N=61) & 0.122 & 0.370 & -1.1 & 1.0 \\
Scores obtained by Govindarajan \& Gupta (1985), (N=58) & 0.018 & 0.478 & -1.0 & 1.0 \\
\hline
\end{tabular}


To facilitate further analysis, the response group was subsequently divided into three subgroups on the basis of strategic mission. Companies with a mission index between 0.1 and 1.0 were classified as build (25), those with an index between 0 and 0.06 as having a hold mission (25) and those with a negative index as having a harvest/divest mission (11). This resulted in two subgroups that consisted of 25 companies each with build and hold missions and a third group of 11 companies with harvest/divest missions. This distribution is similar to the one that Verbeeten (2001) found in his sample of 175 large organizations in the Netherlands ( 91 build, 74 hold, 10 harvest), which lends support for the appropriateness of the allocation.

Snow and Hrebiniak (1980) developed a measurement instrument for the strategic typologies that were originally introduced by Miles and Snow (1978). The instrument is a fairly crude measure because the respondents are simply asked to rank their company on the basis of descriptions of the four strategy types described by Miles and Snow: defender, prospector, analyzer or reactor. Question 50 in our survey instrument replicated Snow and Hrebiniak (1980) with one alteration. The description of type 4, reactor strategies, in the original instrument had a strong negative connotation, which was expected to result in bias against choosing this type of strategy. We rephrased this description and removed negative references like: 'organization does not appear to have a consistent product-market orientation'. The companies in our sample reported the following strategy types:

Table 7.2 Strategic typology

\begin{tabular}{lcccc}
\hline & Defender & Prospector & Analyzer & Reactor \\
\hline Number of companies & 15 & 18 & 23 & 10 \\
$\%$ of total, $(\mathrm{N}=66)$ & $22 \%$ & $21 \%$ & $54 \%$ & $15 \%$ \\
Scores obtained by Snow \& Hrebiniak (1980), number & 80 & 75 & 27 & 50 \\
$\%$ of total, $(\mathrm{N}=247)$ & $32 \%$ & $30 \%$ & $11 \%$ & $15 \%$ \\
\hline
\end{tabular}

As table 7.2 clearly shows, the results obtained from companies in the Netherlands at the end of 2000 deviate substantially from the results Snow and Hrebiniak obtained in the United States more than 20 years earlier. In view of the time that has elapsed between both studies, this is far from surprising. The high percentage of companies claiming to have an analyzer strategy is the most remarkable contrast. The time lag and the difference in countries in which both surveys were conducted make it difficult to draw any conclusions from the comparison. The reason to make the comparison is to detect potential measurement errors. The structure of the question combined with the discrepancies with previous empirical research gives concern with regard to the reliability of the allocation to the four strategic typologies. To address these concerns, further cross validations have been performed that will be discussed in the next section.

For subsequent analysis the variable was recoded into a new range starting with 1 for prospector, 2 for analyzer, 3 for defender and 4 for reactor strategies. This order differs from the structure of the survey question and from the use of the classification by other authors. In accordance with the original work of Miles and Snow (1978), we bring prospector and defender strategies to the extremes of the scale with analyzers in-between. Reactor strategies are deemed to be unsuccessful strategies by Miles and Snow and are therefore coded at the outside of the scale. Doing so ensures that the structure of the scales for mission, type and position is the same and that inferences can be made with regard to the similarity of the results that were found for the three strategy measures. 
Strategic positioning was measured in question 51 using the research questions originally developed by Govindarajan (1988). CFOs were asked to rank six characteristics of their companies' products in comparison to competitors on 7-point Likert scales. The responses to the six questions were added and subsequently divided by 6 to obtain an overall score. In 5 cases individual scores on one of the 6 questions were missing and were replaced by the question mean of the total population for that question. High values for the overall score signify differentiation and low values signify cost leadership, as strategic position for the company. The measurement scale proved to be reliable with a Cronbach alpha of 0.75 , which is both above the acceptable level indicated by Nunnally and Bernstein and others (Nunnally \& Bernstein 1994 , p. 265, Chow et al. 1999, p. 452), and above the level found by Govindarajan (1988) in the initial use of the instrument. The empirical data obtained on strategic positioning are summarized in table 7.3.

Table 7.3 Strategic position

\begin{tabular}{|c|c|c|c|c|}
\hline & Mean & SD & Range & $\begin{array}{c}\text { Cronbach } \\
a\end{array}$ \\
\hline $\begin{array}{l}\text { Score on differentiation or cost leadership strategy } \\
(1=\text { cost leadership, } 7 \text { =differentiation). }(\mathrm{N}=67) \\
\text { Scores obtained by Govindaraian }(1988),(\mathrm{N}=121)\end{array}$ & $\begin{array}{l}4.64 \\
4.63\end{array}$ & $\begin{array}{l}0.75 \\
0.79\end{array}$ & $3-7$ & $\begin{array}{l}0.75 \\
0.68\end{array}$ \\
\hline
\end{tabular}

\subsubsection{Internal consistency of the strategy measures}

The reliable measurement of business strategy can encounter theoretical and methodical problems (Snow \& Hambrick 1980) that caused us to crosscheck the data that were obtained. A number of consistency checks were performed on the basis of hypothesized correlations between the three classifications suggested by Langfield-Smith (1997, p. 213). There is a general consensus that differentiation position, prospector typology and build missions are conceptually similar. Likewise harvest mission, defender type and cost leadership position are expected to be related (Chrisman et al. 1988, Shortell \& Zajac 1990, Abernethy \& Guthrie 1994, Ittner et al. 1997, Langfield-Smith 1997). Overall the scores for mission and type should be highly correlated and both should have a negative correlation with the score for position according to Langfield-Smith (1997).

Before addressing these relationships, an overview of the scores that were obtained for the 4 constructs is provided in figure 7.2. 


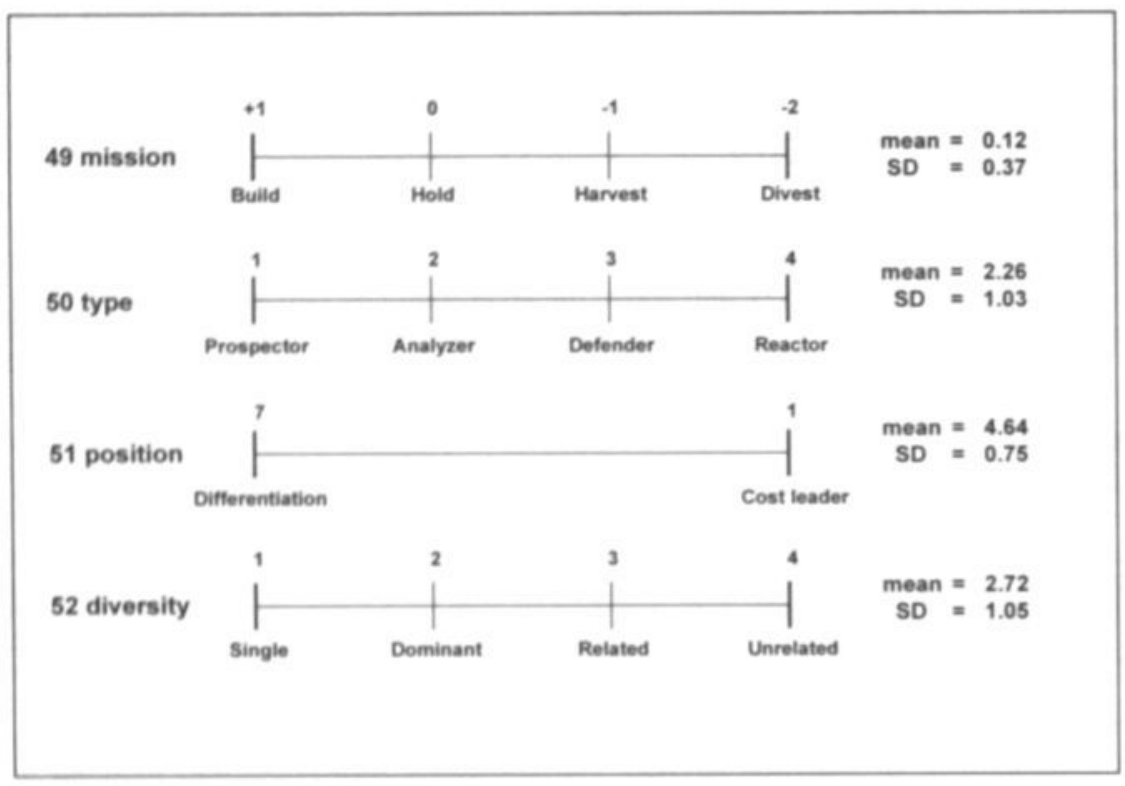

Significant negative correlation was found between the scores for strategy type and position (Pearson correlation coefficient $-0.325,1$-tailed significance 0.004 ). This indicated that prospector and differentiation strategies on the one hand and defender/reactor and cost leadership strategies on the other hand were related, which is in accordance with expectation. Contrary to expectations, significant correlation between mission and strategy type or position scores was not found. With regard to the individual categories, the expected differentiation focus for prospectors was confirmed, as well as the cost leadership focus for defenders, in line with the overall correlation between the scores on type and positioning. The expectation that prospectors would have a build mission and defenders a hold/harvest mission was not confirmed.

It emerges that the reliability of the mission data we obtained is questionable and that any inferences related to mission need to be made with caution. The use of the original measurement instrument produced these results. Why the expected correlation between mission and the other two strategy-constructs cannot be found remains unclear, and is an area for further future research.

For the remainder of this chapter positioning will be the strategic variable that is used.

\subsubsection{Shareholder value creation}

In accordance with our analysis in the previous chapter, the cumulative RTSR for the years from 1997 up to and including 2000 was used as the measure for financial performance. The measure is abbreviated as RTSR $00-97$. The specification and values for the measure are reported in section 6.3.2. In addition the annual RTSR for the years 1998, 1999 and 2000 was used for a number of regression analyses (see chapter 5). 


\subsubsection{Control variables}

The reason to measure diversity in the product portfolio of the companies in the sample was explained in the introduction to this chapter. Diversity will influence the interdependence of various businesses in the portfolio of multi-business firms. It is not a strategic variable as such but it can be used as a control variable to signal the likelihood that the overall strategy that we measure is in fact composed of multiple, possibly divergent, business strategies.

To measure diversity we used a classification developed by Rumelt (1974) and later used by Vancil (1979) and Christie et al. (2003). The classification distinguishes single business, dominant business, related business and unrelated business firms. The CFOs were asked to choose one of these categories for their company, based on a short definition of each in question 52. The answers obtained were coded 1 for single business, 2 for dominant business, 3 for related business and 4 for unrelated business. Consequently a high score signifies a high degree of diversity in the portfolio and limited dependencies between the underlying businesses. Similarly to strategic typology, the measure represents the self-rating of the CFO, using a single-point measurement. The internal consistency of the measurement scale cannot be determined; reliability of the measurement can only be verified against empirical data obtained in other studies. How the CFOs in our sample classified their company is reported in the following table.

Table 7.4 Portfolio diversity

\begin{tabular}{lcccc}
\hline & Single & Dominant & Related & Unrelated \\
\hline Number of companies per category & 11 & 14 & 22 & 18 \\
$\%$ of total, (N=65, 2000 data) & $16 \%$ & $21 \%$ & $32 \%$ & $27 \%$ \\
Scores obtained by Christie et al. (2003), number & 35 & 28 & 33 & 25 \\
$\%$ of total, (N=121, 1987 data) & $29 \%$ & $23 \%$ & $27 \%$ & $21 \%$ \\
Scores obtained by Vancil (1979), number & 58 & 82 & 64 & 87 \\
$\%$ of total, (N=291, 1975 data) & $20 \%$ & $28 \%$ & $22 \%$ & $30 \%$ \\
\hline
\end{tabular}

Comparison with the data obtained by Christie et al. and Vancil, both for the United States, suggests that Dutch companies are more diverse. A shift from single and dominant business firms towards related and unrelated businesses is apparent in the data reported above. Obviously the difference can be affected by country-specific industry characteristics that can be different between the United States and the Netherlands. Christie et al. (2003) confirmed that the measurement scale used is robust to different ways of measuring diversity. This is expected to be the case in the Netherlands also.

Additional control variables used in the analysis of RTSR: BETA, market-to-book ratio and size measured in terms of sales, have already been discussed in the preceding chapters. 


\subsection{Discussion of results}

\subsubsection{Univariate results}

\subsubsection{Hypothesis I}

For the investigation of expected differences in control system characteristics, as a function of strategic mission, type, and position, the 11 importance rankings for management control elements and the 4 factors, both described in chapter 6 , were used. Independent sample t-tests were performed to determine whether management control system characteristics were different for different strategies.

To determine whether companies with different strategic position had differences in management controls, as posited in the hypothesis $\mathrm{Hl}$, the response group was split at the median score for position and the companies with a score below the median (cost leaders) were compared to the companies that had a score above the median (differentiators). The continuous measurement scale used for position made this possible.

The score on diversity was not significantly different between the groups that were compared. Therefore there is no reason to assume that the outcome of the analysis is influenced by differences in the level of diversity.

The comparison of the importance attached to the 11 elements of management control by companies with different strategic positions is reported in table 7.5. 
Table 7.5 Test of the difference in importance attached to elements of management control systems between differentiators and cost leaders (t-test)

\begin{tabular}{|c|c|c|c|c|}
\hline & $\begin{array}{c}\text { Differen- } \\
\text { tiators } \\
(\mathrm{N}=32)\end{array}$ & $\begin{array}{c}\text { Cost } \\
\text { leaders } \\
(\mathrm{N}=35)\end{array}$ & t-value & $\begin{array}{c}\text { Sign. } \\
\text { (2-tailed) }\end{array}$ \\
\hline Mean importance of financial performance measures & 5.78 & 5.61 & 0.631 & 0.530 \\
\hline Mean importance of non-financial performance measures & 4.92 & 4.37 & 2.007 & 0.049 \\
\hline Mean importance of budgeting & 6.09 & 5.70 & 1.516 & 0.134 \\
\hline Mean importance of codes of conduct & 4.50 & 4.13 & 1.071 & 0.288 \\
\hline Mean importance of company culture & 5.31 & 4.70 & 2.223 & 0.030 \\
\hline Mean importance of cost and variance analysis & 4.89 & 4.84 & 0.145 & 0.885 \\
\hline Mean importance of incentives & 5.23 & 5.03 & 0.749 & 0.456 \\
\hline Mean importance of internal controls & 5.38 & 5.13 & 0.995 & 0.324 \\
\hline Mean importance of management style & 5.47 & 5.30 & 0.695 & 0.490 \\
\hline Mean importance of mission statement & 4.00 & 3.96 & 0.130 & 0.897 \\
\hline Mean importance of organizational structure & 5.52 & 5.40 & 0.409 & 0.684 \\
\hline
\end{tabular}

Significant values are in bold.

There is evidence that management control system characteristics are different between the contrasting strategies that we compared. Therefore we find some support for hypothesis HI.

The higher importance attached to non-financial performance measures by differentiators can probably be explained from their focus on innovation and distinguishing product characteristics. These cannot be measured easily using financial performance measures. In contrast, cost leaders can be expected to put more focus on cost prices and margins and can therefore be expected to find non-financial performance measures less important. This outcome is in accordance with earlier findings from Ittner et al. (1997) with respect to performance measures used in bonus contracts. That cost leaders also score lower, although not significantly, on financial performance measures appears to contradict the above reasoning, but that is not necessarily the case. Differentiators will typically encounter higher risks and uncertainties in their business, which can be expected to result in a higher importance being attached to management controls across the board. This is illustrated by the fact that differentiators attach a higher importance to all 11 controls. Most probably differentiators experience higher uncertainty that they want to compensate by higher attention paid to management controls in general. The higher importance attached to company culture is less obvious.

The Mann-Whitney test produced similar results and is therefore not reported here.

The same analysis was also performed for the four management control factors developed in chapter 6 . The outcome of this comparison showed significant differences for factor 2 and factor 4 controls, confirming the above findings.

In summary we can conclude that our data provide some, but limited, support for hypotheses H1. 


\subsubsection{Hypothesis 2}

When we relate the strategy of the companies in our sample to the adoption of VBM we find that $18(51.4 \%)$ cost leaders had adopted VBM by the year 2000 . Out of the total group of 32 differentiators, $16(50 \%)$ have adopted VBM. At first glance this does not indicate a much higher preference for the application of value-based management in the group of cost leaders in our sample, which is against the expectation posited by Lovata and Costigan (2002). To investigate this further we compared the scores for the strategic position of companies that had adopted VBM by the year 2000 and companies that had not done so. The comparison is reported in table 7.6 .

Table 7.6 Test of the difference in score for strategic position between companies that applied VBM by the year 2000 and companies that did not (t-test)

\begin{tabular}{lcccc}
\hline & VBM & No-VBM & 1-value & $\begin{array}{c}\text { Sign. } \\
\text { (2-tailed })\end{array}$ \\
& $(\mathrm{N}=34)$ & $(\mathrm{N}=33)$ & & \\
\hline Strategic position & 4.69 & 4.60 & 0.469 & 0.641 \\
\hline
\end{tabular}

The adoption of VBM appears to be unrelated to the strategic position of the companies in our sample. We have to reject hypothesis $\mathrm{H} 2$ and conclude that we cannot corroborate the earlier findings of Lovata and Costigan (2002) who found a significantly higher adoption of EVA performance measures in defender companies. The adoption of VBM does not appear to differ significantly between companies with different strategies in our empirical data.

\subsubsection{Hypothesis 3}

To be able to determine whether the observed differences in importance attached to certain elements of management control find their reflection in economic performance, we compared the companies that realized a below median RTSR and those that realized an equal to or above median RTSR. The response group was split at the median cumulative RTSR for the four-year period $1997-2000$. The importance attached to the 11 elements of management control were compared between cost leaders and differentiators that produced below median RTSR on the one hand and those that produced above median RTSR on the other, to determine whether there was support for hypothesis H2. The outcome of the comparison is presented in the following table. 


\section{Management Control Systems and Shareholder Value Creation}

Table 7.7 Test of the difference in importance attached to elements of management control systems for cost leaders and differentiators with below median and equal or above median RTSR ( $t$-test, $\mathrm{N}=47$ )

\begin{tabular}{|c|c|c|c|c|}
\hline & \multicolumn{2}{|c|}{ Differentiators } & \multicolumn{2}{|c|}{ Cost leaders } \\
\hline & $\begin{array}{c}\text { Equal or } \\
\text { above } \\
\text { median } \\
\text { RTSR } \\
N=I I\end{array}$ & $\begin{array}{c}\text { Below } \\
\text { median } \\
\text { RTSR } \\
N=10\end{array}$ & $\begin{array}{c}\text { Equal or } \\
\text { above } \\
\text { median } \\
R T S R \\
N=13\end{array}$ & $\begin{array}{c}\text { Below } \\
\text { median } \\
\text { RTSR } \\
N=12\end{array}$ \\
\hline Mean importance of financial performance measures & $\begin{array}{c}5.86 \\
t=0.147\end{array}$ & $\begin{array}{c}5.80 \\
p=0.885\end{array}$ & $\begin{array}{c}6.00 \\
t=1.175\end{array}$ & $\begin{array}{c}5.50 \\
p=0.252\end{array}$ \\
\hline $\begin{array}{l}\text { Mean importance of non-financial performance } \\
\text { measures }\end{array}$ & $\begin{array}{l}4.45 \\
t=-0.085\end{array}$ & $\begin{array}{c}4.50 \\
p=0.933\end{array}$ & $\begin{array}{l}4.62 \\
t=0.479\end{array}$ & $\begin{array}{c}4.38 \\
p=0.636\end{array}$ \\
\hline Mean importance of budgeting & $\begin{array}{c}6.55 \\
t=1.630\end{array}$ & $\begin{array}{c}5.85 \\
p=0.125\end{array}$ & $\begin{array}{c}6.62 \\
t=2.503\end{array}$ & $\begin{array}{c}5.67 \\
p=0.023\end{array}$ \\
\hline Mean importance of codes of conduct & $\begin{array}{c}5.00 \\
t=1.108\end{array}$ & $\begin{array}{c}4.25 \\
p=0.282\end{array}$ & $\begin{array}{c}4.96 \\
t=1.493\end{array}$ & $\begin{array}{c}4.08 \\
p=0.149\end{array}$ \\
\hline Mean importance of company culture & $\begin{array}{l}5.73 \\
t=2.279\end{array}$ & $\begin{array}{c}4.75 \\
p=0.034\end{array}$ & $\begin{array}{c}5.65 \\
t=2.585\end{array}$ & $\begin{array}{c}4.58 \\
p=0.017\end{array}$ \\
\hline Mean importance of cost and variance analysis & $\begin{array}{c}4.77 \\
t=-0.041\end{array}$ & $\begin{array}{c}4.80 \\
p=0.968\end{array}$ & $\begin{array}{c}4.88 \\
t=0.439\end{array}$ & $\begin{array}{c}4.63 \\
p=0.665\end{array}$ \\
\hline Mean importance of incentives & $\begin{array}{c}5.14 \\
t=-0.376\end{array}$ & $\begin{array}{c}5.35 \\
p=0.711\end{array}$ & $\begin{array}{c}5.12 \\
t=-0.182\end{array}$ & $\begin{array}{c}5.21 \\
p=0.857\end{array}$ \\
\hline Mean importance of internal controls & $\begin{array}{c}5.77 \\
t=1.716\end{array}$ & $\begin{array}{c}5.00 \\
\mathrm{p}=0.102\end{array}$ & $\begin{array}{c}5.81 \\
t=2.364\end{array}$ & $\begin{array}{c}4.88 \\
p=0.027\end{array}$ \\
\hline Mean importance of management style & $\begin{array}{c}5.86 \\
t=1.865\end{array}$ & $\begin{array}{c}5.15 \\
p=0.078\end{array}$ & $\begin{array}{c}5.58 \\
t=1.384\end{array}$ & $\begin{array}{c}5.00 \\
p=0.180\end{array}$ \\
\hline Mean importance of mission statement & $\begin{array}{c}3.82 \\
t=-0.313\end{array}$ & $\begin{array}{c}4.00 \\
p=0.758\end{array}$ & $\begin{array}{l}3.96 \\
t=0.398\end{array}$ & $\begin{array}{c}3.75 \\
p=0.694\end{array}$ \\
\hline Mean importance of organizational structure & $\begin{array}{c}6.00 \\
t=2.161\end{array}$ & $\begin{array}{c}5.05 \\
p=0.044\end{array}$ & $\begin{array}{c}6.00 \\
t=2.682\end{array}$ & $\begin{array}{c}4.92 \\
p=0.013\end{array}$ \\
\hline
\end{tabular}

\footnotetext{
Significant values are in bold.
}

The analysis appears to provide support for hypothesis H3. Successful differentiators attach significantly greater importance to company culture, management style and organizational structure in comparison to unsuccessful differentiators. On the other hand, successful cost leaders attach significantly higher importance to budgeting, company culture, internal controls and organizational structure compared to unsuccessful cost leaders. Significant differences were also found (not reported here) when the four management control factors were analyzed. What is unclear is to what extent these differences are significant for the explanation of inter-firm differences in value creation. We address that question in the next section. 


\section{Chapter 7}

\subsubsection{Multivariate results for hypothesis 3}

\subsubsection{Management control system elements}

To investigate the relation between the importance attached by the CFOs to the 11 elements of management control, the strategy pursued by their company and the creation of value for shareholders.

We estimated the following regression equation:

$$
\begin{aligned}
\text { RTSR }_{00-97}= & \beta_{0}+\beta_{1 \ldots 11} \text { IMPMC }_{1.11}+\beta_{12} \text { POSITION }_{00}+\beta_{13} \text { LNSALES }+\beta_{14} \text { MB }_{00-97}+ \\
& \beta_{15} \text { BETA }_{00-97}+\varepsilon
\end{aligned}
$$

The new independent variable was defined as:

POSITION $_{00}$ : strategy variable measuring the strategic position at the end of 2000 on a scale of 1 to 7 in accordance with the distinction between cost leaders and differentiators introduced by Porter (1980), see section 7.3.1

The results of the regression analysis are presented in table 7.8.

Table 7.8 Multivariate results with importance ranking for control system elements and strategic position as

\begin{tabular}{|c|c|c|c|c|c|}
\hline Variable & $\begin{array}{c}\text { Expected } \\
\text { sign }\end{array}$ & $\begin{array}{c}\text { Coeffi- } \\
\text { cient } \\
\text { Value }\end{array}$ & $\begin{array}{c}\text { Standard } \\
\text { error }\end{array}$ & t-value & Sign. \\
\hline Constant & (?) & -3.803 & 1.635 & -2.326 & 0.028 \\
\hline Mean importance of financial performance measures & (?) & 0.508 & 0.204 & 2.492 & 0.028 \\
\hline \multicolumn{6}{|l|}{ Mean importance of non-financial performance } \\
\hline measures & (?) & 0.014 & 0.202 & 0.068 & 0.946 \\
\hline Mean importance of budgeting & (?) & 0.103 & 0.228 & 0.452 & 0.655 \\
\hline Mean importance of codes of conduct & (?) & 0.080 & 0.178 & 0.450 & 0.656 \\
\hline Mean importance of company culture & (?) & 0.406 & 0.199 & 2.046 & 0.051 \\
\hline Mean importance of cost and variance analysis & (?) & -0.211 & 0.122 & -1.730 & 0.095 \\
\hline Mean importance of incentives & (?) & -0.528 & 0.170 & -3.106 & 0.005 \\
\hline Mean importance of internal controls & (?) & 0.073 & 0.200 & 0.364 & 0.719 \\
\hline Mean importance of management style & (?) & -0.034 & 0.169 & -0.203 & 0.841 \\
\hline Mean importance of mission statement & (?) & -0.061 & 0.132 & -0.462 & 0.648 \\
\hline Mean importance of organizational structure & (?) & -0.080 & 0.168 & -0.477 & 0.637 \\
\hline POSITION & (?) & -0.039 & 0.257 & -0.154 & 0.879 \\
\hline LNSALES & $(+)$ & 0.080 & 0.055 & 1.449 & 0.159 \\
\hline $\mathrm{MB}_{00.97}$ & $(+)$ & 0.067 & 0.030 & 2.203 & 0.037 \\
\hline BETA $_{00-97}$ & (?) & 1.148 & 0.417 & 2.751 & 0.011 \\
\hline
\end{tabular}
independent variables and cumulative RTSR as dependent variable

$R^{2}=0.590, N=41,15 d f, F=4.927$, Sign. two-tailed $=0.000$. Significant effects are in bold.

Contrary to our expectation and the postulated relevance of strategy to the explanation of control system differences, we did not find a significant contribution of the strategy variable to the explanation of differences in RTSR, across the companies in our sample. The importance attached to financial performance measures, as well as the importance attached to incentives (negative), remain significant for the explanation of value creation. These results lead us to reject hypothesis $\mathrm{H} 3$, because strategic position did not contribute significantly to the explanation of RTSR differences. 
A similar regression analysis with the four management control factors as independent variables instead of the 11 elements of management control produced comparable results.

\subsubsection{Focus on value creation}

To determine whether a management control system that is focused on shareholder value creation contributes to the creation of RTSR in certain strategic settings, we return to the initial analysis of chapter 5 , adding strategic position as an additional explanatory variable. It needs to be pointed out that the adoption of VBM is a specific characteristic of management control that was measured per year. Consequently, the regression equation needs be estimated separately for each year. To remain parsimonious, we only report the results for the year 2000 and comment on the other years when discussing these results. We estimated the following regression equation:

$$
\text { RTSR }_{00}=\beta_{0}+\beta_{1} \text { VBM }_{00}+\beta_{2} \text { POSITION }_{00}+\beta_{3} \text { LNSALES }+\beta_{4} \text { MB }_{00}+\beta_{5} \text { BETA }_{00}+\varepsilon
$$

The results that were obtained are reported in table 7.9.

Table 7.9 Multivariate results with adoption of value-based management and strategic position as independent variables and RTSR as dependent variable

RTSR 2000

\begin{tabular}{lccccc}
\hline Variable & Expected sign & $\begin{array}{c}\text { Coefficient } \\
\text { value }\end{array}$ & Standard error & t-value & Sign. \\
\hline Constant & $(?)$ & -0.326 & 0.466 & -0.700 & 0.487 \\
VBM & $(+)$ & 0.194 & 0.120 & 1.618 & 0.111 \\
POSITION & $(?)$ & $\mathbf{0 . 1 5 0}$ & $\mathbf{0 . 0 7 6}$ & $\mathbf{1 . 9 6 0}$ & $\mathbf{0 . 0 5 5}$ \\
LNSALES & $(+)$ & 0.014 & 0.021 & 0.659 & 0.513 \\
MB & $(+)$ & 0.006 & 0.005 & 1.181 & 0.242 \\
BETA & $(?)$ & $\mathbf{- 0 . 3 9 5}$ & $\mathbf{0 . 1 1 0}$ & $\mathbf{- 3 . 5 9 0}$ & $\mathbf{0 . 0 0 1}$ \\
\hline
\end{tabular}

$\mathrm{R}^{2}=0.181, \mathrm{~N}=63,5 \mathrm{df}, \mathrm{F}=3.788$, Sign. two-tailed $=0.005$. Significant effects are in bold.

Both strategic position and relative risk measured in terms of BETA contribute to the explanation of RTSR in the year 2000. The adoption of VBM is not significant. When we investigated RTSR 1 and 2 years after adoption of VBM we also found no significant contribution from the adoption of VBM and therefore we have to conclude that it does not contribute significantly to the explanation of RTSR.

The analysis was also performed for RTSR in 1999 and 1998, which produced results that were comparable to those reported in chapter 5. In 1999 the overall regression was not significant, while in 1998 the only factor that contributed significantly to the explanation of RTSR was the market-to-book ratio. Again we have to conclude that there is no support for hypothesis $\mathrm{H} 3$.

\subsubsection{Interaction approach}

In accordance with early research that pursued similar research questions (Govindarajan \& Fisher 1990, Abernethy \& Guthrie 1994, Hartmann 1997, Davilla 2000, Lovata \& Costigan 2002), moderated regression analysis (Hartmann \& Moers 1999) was applied to determine whether variations in the performance of companies could be explained from the interaction between variables, in our case the interaction between strategy and a focus on shareholder value creation in management control. 
To perform the analysis the following regression equation was used:

$$
\begin{aligned}
\text { RTSR }_{00}= & \beta_{0}+\beta_{1} \text { VBM }_{00}+\beta_{2} \text { POSITION }_{00}+\beta_{3} \text { LNSALES }+\beta_{4} \text { MB }_{00}+\beta_{5} \text { BETA }_{00}+ \\
& \beta_{6} \text { VBM }_{00} * \text { POSITION }_{00}+\varepsilon
\end{aligned}
$$

The new interaction variable that was added was coded $\mathrm{VBM}_{00} *$ POSITION 00 and measured the interaction between strategic position and the adoption of VBM. Using a binary coded variable $\left(\mathrm{VBM}_{00}\right.$ is coded 0 or 1 to identify the adoption of VBM) is appropriate for this kind of analysis according to Hartmann (1997, p. 167). The new regression produced the same adjusted R-square $(0.181)$ as the previous model, and an interaction term that was not significant. The results are presented in table 7.10.

Table 7.10 Multivariate results with adoption of value-based management and strategic position, including their interaction, as independent variables and RTSR as dependent variable

\begin{tabular}{lccccc} 
RTSR 2000 & Expected sign & $\begin{array}{c}\text { Coefficient } \\
\text { value }\end{array}$ & Standard error & t-value & Sign. \\
\hline Variable & $(?)$ & 0.226 & 0.718 & 0.315 & 0.754 \\
\hline Constant & $(+)$ & -0.560 & 0.756 & -0.740 & 0.462 \\
VBM & $(?)$ & 0.043 & 0.130 & 0.329 & 0.743 \\
POSITION & $(+)$ & 0.009 & 0.022 & 0.416 & 0.679 \\
LNSALES & $(+)$ & 0.007 & 0.005 & 1.305 & 0.197 \\
MB & $(?)$ & $-\mathbf{0 . 4 0 5}$ & $\mathbf{0 . 1 1 0}$ & $\mathbf{- 3 . 6 6 6}$ & $\mathbf{0 . 0 0 1}$ \\
BETA & $(?)$ & 0.167 & 0.165 & 1.010 & 0.317 \\
VBM*POSITION & & &
\end{tabular}

$\mathrm{R}^{2}=0.181, \mathrm{~N}=63,6 \mathrm{df}, \mathrm{F}=3.328$, Sign. two-tailed $=0.007$. Significant effects are in bold.

The fact that the interaction term is positive but not significant indicates that the interaction between the application of VBM and the strategic position of the company does not explain the differences in RTSR between companies. Consequently we have to conclude that the main effect of strategic position on the explanation of RTSR is significant but that this is not influenced by the adoption of VBM by the companies concerned either as a main effect or through interaction.

\subsection{Summary and conclusions}

In this chapter the relation between management controls and business strategy was investigated and both exploratory and confirmatory analyses were performed to understand the contingency relationship between the two. Three different strategy dimensions were used, based on earlier empirical work by others: strategic position, strategy type and strategic mission. The data obtained on these different dimensions were compared with other empirical studies to test their plausibility. In addition the scores on the three dimensions were validated against each other, which resulted in concern with regard to the reliability of the mission data that were available. In itself this is an area for further research because the measurement instruments that were used for the three dimensions are replications of earlier research. That the postulated internal consistency in the three dimensions is not found in practice raises questions with regard to the reliability of the measurement instrument for strategic mission. 
The CFOs of companies pursuing different strategies rate the importance of certain management controls differently. Differentiators attach greater importance to non-financial performance measures and company culture and they also rate the overall importance of the 11 management control elements higher. The same applies to factor 2 and 4 controls and the overall importance attached to the management control factors. All in all, this confirms that the importance attached to management controls is somewhat dependent on the strategy of the company.

The adoption of shareholder value focused management controls appears to be unrelated to the strategic position of the companies in the response group. The expected preference for VBM in companies that pursue a cost leadership strategy was not confirmed.

Successful differentiators that create above median RTSR were found to attach higher importance to company culture, management style and organizational structure when compared to unsuccessful differentiators. Successful cost leaders distinguished themselves from their less successful colleagues by attaching higher importance to budgeting, company culture, internal controls and organizational structure. One can read this as an indication that successful differentiators have more focus on behavior/input controls, whereas successful cost leaders place more reliance on output-related controls.

Multiple regression analysis showed that the differences in strategy in combination with management control characteristics did not contribute significantly to the explanation of inter-firm differences in RTSR. In that respect the expected impact on performance of the relation between management control characteristics and business strategy could not be supported. Differences in importance attached to certain management controls partly explain value creation, but these are not dependent on the strategy that is followed by the company.

The findings with regard to the relation between company strategy, the adoption of VBM, and the creation of RTSR are not conclusive and are contrary to the empirical findings of others. This leaves room for future research. It is clear that a contingency relation between strategy and management control exists. Additional research is needed to obtain a better understanding of the nature of this relationship and why it appears not to contribute to differences in the creation of value for shareholders. 



\section{Overall summary and conclusions}

\subsection{Introduction}

The goal of this dissertation is to obtain a better understanding of the relation between management control systems (MCS) and the creation of value for shareholders. Value creation is the stated objective of many companies and in view of the fact that management control systems are used to guide organizations and their members towards the realization of their objectives, we assumed that it would be possible to find a relation between MCS and value creation. In this chapter an overview of the empirical findings is provided with discussion of the conclusions and implications that arise from these findings. Limitations of the study and directions for future research will also be addressed. The results of the three empirical studies that were performed are first summarized and commented upon. Subsequently a discussion of the limitations of the study will be provided. The conclusions and implications are discussed together with areas for future research in the last section.

\subsection{Summary of empirical findings}

\subsubsection{Three directions of research}

In essence three research questions have been addressed in this dissertation. All dealt with the relation between management control and the creation of value for shareholders, measured in terms of relative total shareholder return (RTSR). In the first study it was determined whether a management control system that is focussed on the creation of value for shareholders contributes to the creation of RTSR. It can be argued that the implementation of value-based management is in fact the introduction of a specific focus into an organization's management control system. This assertion is the cornerstone of the first study. As a second step the research question was generalized and it was investigated whether management control system characteristics in general explain the creation of value for shareholders. In that case it was not important whether companies had introduced a value-based management focus, but the actual importance attached to elements of management control was studied. The third study addressed the relation between management control system characteristic and company strategy, again in relation to the creation of value for shareholders. 
The empirical material used for the studies was obtained from a questionnaire that was submitted by 68 companies listed in the Netherlands. The companies that cooperated were identified in the questionnaires and consequently financial information and stock market performance of the companies could be obtained and related to the questionnaire results. This distinguishes our research approach from most survey-based studies in this particular area that rely on the perception of survey participants for the measurement of performance.

\subsubsection{Value-based management focused control systems}

To test whether companies that applied value-based management (VBM) were actually achieving superior performance in terms of value creation for their shareholders, four hypotheses were developed. The performance of companies that adopted VBM was compared with the performance of non-adopters in the sample. Performance was measured on three different levels: (1) stock-market performance in terms of RTSR, (2) accounting performance measured by return on equity and earnings per share, and (3) managers' perception of performance. Contrary to the predictions of value-based management theory, the empirical data did not provide support for the assumption that performance improves as a result of the adoption of VBM. These findings were corroborated when lagged performance was measured allowing for a one or two-year learning period after the initial adoption of VBM.

Explanations for the lack of evidence that VBM actually enhances value creation can be that the companies applying the concept are not doing so properly. It may be that the objective is stated but not properly communicated and translated into performance measures and objectives for employees at various levels of the organization. It can also be that VBM is simply not effective and that traditional management controls are just as effective for the achievement of value creation. When we assume that VBM is only appropriate for certain companies under specific circumstances, there may be a problem because of the endogenous nature of choice for VBM. In case only those companies adopt VBM for which it is a suitable management technique, there will be no association between performance and the application of VBM (see on this Ittner et al. 2002, p. 723, with respect to the adoption of Activity Based Costing). Lastly, other independent variables that were not measured may impact share prices and affect our findings.

\subsubsection{Management control system characteristics}

To be able to measure management control systems, a set of 11 management control system characteristics was developed on the basis of Simons' four levers of control (Simons 1995 ${ }^{b}$ ), and input from an expert panel. The analysis of the answers regarding these characteristics showed that the measurement instrument had an acceptable level of reliability. From these 11 elements a unique set of four management control system factors was developed using factor analysis. Both the 11 elements and the 4 factors were used for our subsequent investigation of the relation between management control and shareholder value creation.

Two hypotheses were tested in this study. First, it was investigated whether companies that were more successful in creating value for their shareholders attached a different importance to management controls compared to companies that were less successful. The second enquiry addressed the question whether companies that applied VBM rated the importance of certain management controls differently from companies that did not apply the concept. 
We found that successful value creators attached significantly more importance to certain management controls compared to less successful companies and that this was also the case for certain management control factors. When additional control variables were introduced in the analysis, the existence of differences was confirmed. It emerged that companies that created value for their shareholders attached significantly higher importance to financial performance measures and a significantly lower importance to incentives. The fact that importance attached to incentives had a negative contribution to the explanation of inter-firm differences in the creation of value for shareholders is contrary to the recommendations of VBM theorists (Stewart 1991 and others) who attach high importance to incentives as an element of VBM.

The companies that applied VBM were not found to differentiate their management control system from companies that did not apply VBM. This can possibly be an explanation why a beneficial impact of VBM application on the creation of value for shareholders could not be found in the first study. Apparently the adoption of VBM does not lead to changes in the management control system of the companies in our sample, which can be an indication that the concept is acknowledged but not effectively translated into management control.

\subsubsection{Relations with strategy}

The third study introduced company strategy into our investigation, in accordance with the notion that there is a contingent relationship between company strategy and management control systems (Langfield-Smith 1997 and others). This relationship could be expected to have had influence in the first two studies, which could impair the validity of the conclusions from those studies. Consequently the scope of the investigation was expanded to include company strategy, more specifically the strategic position of the companies in the sample, in accordance with the distinction between cost leaders and differentiators that was introduced by Porter (1980).

First, it was investigated whether management control systems of the companies in the sample differed according to the strategy of the companies. Subsequently the question was addressed whether the adoption of value-based management was associated with the strategy of the companies in the sample. As a final step, the question was addressed whether differences in performance could be explained from different combinations of management control and strategy.

Confirmation was found for the expected differences in management control between cost leaders and differentiators, in line with previous empirical studies. Differentiators were found to attach greater importance to non-financial performance measures and company culture. In addition they were found to attach a higher overall importance to management controls in comparison with cost leaders.

No evidence was found that the adoption of VBM, as a specific form of management control, was related to the strategic position of the companies in the sample. 
Successful differentiators were found to attach higher importance to behavior/input controls like company culture, management style and organizational structure, whereas successful cost leaders additionally focused on budgeting and internal controls. Although these differences could be identified within the two groups of companies that employed different strategies, an overall relation between business strategy and management control that explained the creation of value for shareholders could not be established. However, it was established that, in addition to financial performance measures and incentives, also company culture and cost and variance analysis were areas that contributed significantly to the explanation of differences in RTSR.

The findings from this third study are not conclusive and in some instances are contrary to the empirical findings of others that addressed similar research questions.

\subsection{Limitations of the studies}

The use of survey data in management accounting research has frequently been criticized (e.g. Young 1996) and therefore can be seen as a weakness. The criticism points towards the limited use of sampling techniques and lack of examination of non-response bias, to small sample sizes, the use of self-reported performance measures and the common-method problem.

The use of sampling techniques was not an issue in our study because all companies listed on the Amsterdam stock exchange were actually invited to participate in the research, with the exception of those that were not comparable in view of their business. The $40.2 \%$ response that was obtained was adequate and compared favorably with other studies that approached a similar audience. Due to the mixed research design that used survey data, stock market performance and financial information of the companies that participated, it was furthermore possible to determine the extent to which the response group mirrored the market. This showed that the participants were larger in size than the average company listed in Amsterdam. No evidence of non-response bias was found in the surveys that were returned.

The sample was small, with 68 useable responses. This could be expected as a consequence of the research design. CFOs of listed companies were asked to reply to the survey and they were expected to have a limited willingness to participate. This was accepted in view of the expectation that this disadvantage would be counterbalanced by the fact that the CFOs were the most knowledgeable with respect to their companies' application of value-based management and the design of the management control system. However, this also entailed the risk that the information obtained measured the opinion of the CFO with respect to VBM and MCS, and not necessarily how these concepts were employed and perceived to function by other members of the organization.

As a function of the research design, independent market-based performance measures could be used in addition to self-perceived performance. Therefore this criticism of survey-based research is not applicable in our case. 
Lastly the measurement of VBM and MCS can be impacted by the common-method problem that results from the fact that survey respondents are likely to provide consistent and socially desirable answers. This risk cannot be argued away with respect to our study, notably with respect to value-based management. At the time that the survey was conducted VBM was regarded as an innovative management technique that received widespread support. Some CFOs may therefore have been inclined to state that they apply the concept simply to avoid appearing old-fashioned. Although the application of VBM was measured through a number of questions to prevent companies that merely applied lip service to the concept from being classified as applicants of VBM, it cannot be ruled out that this occurred in some cases. Due to the fact that an a priori preference for certain management controls is not very likely and that a comprehensive set of questions was used to measure MCS, the risk of the commonmethod problem for these data is deemed to be much lower.

A specific limitation of our study is related to the use of stock market performance to determine value creation. Although this is an objective measure that is not biased, it has the inherent disadvantage that it is impacted by numerous factors. Conclusive models that fully explain the differences in share price performance between companies are not available and many variables have been identified that impact these differences. Although a number of control variables have been used that are known to influence the average return of shares, it is by no means certain that all relevant control variables were included (Fama \& French 1992 , 1993), and therefore our findings may be influenced by variables that were not included in our research. It cannot be ruled out that an omitted variable problem is present in our study.

Another specific limitation of the study is that the choice of value-based management may be endogenous and that only those companies that will benefit from the concept actually adopt it. If that is the case there is no difference to be expected between companies that apply VBM and companies that do not do so. The endogenous nature of the choice of certain management control concepts has been mentioned as a possible explanation for the absence of performance differences between adopters and non-adopters (Ittner et al. 2002), and this could also be the case in our study.

In summary we have to conclude that our study is subject to limitations and therefore our inferences need to be judged with some reservation. The fact that only very limited empirical research is available with regard to the research questions we pursued outweighs these concerns in our view and means that our works contributes to the understanding of management control.

\subsection{Conclusions, implications and directions for future research}

Value-based management is a relatively new concept that was expected to have implications for management control in organizations. The combination of survey data and stock market returns has proved to be a worthwhile research approach that enhances our understanding of the consequences and results of the application of value-based management. However, our studies only provide partial understanding and, to some extent, evidence that is conflicting with the empirical findings of other researchers or the views expressed in the value-based management literature. In itself this contributes to the scientific discourse and therefore adds value, certainly in view of the fact that this area of research has not been widely explored to date. 
Overall we did not find that the application of value-based management results in a better performance in terms of shareholder value creation. Companies that apply the concept should therefore consider whether they have translated the concept into a true value-based management culture, as recommended by Haspeslagh et al. (2001). The fact that we did not find distinctive differences in management control systems between companies that applied valuebased management and those that did not, can be read as a sign that insufficient steps are taken to deploy value-based management and integrate it in management control on various levels of the organizations. It can also be that the successful application of VBM requires learning and therefore only becomes apparent after a number of years. We did not find evidence for this when we investigated the one and two year lagged performance of the companies in our sample, but that could be due to the limited time window that was used. Two areas for future research emerge from these observations. It would be worthwhile to investigate the understanding and awareness of value-based management on different levels within the companies that adopted VBM, to learn whether lack of deployment of the concepts is an explanation for the failure of VBM to contribute to value creation. Case studies in companies that employ VBM can certainly contribute to our understanding in this respect. Long-interval return studies comparing the performance of VBM-adopters with the performance of a matched sample of non-adopters can be used to obtain more pertinent evidence on the effectiveness of VBM and the question whether this effectiveness depends on a certain period of learning.

That differences in importance attached to certain management controls are found to partially explain the creation of value for shareholders is a confirmation of earlier empirical work into the relation between management control and economic performance. For companies that are nursuine value creation obiectives, these findings indicate that a focus on certain management controls, notably attaching a high importance to financial performance measures and company culture and attaching less importance to cost and variance analysis and incentives can contribute to the creation of value for shareholders. Although not directly the subject of our study, our findings with respect to incentives can be read as an indication that a high importance attached to incentives is detrimental to shareholder value creation. Such a conclusion is contrary to the findings of others (e.g. Wallace 1997, 1998) and therefore future research into the importance of incentives for the creation of shareholder value is certainly desirable.

The evidence that was found of the differences in management control as a function of the strategy pursued is in accordance with earlier empirical work. However, these differences do not contribute to a better explanation of the creation of shareholder value. That is contrary to other contingency studies into the relation between management control systems and strategy and warrants further investigation. The same applies to the fact that we did not find a significant difference in the adoption of VBM between companies with different strategic positions.

Our research design differs from other studies in this area in view of the fact that we can use survey data to determine whether companies apply VBM, whereas other studies (performed in the United States) use publicly disclosed information with respect to incentive plans to determine this. It would be worthwhile to replicate our investigation in a US setting to be able to determine whether both ways to measure adoption of VBM produce comparable results. 
Further investigation of the correlation between the three strategy dimensions: (1) strategic mission, (2) strategy type, and (3) strategic position is also warranted. The postulated correlation between these dimensions could only be partially confirmed, which raises questions with respect to the reliability of the data that were found. Further work in this area is needed to confirm the reliability of the instruments used to measure the constructs and to validate the theory that they are conceptually related. 


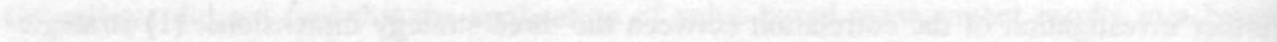

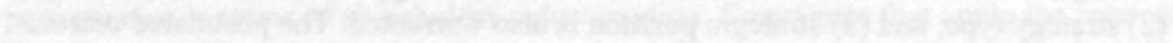

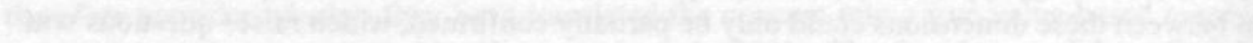
3 and

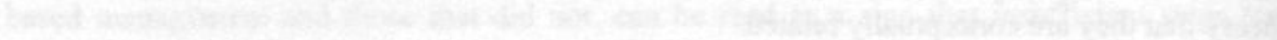

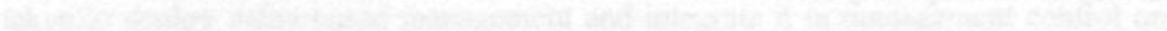

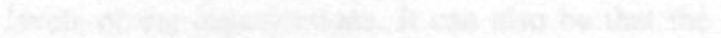

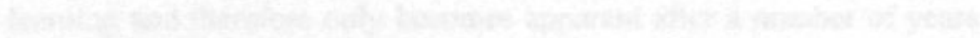




\section{Appendix 1. A. Target audience and response}

\begin{tabular}{|c|c|c|c|c|c|}
\hline & Company & $x^{2}=$ & $\begin{array}{c}\text { Participated } \\
N=68 \\
40.2 \%\end{array}$ & $\begin{array}{c}\text { Leverage } \\
\text { used to } \\
\text { obtain } \\
\text { participation }\end{array}$ & $\begin{array}{l}\text { Date when } \\
\text { response } \\
\text { was } \\
\text { collected }\end{array}$ \\
\hline 1 & Aalbers Industries NV & & Yes & & 22.6 .01 \\
\hline 2 & Accell Group NV & & & & \\
\hline 3 & AFC Ajax NV & & Yes & & 6.4 .01 \\
\hline 4 & Aino NV & & & & \\
\hline 5 & Airspray NV & & & & \\
\hline 6 & Akzo Nobel NV & & Yes & Yes & 1.6 .01 \\
\hline 7 & Alanheri NV & & Yes & Yes & 11.5 .01 \\
\hline 8 & Amstelland NV & & Yes & & 6.4 .01 \\
\hline 9 & Apothekers Coöperatie OPG U.A. & & Yes & & 6.4 .01 \\
\hline 10 & Arcadis NV & & & & \\
\hline 11 & ASM International NV & & & & \\
\hline 12 & ASM Lithography Holding NV & & & & \\
\hline 13 & Athlon Groep NV & & & & \\
\hline 14 & Axa Stenman Industries NV & & & & \\
\hline 15 & AXXICON Group NV & & Yes & & 20.4 .01 \\
\hline 16 & Ballast Nedam NV & & Yes & & 11.5 .01 \\
\hline 17 & Batenburg Beheer NV & & & & \\
\hline 18 & BE Semiconductor Industries NV & & & & \\
\hline 19 & Beers NV & & & & \\
\hline 20 & Beter Bed Holding NV & & Yes & & 6.4 .01 \\
\hline 21 & Blue Fox Enterprises NV & & & & \\
\hline 22 & Blydenstein-Willink NV & & Yes & & 20.4 .01 \\
\hline 23 & Brunel International NV & & & & \\
\hline 24 & Buco NV & & & & \\
\hline 25 & Buhrmann NV & & & Yes & \\
\hline 26 & Elofer NV & & & & \\
\hline 27 & C/TAC-Align NV & & Yes & & 11.5 .01 \\
\hline 28 & Cap Gemini NV & & Yes & & 6.4 .01 \\
\hline 29 & Cardio Control NV & & & & \\
\hline 30 & CMG ple & & Yes & & 6.4 .01 \\
\hline 31 & Computer Services Solutions Holdir & ng NV & & & \\
\hline 32 & Copaco NV & & Yes & & 6.4 .01 \\
\hline 33 & Corus Group plc & & Yes & & 6.4 .01 \\
\hline 34 & Crucell NV & & & & \\
\hline 35 & CSM NV & & & & \\
\hline 36 & De Drie Electronics Beheer NV & & & & \\
\hline 37 & De Vries Robbé Groep NV & & & & \\
\hline 38 & Delft Instruments NV & & Yes & & 6.4 .01 \\
\hline 39 & Devote NV & & & & \\
\hline 40 & DNC De Nederlanden Compagnie $\mathrm{P}$ & & & & \\
\hline
\end{tabular}




\begin{tabular}{|c|c|c|c|c|}
\hline & Company & $\begin{array}{c}\text { Participated } \\
N=68 \\
40.2 \%\end{array}$ & $\begin{array}{c}\text { Leverage } \\
\text { used to } \\
\text { obtain } \\
\text { participation }\end{array}$ & $\begin{array}{c}\text { Date when } \\
\text { response } \\
\text { was } \\
\text { collected }\end{array}$ \\
\hline 41 & DOCdata NV & Yes & & 11.5 .01 \\
\hline 42 & DPA Holding NV & Yes & & 15.6.01 \\
\hline 43 & Draka Holding NV & Yes & & 6.4 .01 \\
\hline 44 & DSM NV & Yes & Yes & 8.6 .01 \\
\hline 45 & EMBA Techniek Groep NV & & & \\
\hline 46 & ERIKS Holding NV & Yes & & 20.4.01 \\
\hline 47 & European Marketing Information Services NV & Yes & & 6.4 .01 \\
\hline 48 & Exact Holding NV & Yes & Yes & $>22.6 .01$ \\
\hline 49 & Fornix BioSciences NV & & & \\
\hline 50 & Fox Kids Europe NV & & & \\
\hline 51 & Free Record Shop Holding NV & & & \\
\hline 52 & Fugro NV & Yes & & 20.4.01 \\
\hline 53 & Gamma Holding NV & & Yes & \\
\hline 54 & Getronics NV & Yes & & 11.5 .01 \\
\hline 55 & Geveke NV & Yes & & 6.4 .01 \\
\hline 56 & Gouda Vuurvast Holding NV & & & \\
\hline 57 & Grontmij NV & Yes & & 20.4 .01 \\
\hline 58 & Groothandelsgebouwen NV & & & \\
\hline 59 & GTI NV & & & \\
\hline 60 & H.E.S. Beheer NV & & & \\
\hline 61 & Hagemeyer NV & & & \\
\hline 62 & HAL Holding N.V. & & & \\
\hline 63 & Heijmans NV & & & \\
\hline 64 & Heineken NV & & & \\
\hline 65 & Helvoet Holding NV & Yes & & 11.5 .01 \\
\hline 66 & HITT NV & Yes & & 6.4 .01 \\
\hline 67 & Holland Colours NV & Yes & & 6.4 .01 \\
\hline 68 & Hollandsche Beton Groep NV & Yes & & 6.4 .01 \\
\hline 69 & Huhtamaki Van Leer Oyi & & & \\
\hline 70 & Hunter Douglas NV & Yes & & 6.4 .01 \\
\hline 71 & ICT Automatisering NV & & & \\
\hline 72 & IHC Caland NV & & & \\
\hline 73 & InnoConcepts NV & & & \\
\hline 74 & Internatio-Müller NV & Yes & & 20.4 .01 \\
\hline 75 & ISOTIS NV & Yes & & 11.5 .01 \\
\hline 76 & KNSF NV & & & \\
\hline 77 & Koninklijke Ahold NV & Yes & & 6.4 .01 \\
\hline 78 & Koninklijke Ahrend NV & & & \\
\hline 79 & Koninklijke BAM Groep NV & & & \\
\hline 80 & Koninklijke Begemann Group (RBG) NV & & & \\
\hline 81 & Koninklijke Boskalis Westminster NV & & & \\
\hline 82 & Koninklijke Brill NV & Yes & & 6.4 .01 \\
\hline 83 & Koninklijke Econosto NV & & & \\
\hline 84 & Koninklijke Frans Maas Groep NV & Yes & Yes & 15.6.01 \\
\hline 85 & Koninklijke Grolsch NV & & & \\
\hline 86 & Koninklijke KPN NV & & & \\
\hline 87 & Koninklijke Luchtvaart Maatschappij NV & Yes & & 6.4 .01 \\
\hline 88 & Koninklijke Nedlloyd NV & Yes & & 20.4 .01 \\
\hline 89 & Koninklijke Nedschroef Holding NV & Yes & & 1.6 .01 \\
\hline
\end{tabular}




\begin{tabular}{|c|c|c|c|c|}
\hline & Company & $\begin{array}{c}\text { Participated } \\
N=68 \\
40.2 \%\end{array}$ & $\begin{array}{c}\text { Leverage } \\
\text { used to } \\
\text { obtain } \\
\text { participation }\end{array}$ & $\begin{array}{c}\text { Date when } \\
\text { response } \\
\text { was } \\
\text { collected }\end{array}$ \\
\hline 90 & Koninklijke Numico NV & & & \\
\hline 91 & Koninklijke Ten Cate NV & & & \\
\hline 92 & Koninklijke Textielgroep Twenthe NV & & & \\
\hline 93 & Koninklijke Volker Wessels Stevin NV & Yes & & 6.4 .01 \\
\hline 94 & Koninklijke Vopak NV & Yes & & 20.4 .01 \\
\hline 95 & Koninklijke Wessanen NV & Yes & & 6.4 .01 \\
\hline 96 & Koninklijke/Shell Group NV & Yes & Yes & $>22.6 .01$ \\
\hline 97 & KPNQwest NV & & & \\
\hline 98 & KSI International NV & & & \\
\hline 99 & Kühne + Heitz NV & & & \\
\hline 100 & Landis Group NV & & & \\
\hline 101 & Laurus NV & & & \\
\hline 102 & LCI Technology Group NV & & & \\
\hline 103 & Libertel NV & Yes & & $>22.6 .01$ \\
\hline 104 & Macintosh Retail Group NV & & & \\
\hline 105 & Magnus Holding NV & Yes & & 20.4 .01 \\
\hline 106 & Management Share NV & & & \\
\hline 107 & McGregor Fashion Group NV & & & \\
\hline 108 & Naeff NV & & & \\
\hline 109 & NAGRON Nationaal Grondbezit NV & & & \\
\hline 110 & Nedcon Groep NV & & & \\
\hline 111 & NedGraphics Holding NV & & & \\
\hline 112 & New Skies Satellites NV & & & \\
\hline 113 & Neways Electronics International NV & Yes & & 6.4 .01 \\
\hline 114 & Newconomy NV & & & \\
\hline 115 & Nutreco Holding NV & Yes & & 11.5 .01 \\
\hline 116 & NV Dico International & Yes & & 20.4 .01 \\
\hline 117 & NV Gemeenschap. Bezit Crown Van Gelder & & & \\
\hline 118 & NV Holdingmaatschappij De Telegraaf & & & \\
\hline 119 & NV Koninklijke Porceleyne Fles anno 1653 & & & \\
\hline 120 & NV Nederlandsche Apparatenfabriek NEDAP & & & \\
\hline 121 & NV Twentsche Kabel Holding & & & \\
\hline 123 & Océ NV & & & \\
\hline 122 & Nyloplast NV & Yes & & $>22.6 .01$ \\
\hline 124 & Ordina NV & & & \\
\hline 125 & Petroplus International NV & & & \\
\hline 126 & Pharming Group NV & Yes & & 20.4 .01 \\
\hline 127 & Philips Electronics NV & Yes & & 6.4 .01 \\
\hline 128 & PinkRoccade NV & Yes & & 11.5 .01 \\
\hline 129 & Polynorm NV & & & \\
\hline 130 & Prolion NV & & & \\
\hline 131 & Randstad Holding NV & Yes & & 11.5 .01 \\
\hline 132 & Reed Elsevier & Yes & & 11.5 .01 \\
\hline 133 & Reesink NV & & & \\
\hline 134 & RING!ROSA Products NV & & & \\
\hline 135 & Rood Testhouse International NV & & & \\
\hline 136 & Roto Smeets De Boer NV & & & \\
\hline 137 & Rubber Cultuur Maatschappij Amsterdam NV & & & \\
\hline 138 & Samas-Groep NV & & & \\
\hline
\end{tabular}




\begin{tabular}{|c|c|c|c|c|}
\hline & Company & $\begin{array}{c}\text { Participated } \\
N=68 \\
40.2 \%\end{array}$ & $\begin{array}{c}\text { Leverage } \\
\text { used to } \\
\text { obtain } \\
\text { participation }\end{array}$ & $\begin{array}{c}\text { Date when } \\
\text { response } \\
\text { was } \\
\text { collected }\end{array}$ \\
\hline 139 & Schuitema NV & Yes & & 1.6 .01 \\
\hline 140 & Schuttersveld NV & Yes & & 20.4.01 \\
\hline 141 & Seagull Holding NV & & & \\
\hline 142 & Simac Techniek NV & Yes & & 22.6 .01 \\
\hline 143 & Sligro Beheer NV & & & \\
\hline 144 & Smit Internationale NV & & & \\
\hline 145 & SNT Groep NV & Yes & & 6.4 .01 \\
\hline 146 & Sopheon plc & & & \\
\hline 147 & Stern Groep NV & & & \\
\hline 148 & Stork NV & Yes & & 6.4 .01 \\
\hline 149 & TIE Holding NV & Yes & & 6.4 .01 \\
\hline 150 & TNT Post Groep NV & Yes & & 11.5 .01 \\
\hline 151 & Toolex International NV & & & \\
\hline 152 & Tulip Computers NV & & & \\
\hline 153 & UCC Groep NV & & & \\
\hline 154 & Unilever NV & Yes & & 11.5 .01 \\
\hline 155 & Unit $4 \mathrm{NV}$ & & & \\
\hline 156 & United Pan-Europe Communications NV & & & \\
\hline 157 & United Services Group NV & Yes & & 6.4 .01 \\
\hline 158 & Van Dorp Despec Groep NV & & & \\
\hline 159 & Van Heek-Tweka NV & & & \\
\hline 160 & Van Melle NV & Yes & & 11.5 .01 \\
\hline 161 & Vedior NV & Yes & & 22.6 .01 \\
\hline 162 & Vendex KBB NV & Yes & Yes & 11.5 .01 \\
\hline 163 & VersaTel Telecom Industries NV & & & \\
\hline 164 & Vilenzo International NV & & & \\
\hline 165 & VNU NV & & & \\
\hline 166 & Vredestein NV & & & \\
\hline 167 & Wegener NV & Yes & & 6.4 .01 \\
\hline 168 & Weweler NV & & & \\
\hline 169 & Wolters Kluwer NV & & & \\
\hline
\end{tabular}




\section{Appendix 1. B. Companies excluded from target audience}

\begin{tabular}{lll}
\hline & Company name & Reason for exclusion \\
\hline 1 & ABN AMRO Holding NV & Financial institution \\
2 & Aegon NV & Financial institution \\
3 & AND International Publishers NV & Bankruptcy in 2001 \\
4 & Antonov plc & Foreign company \\
5 & AOT NV & Financial institution \\
6 & ATAG Group NV & Bankruptcy in 2001 \\
7 & Bever Holding & Financial institution \\
8 & Chicago Bridge \& Iron Company NV & Foreign company \\
9 & EVC International NV & Foreign company \\
10 & Fortis & Financial institution \\
11 & Gucci Group NV & Foreign company \\
12 & ING Groep NV & Financial institution \\
13 & Ispat International NV & Foreign company \\
14 & Kas-Associatie NV & Financial institution \\
15 & Kempen \& Co. NV & Financial institution \\
16 & Scala Business Solutions NV & Foreign company \\
17 & Van der Hoop Effektenbank NV & Financial institution \\
18 & Van der Moolen Holding NV & Financial institution \\
19 & Van Lanschot NV & Financial institution \\
\hline
\end{tabular}




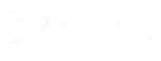

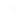

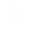

.

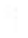




\section{Appendix 2. Summary of the research instrument}

The research instrument consisted of 52 questions that addressed various aspects of management control, shareholder value creation and company strategy. The questions are summarized below. The summary also indicates the scoring range that was used and, where the question replicates previous studies, contains a reference to the source of the question. The questions are numbered in accordance with the research instrument, and these question numbers are used as reference in the study. In some questions CFOs were asked to indicate the importance they attached to certain aspects of management control. For these questions a 7 point Likert-like scale was provided that was anchored at three points $(1=$ not important, 4 = average importance, 7 = very important). A score was asked for both the current (end of 2000) importance and for the importance four years earlier. In this summary we will refer to this scale as the 7-point importance scale. A number of questions were introduced with a brief explanation of the concept that was addressed in the question, for example a brief explanation of the balanced scorecard preceded question 3. These descriptions are not reproduced in this summary.

\section{Overview of the questions}

1. According to Tom Copeland (Valuation: Measuring and Managing the Value of Companies, J. Wiley, 1995, page 166) "Performance measurement systems to support value-based management may require significant changes from a company's traditional approach. In particular, performance measurement has to move away from being accounting driven to being management driven". What is your opinion about his point of view? (5-point anchored scale, strongly agree/strongly disagree).

2. a. Please indicate the importance of financial performance measures for management control in your company. (7-point importance scale).

2. b. Same question for non-financial performance measures. (7-point importance scale)

3. Does your organization use balanced scorecards? (No, yes since year). 
4. To what extent do superiors rely on accounting information such as budgets, spending limits, and financial targets in judging managerial performance?

4.a. Accounting numbers play an important role when the performance of managers is judged.

4.b. Activities are principally controlled through periodic reporting of accounting information.

4.c. Superiors are principally preoccupied with the ability of managers to meet their financial targets expressed in accounting numbers.

(Scored on 7-point scale anchored at three points from definitely false to definitely true). Based on Abernethy and Brownell 1997.

5.a. Does your organization systematically measure (quantify) shareholder value (creation)? (No, yes since year).

5.b. Indicate the type of value creation measure(s) that your organization uses. (ROE on book value, ROE on market value, RONA, EPS, Growth in EPS, TSR, EVA/SVA, CFROI, other). Based on Buhr \& Desjardins 1998.

6. Please indicate the importance of budgeting for management control in your company. (7-point importance scale).

7. How often are budgets (including rolling forecasts) updated in your organization? (Annually, twice a year, quarterly, monthly or more frequently).

8. How high is the likelihood that the budget will actually be met or exceeded in your organization? (7-point scale anchored at three points: very low, neither high nor low and very high).

9. Over the last 4 years, how large has the average difference between budgeted and actual profitability been, in your estimation? $(<5 \%, 5-15 \%, 15-25 \%, 25-50 \%,>50 \%)$.

10. To what degree are profit center managers (budget holders) in your organization involved in setting their own budget targets? (7-point scale anchored at two points, $1=$ not at all, and $7=$ very high).

11. How often do you review the actual performance of your businesses in relation to budgets and/or forecasts in formal review meetings? (Annually, quarterly, monthly, more frequent).

12. Please indicate the importance of codes of conduct for management control in your company. (7-point importance scale).

13. Does your organization have a formal code of conduct that describes how the organization wants to act as a corporate citizen and what behavior of the organization and its employees is deemed to be inappropriate and undesirable? (Yes, no).

14. If yes, in your view how widely is the content of the code of conduct known inside your organization (across all employees)? $(<5 \%, 5-15 \%, 15-25 \%, 25-50 \%,>50 \%$ ).

15. Please indicate the importance of company culture for management control in your company. (7-point importance scale). 
16. Please indicate the importance of cost and variance analysis for management control in your company. (7-point importance scale).

17. Please indicate the importance of incentives for management control in your company. (7-point importance scale).

18. Are any of the following value-based performance measures tied to incentives in your organization? (ROE, RONA, EPS, growth of EPS, TSR, EVA/SVA, CFROI).

Based on Buhr \& Desjardins 1998.

19. In the previous question a number of value-based performance measures were mentioned. Down to which level are they used to evaluate and reward performance in your organization? (Board of management, senior management, subsidiary or business unit, supervisory and line manager, employee).

Based on Buhr \& Desjardins 1998.

20. Are any of the following performance measures tied to incentives for managers in your organization? (Sales (growth), customer satisfaction, market share, quality, production efficiency improvements, innovation, none of the above).

21. Incentives for managers are based on: (objective measures of output performance, subjective estimates of the efforts of the executives, a combination of the two).

22. Criteria for incentives can be based on the performance of the business that an employee works in but they can also be based to some extent on the performance of the whole group or a combination of businesses. Are incentives in your organization principally based on the performance of the own business or is there a considerable ( $25 \%$ or more) dependence on the performance of the total group/combination of businesses? (own business or total group/combination of businesses).

23. What is the most important benchmark for setting performance goals for managers' incentives (both value-based and others) in your organization? (Budget, past performance, competitor's performance, stock market expectations).

24. What portion of executive compensation is tied to performance (both value-based and/or other)? In answering this question please read executive compensation as the compensation of members of the Board of Management and the next lower management level reporting to the Board of Management. (None, <10\%, $10-25 \%, 25-50 \%,>50 \%$ )

25. Please indicate the importance of internal controls for management control in your company. (7-point importance scale).

26. Please indicate the importance of management style for management control in your company. (7-point importance scale).

27. Do senior managers in your organization, including yourself, rely heavily on formal documents or do they prefer conversations and informal contacts for management control? (7-point scale anchored on two points, $1=$ very formal and $7=$ very informal). 
28. Do managers prefer to use tight or loose control? (7-point scale anchored on two points, $1=$ very tight and $7=$ very loose).

29. Please indicate the importance of a mission statement for management control in your company. (7-point importance scale).

30. Does your organization have a written mission statement (or strategy or vision statement)? (Yes, no).

31. If yes, how widely do you think this statement is known among the employees of your organization (across all employees)? (<5 \%, $5-15 \%, 15-25 \%, 25-50 \%,>50 \%$ ).

32. If yes, which, if any, of the following groups are explicitly identified in your organization's mission statement? (Customers, employees, shareholders, suppliers, the public /community).

Based on Buhr \& Desjardins 1998.

33.a. Does your organization explicitly refer to "creating shareholder value" as one of its key corporate objectives in external communications? (Yes, no).

33.b. Same question for internal communications? (Yes, no).

Based on Buhr \& Desjardins 1998.

34. If yes, when did "creating shareholder value" become one of the key corporate objectives? Fiscal year.

35. When the concept of shareholder value was introduced in your company, did you use the support of any of the following advisors? (Value-based management consultants, management consultants, (investment) banks, academics providing consulting services, academics providing training, none of the above).

36. Organizational structure is the way in which work units are arranged to form an organization. The organizational structure determines accountability. Accountability can be allocated to different types of responsibility centers (revenue, cost, profit or investment centers). Please indicate the importance of organizational structure for management control in your company. (7-point importance scale).

37. To what extent is authority delegated to business unit managers to make each of the following classes of decisions in your organization? Rate the extent of delegation from 1 (extremely low) to 7 (extremely high). (Development of new outputs, purchase of capital equipment, hiring and firing of personnel, sourcing of inputs, operating procedures and schedules, pricing of outputs, distribution of outputs, making tradeoffs within the unit's current period budget).

Based on Chow et al. 1999.

38. Which control is used interactively in your organization? (Financial performance measures, non-financial performance measures, budgeting system, code of conduct, company culture, cost and variance analysis, incentives, internal control, management style, mission statements, organizational structure, none, other). 
39.a. In organizations that comprise of different businesses (serving different product-market combinations), management control systems can be differentiated to take into account the different characteristics of these businesses. Does your organization comprise of different businesses? (No, yes).

39.b. Please indicate to what degree management control systems are differentiated across these businesses. (7-point scale anchored on two points $1=$ not at all and $7=$ very much).

40. Which of the following metrics do you believe correlates best with the share price of your organization? (ROE, RONA, EPS, growth in EPS, TSR, EVA/SVA, CFROI, none).

Based on Buhr \& Desjardins 1998.

41. Down to which level in your organization do you measure value-based performance? (Corporate, division/subsidiary/business unit, individual product-market, customer, not measured).

42. Are shareholder value measures explicitly considered while making strategic and major operational decisions? (Yes, no).

Based on Buhr \& Desjardins 1998.

43. Does your organization calculate a weighted-average cost of capital for the determination of shareholder value creation? (Yes, no).

Based on Buhr \& Desjardins 1998.

44. Does your organization use different costs of capital for different business activities or investment opportunities? (Yes, no).

Based on Buhr \& Desjardins 1998.

45. What is the current estimate (in nominal terms) of the weighted average cost of capital for your organization as a whole? $(\%)$.

Based on Buhr \& Desjardins 1998.

46. In calculating invested capital, which of the following adjustments to book value do you make within your organization? (Capitalize operating leases, deferred taxes, cumulative goodwill amortization, addition for unrecorded goodwill, current value of property, plant and equipment, bad debt reserves, restructuring cost provisions, warranty provisions/liabilities, others, non, invested capital is not used).

Based on Buhr \& Desjardins 1998.

47. Over the past 4 years, have you been: (very, somewhat, neither satisfied or somewhat, very dissatisfied) with your organization's performance in creating shareholder value?

Based on Buhr \& Desjardins 1998.

48. Are you, in general: (very, somewhat, neither satisfied or somewhat, very dissatisfied) with the pricing of your shares in the market place?

Based on Buhr \& Desjardins 1998. 
49. Please indicate what percentage of your company's current sales is accounted for by products represented by each of the strategies described. Your answers should total $100 \%$.

(Products sold to increase sales and market share, for which you are willing to accept low returns on investment in the short-to-medium term, if necessary. Products sold to maintain market share and obtain reasonable return on investment. Products sold to maximize profitability and cash flow in the short-to-medium term, for which you are willing to sacrifice market share if necessary. Products from activities that you are preparing for sale or liquidation. None of the above (please specify)).

Based on Govindarajan \& Gupta 1985.

50. Which one of the following descriptions most closely fits your company compared to other companies in the industry? (Please consider your company as a whole and note that none of the types listed below is inherently "good" or "bad").

(Type 1. This type of company attempts to locate and maintain a secure niche in a relatively stable product or service area. The company tends to offer a more limited range of products or services than its competitors, and it tries to protect its domain by offering higher quality, superior services, lower prices, and so forth. Often this type of company is not at the forefront of developments in the industry - it tends to ignore industry changes that have no direct influence on current areas of operation and concentrates instead on doing the best possible in a limited area.

Type 2. This type of company typically operates within a broad product-market domain that undergoes periodic redefinition. The company values being "first in" in new product and market areas even if not all of these efforts prove to be highly profitable. The company responds rapidly to early signals concerning areas of opportunity, and these responses often lead to a new round of competitive actions. However, this type of company may not maintain market strength in all of the areas it enters.

Type 3. This type of company attempts to maintain a stable, limited line of products or services, while at the same time moving out quickly to follow a carefully selected set of the more promising new developments in the industry. The company is seldom "first in" with new products or services. However, by carefully monitoring the actions of major competitors in areas compatible with its stable product-market base, the company can frequently be "second in" with a more efficient product or service.

Type 4. This type of company combines different product-market orientations. The company is less aggressive in maintaining established products and markets than some of its competitors, and does not take as many risks as other competitors. The company responds in those areas where it is forced by environmental pressures to do so).

Based on Snow \& Hrebiniak 1980.

51. Please indicate how your products are positioned relative to the products of leading competitors in the following six areas: product selling price, percent of sales spent on research and development, percent of sales spent on marketing expenses, product quality, brand image, product features. ( 1 significantly lower, 4 at par, 7 significantly higher).

Based on Govindarajan 1988. 
52. In this question, a business unit means a set of activities associated with a single product/service or a line of closely related products/services (examples of business units: Automobiles, Photographic supplies, Shaving supplies, Electric power generating equipment, Soap, detergents and cleaning preparations). According to this definition, what is the degree of diversity of your company?

(Type 1: SINGLE business (more than $95 \%$ of the company revenues are attributable to one single business unit).

Type 2: DOMINANT business (70 \% to $95 \%$ of the company revenues are attributable to one single business unit).

Type 3: RELATED business ( $70 \%$ or more of the company revenues are attributable to one group of related business units). A business unit is part of a group of related business units as long as it is tangibly related to at least one other business unit in the group. Examples of group of related business units: Photographic film, cameras, dyes, pigments and textile chemicals; Tape, adhesives, coated paper and film).

Type 4: UNRELATED business (less than $70 \%$ of the company revenues are attributable to any one group of related business units)).

Based on Christie et al. 2003. 



\section{References}

Abernethy, M. and P. Brownell, (1997), Management Control Systems in Research and Development Organizations: The Role of Accounting, Behavioral and Personnel Con trols, Accounting, Organizations and Society, 22, 233 - 248.

Abernethy, M. and C. Guthrie, (1994), An Empirical Assessment of the "Fit" Between Strategy and Management Information System Design, Accounting and Finance, $49-66$.

Ansari, S., (1977), An Integrated Approach to Control System Design, Accounting. Organizations and Society, 2, $101-112$.

Anthony, R., (1965), Planning and Control Systems: a Framework for Analysis, Harvard University, Boston.

Anthony, R., J. Dearden and N. Bedford, (1984), Management Control Systems, Richard D. Irwin, Homewood.

Anthony, R. and V. Govindarajan, (1998), Management Control Systems, Irwin McGraw-Hill, Boston.

Arnold, G. and M. Davies (ed.), (2000), Value-based Management: Context and Application. John Wiley \& Sons, Chichester.

Backes-Gellner, U. von and K. Pull, (1999), Betriebliche Sozialpolitik und Maximierung des Shareholder Value: ein Widerspruch? Zeitschrift Für Betriebswirtschaft, 69, 51 - 70.

Bacidore, J., J. Boquist, T. Milbourn and A. Thakor, (1997), The Search for the Best Financial Performance Measure, Financial Analysts Journal, 11 - 20.

Biddle, G., G. Seow and A. Siegel, (1995), Relative versus Incremental Information Content, Contemporary Accounting Research, 12, 1-23.

Biddle, G., R. Bowen and J. Wallace, Does EVA ${ }^{*}$ Beat Earnings? (1997), Journal of Accounting and Economics, 24, $301-336$.

Biddle, G., R. Bowen and J. Wallace, (1999), Evidence on EVA ${ }^{*}$, Journal of Applied Corporate Finance, 12, $8-18$.

Black, A., P. Wright, J. Bachman and J. Davies, (1998), In Search of Shareholder Value, Managing the Drivers of Performance, Financial Times/Pitman Publishing, London.

Blij, I. and H. Dekker, (2000), EVA ${ }^{\mathrm{TM}}$ en de creatie van economische waarde, Maandblad voor Accountancy en Bedrijfseconomie, 74, 101 - 110.

Boston Consulting Group, (1999), The Value creators: A Study of The World's Top Performers, The Boston Consulting Group.

Boston Consulting Group, (2000), The Boston Consulting Group Top-40 voor 1995 - 1999. Het Financieele Dagblad, 30 - 10 - 2000.

Bouma, J., (1980), Leerboek der bedrijfseconomie, deel II, Delwel, Wassenaar.

Bouwens, J. and L. van Lent, (2000), Financiële prestatiemeting door EVA ${ }^{T M}$ : waarde creatie door toepassing van economic value added, Kluwer, Deventer. 
Bowen, R., D. Burgsthaler and L. Daley, (1987), The Incremental Information Content of Accruals versus Cash Flows, The Accounting Review, 62, 723 - 747.

Bromwhich, M., (1998), Value Based Financial Management Systems, Management Accounting Research, 9, 387 - 389.

Bromwhich, M. and M. Walker, (1998), Residual Income Past and Future, Management Accounting Research, 9, $391-419$.

Brownell, P. (1995), Research Methods in Management Accounting, Coopers \& Lybrand, Melbourne.

Bughin, J. and T. Copeland, (1997), The Virtuous Cycle of Shareholder Value Creation, McKinsey Quarterly, 156 - 167.

Buhr, N. and J. Desjardins, (1998), Shareholder Value Measurement in Canada, 1997 Survey. The Canadian Institute of Chartered Accountants, Toronto.

Centraal Bureau voor de Statistiek, (1999) Beleggingsjaarboek 1999, Kluwer/CBS, Den Haag.

Centraal Bureau voor de Statistiek, (2000) Beleggingsjaarboek 2000, Kluwer/CBS, Den Haag.

Chandler, A., (1962), Strategy and Structure: Chapters in the History of the Industrial Enterprise, The MIT Press, Cambridge.

Chapman, C., (1997), Reflections on a Contingent View of Accounting, Accounting Organizations and Society, 22, $189-205$.

Chen. S. and J. Dodd, (1997), Economic Value Added (EVA $\left.{ }^{\mathrm{TM}}\right)$ : An Empirical Examination of a New Corporate Performance Measure, Journal of Managerial Issues, 9, $318-333$.

Chen, S. and J. Dodd, (2001), Operating Income, Residual Income and EVA ${ }^{\text {M }}$ : Which Metric is More Value Relevant? Journal of Managerial Issues, 13, 65 - 86.

Chenhall, R., (2003), Management Control Systems Design within its Organizational Context: Findings from Contingency-based Research and Directions for the Future, Accounting, Organizations and Society, 28, 127 - 168.

Chenhall, R. and K. Langfield-Smith, (1998), The Relationship Between Strategic Priorities, Management Techniques and Management Accounting: an Empirical Investigation Using a Systems Approach, Accounting, Organizations and Society, 23, 243 - 264.

Chow, C., M. Shields and A. Wu, (1999), The Importance of National Culture in the Design and Preference for Management Controls for Multi-National Operations, Accounting. Organizations and Society, 24, $441-461$.

Chrisman, J., C. Hofer and W. Boulton, (1988), Toward a System of Classifying Business Strategies, Academy of Management Review, 13, 413 - 428.

Christie, A., M. Joye and R. Watts, (2003), Decentralization of the Firm: Theory and Evidence, Journal of Corporate Finance, 9, 3-36.

Coakes, S. and L. Steed, (1999), SPSS: Analysis without Anguish, John Wiley \& Sons Australia, Brisbane.

Cools, K. and M. van der Ven, (1995), CFROI stuurt beter dan ROI of EVA, Tijdschrift Financieel Management, 59 - 70.

Cools, K. and M. van Praag, $\left(2000^{\mathrm{a}}\right)$, The Value Relevance of a Single-Valued Corporate Target: an Empirical Analysis, Working Paper, University of Groningen/Amsterdam.

Cools, K. and M. van Praag, $\left(2000^{\mathrm{b}}\right)$, Performance Measure Selection: Aligning the Principal's Objective and the Agent's Effort, Working Paper, University of Groningen/Amsterdam. 
Cools, K. and M. van Praag, $\left(2000^{\circ}\right)$, On the Virtues of Transparency and Simplicity: Empirical Analysis of the Value Relevance of Targets, Maandblad voor Accountancy en Bedrijfseconomie, 74, 24 - 37.

Copeland, T., T. Koller and J. Murrin, (1995), Valuation, Measuring and Managing the Value of Companies, John Wiley \& Sons, New York.

Cox. B., D. Binder, B. Nanjamma Chinnappa, A. Christianson, M. Colledge and P. Kott (Ed.), (1995), Business Survey Methods, J. Wiley and Sons, New York.

Daniel, S. and W. Reitsperger, (1992), Management Control Systems for Quality: An Empirical Comparison of the U.S. and Japanese Electronics Industries, Journal of Management Accounting Research, 64 - 78.

Davila, T., (2000), An Empirical Study on the Drivers of Management Control Systems' Design in New Product Development, Accounting, Organizations and Society, 25, $383-409$.

Day, G. and L. Fahey, (1990), Putting Strategy into Shareholder Value Analysis, Harvard Business Review, 156 - 162.

Dent, J., (1990), Strategy, Organization and Control: Some Possibilities for Accounting Research, Accounting, Organizations and Society, 15, 3-25.

Desjardins, J., (1998), The Measurement of Shareholder Value Creation, The Canadian Institute of Chartered Accountants, Toronto.

Dillman, D., (1978), Mail and Telephone Surveys: The Total Design Method, J. Wiley \& Sons, New York.

Dillman, D., (2000), Mail and Internet Surveys: The Tailored Design Method, John Wiley \& Sons, New York.

Dorsman, A. and H. Rijken, (1998), Value based management: EVA, een beperkt hulpmiddel bij prestatiemeting, Research Memorandum, Vrije Universiteit, Amsterdam.

Donovan, J., R. Tully and B. Wortman, (1998), The Value Enterprise: Strategies for Building a Value-Based Organization, McGraw-Hill Ryerson, Toronto.

Euske, K., M. Lebas and C. McNair, (1999), Performance Management in an International Setting, Management Accounting Research, 4, 275 - 299.

Fama, E. and K. French, (1992), The Cross-Section of Expected Stock Returns, The Journal of Finance, 47, 427 - 465.

Fama, E. and K. French, (1993), Common Risk Factors in the Returns on Stocks and Bonds Journal of Financial Economics, 33, 3 - 56.

Flamholtz, E., T. Das and A. Tsui, (1985), Toward and Integrative Framework of Organizational Control, Accounting, Organizations and Society, 10, 35 - 50.

Francis, G. and C. Minchington, (2000), Value-Based Management in Practice, Management Accounting, $46-47$.

Goldberg, S., (1999), Economic Value Added: A Better Measure for Performance and Compensation? The Journal of Corporate Accounting and Finance, 55 - 67.

Goold, M. and A. Campbell, (1987), Strategies and Styles; The Role of the Centre in Managing Diversified Corporations, Basil Blackwell, Oxford.

Goold, M., A. Campbell and M. Alexander, (1994), Corporate-Level Strategy: Creating Value in the Multibusiness Company, John Wiley \& Sons, New York.

Goold, M. and J. Quinn, (1990), The Paradox of Strategic Controls, Strategic Management Journal, 11, 43-57. 
Gordon, L. and V. Narayanan, (1984), Management Accounting Systems, Perceived Environmental Uncertainty and Organizational Structure: An Empirical Investigation, Accounting, Organizations and Society, 9, 33 - 47.

Govindarajan, V., and A. Gupta, (1985), Linking Control Systems to Business Unit Strategy: Impact on Performance, Accounting, Organizations and Society, 10, 51 - 66.

Govindarajan, V., (1988), A Contingency Approach to Strategy Implementation at the Business-Unit Level: Integrating Administrative Mechanisms with Strategy, Academy of Management Journal, 31, 828 - 853.

Govindarajan, V. and J. Fisher, (1990), Strategy, Control Systems, and Resource Sharing: Effects on Business-Unit Performance, Academy of Management Journal, 33, $259-285$.

Gray, B., (1990), The Enactment of Management Control Systems: A Critique of Simons, Accounting, Organizations and Society, 15, 145 - 148.

Gupta, A., (1987), Matching Managers to Strategies: Point and Counterpoint, Human Resource Management, 25, 215 - 234.

Gupta, A. and V. Govindarajan, (1984), Business Unit Strategy, Managerial Characteristics and Business Unit Effectiveness at Strategy Implementation, Academy of Management Journal, 27, 24 - 41.

Hambrick, D., (1983), Some Tests of the Effectiveness and Functional Attributes of Miles and Snow's Strategic Types, Academy of Management Journal, 26, 5 - 26.

Hartmann, F., (1997), Accounting for Performance Evaluation: Effects of Uncertainty on the Appropriateness of Accounting Performance Measures, PhD Dissertation, Faculty of Economics and Business Administration, Maastricht University.

Hartmann, F. and F. Moers, (1999), Testing Contingency Hypotheses in Budgetary Research: an Evaluation of the Use of Moderated Regression Analysis, Accounting. Organizations and Society, 24, $291-315$.

Haspeslagh, P., T. Noda and F. Boulos, (2001), Managing for Value: It's Not Just About the Numbers, Harvard Business Review, July - August, 64 - 75.

Herst, A., S. Poirters and J. Spekreijse, De investeringsbeslissing: theorie versus praktijk, TBA, $70-76$.

Het Financieele Dagblad, (1999), Handboek Nederlandse Beursfondsen 1999, Amsterdam.

Het Financieele Dagblad, (2001), Handboek Nederlandse Beursfondsen 2001, Amsterdam.

Hofstede, G., (1970), The Game of Budget Control, Van Gorcum, Assen.

Hogan, C. and C. Lewis, (1999), The Long-Run Performance of Firms Adopting Compensation Plans Based on Economic Profits, Working Paper, Owen Graduate School of Management, Vanderbilt University.

Hopwood, A., (1976), Accounting and Human Behaviour, Prentice Hall, Englewood Cliffs.

IMA (Institute of Management Accountants), (1997), Practices and Techniques: Measuring and Managing Shareholder Value Creation, Statement No. 4AA, Institute of Management Accountants, Montvale.

IFAC (International Federation of Accountants), (1998), Management Accounting Concepts, International Management Accounting Practice Statement, IFAC, New York.

IFAC (International Federation of Accountants), $\left(1999^{\mathrm{a}}\right)$, The Role of Management Accounting in Creating Value, Annual Theme Booklet, IFAC, New York.

IFAC (International Federation of Accountants), (1999 $\left.{ }^{b}\right)$, Enhancing Shareholder Wealth by Better Managing Business Risk, Study 9, IFAC, New York. 
Ittner C., W. Lanen and D. Larcker, (2002), The Association Between Activity-Based Costing and Manufacturing Performance, Journal of Accounting Research, 40, $711-726$.

Ittner, C., D. Larcker and M. Rajan, (1997), The Choice of Performance Measures in Annual Bonus Contracts, The Accounting Review, 72, 231 - 255.

Ittner, C. and D. Larcker, (1998), Innovations in Performance Measurement: Trends and Research Implications, Journal of Management Accounting Research, 10, 205 - 238.

Ittner, C. and D. Larcker, (2000), Assessing Empirical Research in Management Accounting: A Value-Based Management Perspective, Journal of Accounting and Economics, Forthcoming.

Kennedy, A., (2000), The End of Shareholder Value: Corporations at the Crossroads, Persues Publishing, Cambridge.

Khandwalla, P., (1972), The Effect of Different Types of Competition on the Use of Management Controls, Journal of Accounting Research, 275 - 285.

Kluyver, C. de, (2000), Strategic Thinking: An Executive Perspective, Prentice Hall, Upper Saddle River.

Knight, J., (1998), Value-Based Management: Developing a Systematic Approach to Creating Shareholder Value, McGraw-Hill, New York.

KPMG Consulting, (1996), Value Based Management: A Survey of European Industry, KPMG International, Amsterdam.

KPMG Consulting, (1999), Value Based Management: The Growing Importance of Shareholder Value in Europe, KPMG International, Amsterdam.

Langendijk, H., M. Hagman and Y. Uclu, (1999), The Effect of Multinationality on the Profitability of Fortune Global 500 Firms, Working Paper, University of Amsterdam/University Nyenrode.

Langfield-Smith, K., (1997), Management Control Systems and Strategy: A Critical Review, Accounting, Organizations and Society, 22, $207-232$.

Leeuwen, O. van, and P. Wemmenhove, (1999), Trends in finance \& control: de stand van zaken binnen Nederlandse multinationals, KPMG, Woerden.

Lev, B., (2000), Knowledge and Shareholder Value, Working Paper, Stern School of Business, New York University.

Lewis Thomas, G., (1994), Steigerung des Unternehmenswertes: Total Value Management, Verlag Moderne Industrie, Landsberg/Lech.

Lewy, C., (1992), Management Control Regained, Kluwer Bedrijfswetenschappen, Deventer. Lewy, C., (1998), Will Value Based Management make it to 2005, 1998.

Loughran, T. and J. Ritter, (1995), The New Issues Puzzle, The Journal of Finance, 50, $23-51$.

Lovata, L. and M. Costigan, (2002), Empirical Analysis of Adopters of Economic Value Added, Management Accounting Research, 13, 215 - 228.

McTaggart, J., P. Kontes and M. Mankins, (1994), The Value Imperative: Managing for Superior Shareholder Returns, The Free Press, New York.

Merchant, K., (1981), The Design of the Corporate Budgeting System: Influences on

Managerial Behavior and Performance, The Accounting Review, 56, 813-829.

Merchant, K., $\left(1985^{\mathrm{a}}\right)$, Control in Business Organizations, Pitman, Boston. 
Merchant, K., $\left(1985^{\mathrm{b}}\right)$, Organizational Controls and Discretionary Program Decision Making: a Field Study, Accounting, Organizations and Society, 10, $67-85$.

Merchant, K., (1998), Modern Management Control Systems, Prentice Hall, Upper Saddle River.

Miles, R. and C. Snow, (1978), Organizational Strategy, Structure and Process, McGraw-Hill, New York.

Miller, D. and P. Friesen, (1982), Innovation in Conservative and Entrepreneurial Firms: Two Models of Strategic Momentum, Strategic Management Journal, 3, 1 - 25.

Mills, R., J. De Bono, V. De Bono, D. Ewers, D. Parker and C. Print, (1996), The Use of 'Shareholder Value Analysis' in Acquisition and Divestment Decisions by Large UK Companies, Working Paper Series, Henley Management College, Henley-on-Thames.

Mintzberg, H., (1978), Patterns in Strategy Formation, Management Science, 24, 934 - 948.

Mintzberg, H., B. Ahlstrand and J. Lampel, (1998), Strategy Safari, Prentice Hall Europe, Hemel Hempstead.

Moers, F., (2001), Performance Measures and Performance Targets in Incentive Systems: An Empirical Study of Use and Effects. PhD dissertation, Faculty of Economics and Business Administration, Maastricht University.

Mouritsen, J., (1998), Driving Growth: Economic Value Added versus Intellectual Capital, Management Accounting Research, 9, 461 - 482.

Nichols, P., (1998), Unlocking Shareholder Value, Thorogood, London.

Nilsson, F., (2000), Parenting Styles and Value Creation: a Management Control Approach, Management Accounting Research, 11, 80-112.

Nunnally, J. and I. Bernstein, (1994), Psychometric Theory, McGraw-Hill, New York.

O'Byrne, S., (1996), EVA and Market Value, Journal of Applied Corporate Finance, 9, $116-125$.

Ogden, S. and R. Watson, (1999), Corporate Performance and Stakeholder Management: Balancing Shareholder and Customer Perspectives in the U.K. Privatized Water Industry, Academy of Management Journal, 42, 526 - 538.

O'Hanlon, J. and K. Peasnell, (1998), Wall Street's Contribution to Management Accounting: the Stern Stewart EVA ${ }^{*}$ Financial Management System, Management Accounting Research, 9, $421-444$.

O'Hanlon, J. and P. Pope, (1999), The Value-Relevance of UK Dirty Surplus Accounting Flows, British Accounting Review, 32, 459 - 482.

Otley, D., (1980), The Contingency Theory of Management Accounting: Achievement and Prognosis, Accounting, Organizations and Society, 5, 413 - 428.

Otley, D., (1994), Management Control in Contemporary Organizations: a Wider Perspective, Management Accounting Research, 5, 289 - 299.

Otley, D., (1999), Performance Management: a Framework for Management Control Systems Research, Management Accounting Research, 10, 363 - 382.

Ouchi, W., (1977), The Relationship between Organizational Structure and Organizational Control, Administrative Science Quarterly, 22, 95 - 113.

Ouchi, W., (1979), A Conceptual Framework for the Design of Organizational Control Mechanisms, Management Science, 25, 833 - 848.

PA Consulting, (1997), Managing for Shareholder Value: 1997 Survey UK and Ireland, PA Consulting, London.

PA Consulting. (1998 ${ }^{\mathrm{a}}$ ), Managing for Shareholder Value: Survey of US Companies 1998, PA Consulting, London. 
PA Consulting, $\left(1998^{b}\right)$, Managing for Shareholder Value: Survey of Benelux listed companies 1998, PA Consulting, London.

PA Consulting, (2001), Managing for Shareholder Value: International Survey Results 2001, PA Consulting, London.

Poel, J. van de, (1996), Managing Value Creation, Philips Electronics, Eindhoven.

Porter, M., (1980), Competitive Strategy, The Free Press, New York.

Rappaport, A., (1986), Creating Shareholder Value: The New Standard for Business Performance, The Free Press, New York.

Rappaport, A., (1988), Aandeelhouderwaarde creëren: Een nieuwe norm voor bedrijfsprestaties, Kluwer Bedrijfswetenschappen/NIVE, Deventer.

Rappaport, A., (1992), CFOs and Strategists: Forging a Common Framework, Harvard Business Review, 84 - 91 .

Rappaport, A., (1999), New Thinking on How to Link Executive Pay with Performance, Harvard Business Review, March-April, 91 - 101.

Ross, S., R. Westerfield and J. Jaffe, (1996), Corporate Finance, Irwin McGraw-Hill, Boston.

Rumelt, R., (1974), Strategy, Structure, and Economic Performance, Harvard University, Boston.

Shortell, S. and E. Zajac, (1990), Perceptual and Archival Measures of Miles and Snow's Strategic Types: a Comprehensive Assessment of Reliability and Validity, Academy of Management Journal, 33, 817 - 832.

Simons, R., (1987 ${ }^{\mathrm{a}}$ ), Planning, Control, and Uncertainty: A Process View, in: Burns, W. and R. Kaplan (Ed.), Accounting and Management: Field Study Perspectives, Harvard Business School Press, Boston.

Simons, R., $\left(1987^{b}\right)$, Accounting Control Systems and Business Strategy: an Empirical Analysis, Accounting, Organizations and Society, 12, 357 - 374.

Simons, R., (1988), Analysis of the Organizational Characteristics Related to Tight Budget Goals, Contemporary Accounting Research, 5, 267 - 283.

Simons, R., (1990), The Role of Management Control Systems in Creating Competitive Advantage: New Perspectives, Accounting, Organizations and Society, 15, 127 - 143.

Simons, R., (1991), Strategic Orientation and Top Management Attention to Control Systems, Strategic Management Journal, 12, 49 - 62.

Simons, R., (1994), How New Top Managers use Control Systems as Levers of Strategic Renewal, Strategic Management Journal, 15, 169 - 189.

Simons, R., $\left(1995^{\mathrm{a}}\right)$, Control in an Age of Empowerment, Harvard Business Review, 80 - 88.

Simons, R., $\left(1995^{6}\right)$, Levers of Control: How Managers Use Innovative Control Systems to Drive Strategic Renewal, Harvard Business School Press, Boston.

Simons, R., $\left(1999^{\mathrm{a}}\right)$, How Risky is Your Company, Harvard Business Review, May-June, $85-94$.

Simons, R., $\left(1999^{\mathrm{b}}\right)$, Performance Measurement and Control Systems for Implementing Strategy, Prentice-Hall, Upper Saddle River.

Snow, C. and D. Hambrick, (1980), Measuring Organizational Strategies: Some Theoretical and Methodical Problems, Academy of Management Review, 5, 527 - 538 .

Snow, C. and L. Hrebiniak, (1980), Strategy, Distinctive Competence, and Organizational Performance, Administrative Science Quarterly, 25, 317 - 336.

Solomons, D., (1983), Divisional Performance: Measurement and Control, Markus Wiener Publishing. 
Stark, A. and H. Thomas, (1998), On the Empirical Relationship between Market Value and Residual Income in the U.K., Management Accounting Research, 9, 445 - 460.

Steens, H., (2000), Business controls voor value based management, Management Control \& Accounting, $29-37$.

Stewart, G. Bennett, (1991), The Quest for Value: The EVA ${ }^{T M}$ Management Guide, Harper Business, New York.

Tijd Beursmedia, (2000), Jaarboek van Nederlandse ondernemingen 2000, 13e editie, Tijd Beursmedia, Amsterdam.

Traas, L., (1995 $)$, CFROI beter dan ROI of EVA (II), Tijdschrift Financieel Management, $84-87$.

Traas, L., $\left(1995^{b}\right)$, Kengetallen voor rentabiliteit en ondernemingswaarde (I), Tijdschrift Financieel Management, 21 - 30.

Traas, L., (1996), Rentabiliteit en ondernemingswaarde(II), Tijdschrift Financieel Management, $10-21$.

Tully, S., (1993), The Real Key to Creating Wealth, Fortune, 20 - 9-1993, 24 - 32.

Vancil, R., (1979), Decentralization: Managerial Ambiguity by Design, Dow Jones-Irwin, Homewood.

Ven, A. van de, and R. Drazin (1985), The Concept of Fit in Contingency Theory, Research in Organizational Behavior, 7, 333 - 365.

Verbeeten, F., (2001), The Impact of Uncertainty on Capital Budgeting Practices, WLP, Nijmegen.

Wallace, J., (1997), Adopting Residual Income-Based Compensation Plans: Do You Get What You Pay For? Journal of Accounting and Economics, 24, 275 - 300.

Wallace, J., (1998), EVA ${ }^{*}$ Financial Systems: Management Perspectives, Advances in Management Accounting, 6, 1-15.

Wallace, R. and C. Mellor, (1988), Nonresponse Bias in Mail Accounting Surveys: a Pedagogical Note, British Accounting Review, 20, 131 - 139.

Weston, J. and E. Brigham, (1981), Managerial Finance, The Dryden Press, Hinsdale.

Wijerwardena, H. and A. De Zoysa, (1999), A Comparative Analysis of Management Accounting Practices in Australia and Japan, The International Journal of Accounting, 34, $49-70$.

Wit, B. de, and R. Meyer, (1999), Strategy: Process, Content, Context, International Thomson Business Press, London.

Young, S., (1996), Survey Research in Management Accounting: A Critical Assessment, in: A. Richardson ed., Research Methods in Accounting: Issues and Debates, CGA-Canada Research Foundation.

Zimmerman, J., (1997), EVA and Divisional Performance Measurement: Capturing Synergies and other Issues, Journal of Applied Corporate Finance, 10, 98 - 10. 


\section{Summary in Dutch}

The Relation Between Management Control Systems and Shareholder Value Creation.

Dit proefschrift bevat een drietal empirische onderzoeken naar de relatie tussen de creatie van aandeelhouderswaarde en de inrichting van het management control systeem van bedrijven. Het bespreekt de opzet, uitvoering en resultaten van een onderzoek dat begin 2001 werd uitgevoerd bij Nederlandse beursfondsen.

Hoofdstuk 1 geeft een inleiding in het proefschrift en beschrijft hoe de onderzoeksvragen hun oorsprong vinden in - enerzijds - concepten die in het management control vakgebeid zijn ontwikkeld en - anderzijds - in theorie met betrekking tot ondernemingstrategie en tot financiering. Het proefschrift onderzoekt de effecten van het toepassen van 'value-based management' (VBM), een formele en systematische management aanpak die erop gericht is de doestelling van maximale waardecreatie voor aandeelhouders te realiseren. VBM is een concept met een achtergrond in de financieringstheorie, in dit proefschrift wordt VBM gezien als een bijzondere vorm van management control. Management control systemen zijn alle acties en maatregelen (processen) die de ondernemingsleiding gebruikt om zeker te stellen dat de strategie van de onderneming wordt gerealiseerd of, indien en voor zover nodig, wordt bijgesteld. Waar management control zich bezighoudt met de vraag hoe de ondernemingleiding de realisatie van strategisch doestellingen kan waarborgen, richt ondernemingstrategie zich op de vraag wat deze doelstellingen moeten zijn en hoe zij totstandkomen, evenals de vraag hoe die doestellingen uiteindelijk gerealiseerd gaan worden en welke middelen daarvoor nodig zijn. Vanuit deze concepten zijn een drietal kernvragen ontwikkeld die in het proefschrift centraal staan. Deze vragen zijn: (1) of de toepassing van VBM bijdraagt tot een verbetering van de creatie van waarde voor aandeelhouders; (2) of er een relatie bestaat tussen kenmerken van het management control systeem en de creatie van waarde voor aandeelhouders; en (3) in hoeverre de afstemming van de kenmerken van het management control systeem op de strategie van de onderneming bijdraagt tot creatie van waarde voor aandeelhouders? 
De voor dit proefschrift relevante concepten en theorieën komen in hoofdstuk 2 aan de orde. Ten aanzien van VBM is de aandacht gericht op de definitie van het concept en de daaruit afgeleide prestatiemaatstaven. De diverse, door management consultants ontwikkelde, VBM aanpakken worden niet uitgebreid besproken. Wel komt de inbedding van VBM in de theorie met betrekking tot ondernemingsfinanciering en relatie met het reeds lang in de economie bekende 'residual income' begrip aan de orde. De oorspronkelijke, op cybernetische principes gebaseerde, normatieve benadering van management control krijgt de aandacht evenals de verdere ontwikkeling in het denken over management control, waarbij gedragsaspecten van werknemers en managers, 'empowerment' en de invloed van externe onzekerheid en verandering aan de orde komen. Ook contingentie onderzoek naar de relatie tussen de inrichting van het management control systeem en diverse omgevingsfactoren wordt besproken. De inhoud van het begrip ondernemingstrategie wordt verder uitgewerkt op twee niveaus: (1) 'corporate' strategie die beschrijft hoe het hoofdkantoor individuele business units aanstuurt en keuzes maakt ten aanzien van de samenstelling van de portefeuille van business units; en (2) business strategie die beschrijft hoe individuele business units opereren in de markt en welke concurrentiestrategie zij volgen. Een drietal classificaties voor strategie wordt gepresenteerd: (1) strategische positie volgens het model van Porter (1980); (2) strategische typologie volgens Miles en Snow (1978); en (3) strategische missie zoals beschreven door Gupta en Govindarajan (1984).

Hoofdstuk 3 gaat in op eerdere empirische studies die voor dit proefschrift relevant zijn. Naar de effecten van de toepassing van VBM is met name onderzoek gedaan door management consultants. Uit dat onderzoek blijkt dat VBM inderdaad bijdraagt tot waardecreatie. Interpretatie van deze uitkomsten is echter lastig omdat de wetenschappelijke onderbouwing van de conclusies zwak is of ontbreekt. Studies naar de relatie tussen aandelenrendementen en de ontwikkeling van bepaalde value-based prestatiemaatstaven, met name Economic Value Added (EVA), wijst uit dat deze maatstaven wel additionele informatiewaarde voor de kapitaalmarkt hebben, maar dat ze traditionele boekhoudkundige prestatiemaatstaven in dit opzicht niet overtreffen. Onderzoek naar de toepassing van value-based prestatiemaatstaven voor de vaststelling van prestatieafhankelijke beloning toont aan dat hierdoor het gedrag van managers wordt beïnvloed. Daarbij is echter niet vastgesteld of deze gedragsverandering meer waarde voor de aandeelhouders oplevert. Onderzoek naar de relatie tussen management control en business strategie heeft aangetoond dat aspecten als de toepassing van objectieve of subjectieve maatstaven, het belang dat wordt toegekend aan kostenbeheersing en de mate waarin 'tight' of 'loose' controls worden toegepast, afhankelijk zijn van de gevolgde strategie. 
Hoofdstuk 4 behandelt de opzet en uitvoering van het empirische onderzoek dat gebruik maakte van een enquête onder de Chief Financial Officers (CFOs) van bedrijven die eind 2000 aan de Amsterdamse beurs waren genoteerd (met uitzondering van financięle instellingen en buitenlandse bedrijven). In het voorjaar van 2001 zijn 169 bedrijven aangeschreven waarvan er uiteindelijk 68 de enquête retourneerden. Naast de enquêtegegevens zijn voor de betreffende bedrijven tevens gegevens over financięle prestaties en over koersontwikkeling van de aandelen verzameld. Aangezien de enquête niet anoniem was, bestond de mogelijkheid de enquêtegegevens te relateren aan de prestatie op beurs, wat nodig was voor de beantwoording van de onderzoeksvragen. Onderzoek naar de representativiteit van de responsgroep voor de gehele beurs geeft aan dat de bedrijven die meewerkten groter van omvang waren dan het gemiddelde van de aan de Amsterdamse beurs genoteerde bedrijven. Verder blijkt uit onderzoek van de terugontvangen enquêtes dat er geen aanwijzingen zijn dat de daarin opgenomen antwoorden afwijken van de antwoorden die gegeven zouden zijn door bedrijven die niet aan het onderzoek hebben meegewerkt.

In hoofdstuk 5 worden vier hypotheses ontwikkeld met betrekking tot de vraag of het hanteren van waardecreatie als centrale doestelling, met andere woorden VBM toepassen, bijdraagt aan de creatie van waarde voor aandeelhouders. Waardecreatie wordt daarbij primair gemeten in termen van 'Relative Total Shareholder Return' (RTSR), de relatieve waardestijging van het aandeel (koersverandering en dividend) van de onderneming ten opzichte van de beursindex. Het blijkt dat meer dan $50 \%$ van de onderzochte bedrijven VBM toepassen, maar dat die bedrijven niet beter presteren dan de groep die geen VBM toepast. Daarnaast is onderzocht of een verbetering van het rendement op eigenvermogen en van de winst per aandeel, afhangt van de toepassing van VBM. Ook hier was geen sprake van aantoonbaar betere prestaties bij bedrijven die VBM toepassen. In de laatste plaats is onderzocht in hoeverre de CFOs van de bedrijven die VBM toepassen meer tevreden zijn over de prestaties van hun onderneming, op het gebied van waardecreatie, dan hun collega's bij bedrijven die geen VBM toepassen. Dat blijkt voor een deel het geval te zijn. In zijn algemeenheid blijkt dat het toepassen van VBM bij de onderzochte bedrijven geen prestatieverbetering heeft opgeleverd. Dit kan duiden op een onjuiste toepassing van het concept, of op het feit dat CFOs weliswaar zeggen VBM toe te passen maar dit onvoldoende doorvoeren op lagere organisatieniveaus. Het kan ook zijn dat VBM gewoon niet werkt.

In hoofdstuk 6 komt het onderzoek naar de vraag of de inrichting van het management control systeem invloed heeft op de creatie van waarde voor de aandeelhouder aan de orde. Een tweetal onderzoeksvragen op dit gebied is geformuleerd. De inrichting van het management control systeem wordt gemeten aan de hand van het belang dat de CFOs toekennen aan 11 verschillende elementen van management contol. De informatie hieromtrent is gerelateerd aan de waardecreatie van de onderzochte ondernemingen. Daaruit blijkt dat bedrijven die succesvol zijn in het creëren van waarde voor hun aandeelhouders meer belang hechten aan financiële prestatiemaatstaven en aan prestatieafhankelijke beloning. Bedrijven die VBM toepassen hechten echter geen grotere waarde aan die specifieke aspecten van management control. Hierin kan een verklaring liggen voor het feit dat in de eerste studie geen hogere waardecreatie aangetoond kon worden voor bedrijven die VBM toepassen, blijkbaar vertalen die bedrijven het concept onvoldoende naar een op aandeelhouderswaarde gerichte inrichting van het management control systeem. 
In de laatste, in hoofdstuk 7 besproken, studie is de relatie tussen de inrichting van het management control systeem en de strategie van de betrokkene onderneming onderzocht. De onderzochte bedrijven zijn ingedeeld op basis van strategische positie, waarbij eveneens de door de CFOs ingevulde enquêtes als informatiebron dienden. Het blijkt dat de strategie inderdaad invloed heeft op het relatieve belang dat CFOs aan bepaalde management controls toekennen. Meer specifiek, wanneer een differentiatiestrategie wordt gevolgd wordt een hoog belang gehecht aan niet-financięle prestatiemaatstaven en ondernemingscultuur. Geen relatie werd gevonden tussen de gevolgde strategie en de adoptie van VBM. Op basis van de door de ondernemingen gerealiseerde RTSR is verder vastgesteld dat succesvolle bedrijven met een differentiatiestrategie meer belang hechten aan ondernemingscultuur, stijl van management en organisatiestructuur terwijl succesvolle bedrijven met een op kostenleiderschap gerichte strategie veel belang hechten aan budgettering, ondernemingcultuur, interne controle en organisatiestructuur. De afsluitende regressieanalyses hebben echter aangetoond dat de relatie tussen strategie en de kenmerken van het management control systeem geen significante bijdrage levert tot de verklaring van verschillen tussen ondernemingen in gerealiseerde RTSR, waarmee de conclusies uit deze studie niet eensluidend zijn en een gebied voor verder onderzoek opleveren.

Hoofdstuk 8 bevat een samenvatting van de in het voorafgaande gepresenteerde conclusies, aanbevelingen voor verder onderzoek en een bespreking van een aantal beperkingen van het empirische onderzoek. 


\section{Curriculum Vitae}

Peter Sampers was born on June 7, 1961 in Linne. He studied business economics and accounting at the school for 'Hoger Economisch en Administratief Onderwijs' in Sittard from 1978 to 1981. After graduation he joined the Internal Audit department of Nederlandse Philips Bedrijven. Shortly after joining the company, he transferred to the Corporate Treasury department of Philips International B.V. where he was employed until 1989, when he moved to NV DSM to become Corporate Cash Manager. Subsequently he joined the Royal Frans Maas Group N.V. as Group Controller in 1991 before returning to Philips in 1996. Currently he is a vice-president of the company with responsibility for accounting policies as Manager Policies and Directives within Corporate Control.

From 1981 to 1987 he studied, part-time, to become 'Register Accountant' with the 'Nederlands Instituut voor Register Accountants (NIVRA)'. Subsequently he was active in a number of capacities in Royal NIVRA and the 'Controllers Instituut' in the Netherlands. He currently represents the Netherlands in the Financial and Management Accounting Committee of the International Federation of Accountants. 


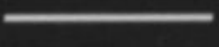

